\title{
Center for Coal-Derived Low Energy Materials for Sustainable Construction
}

\author{
Final Scientific/Technical Report
}

Project Period: October 12009 to March 302012

Principal Authors

Robert Jewell

Tom Robl

Robert Rathbone

July 2012

\section{WORK PERFORMED UNDER AGREEMENT \\ DE-FE0000660 \\ SUBMITTED BY \\ University of Kentucky Research Foundation \\ On Behalf of}

The University of Kentucky Center for Applied Energy Research

2540 Research Park Drive

Lexington, KY 40511

PRINCIPAL INVESTIGATOR

Thomas L. Robl

859-257-0272

robl@caer.uky.edu

\section{SUBMITTED TO}

U. S. Department of Energy

National Energy Technology Laboratory

Morgan Mike Mosser

morgan.mosser@netl.doe.gov 


\section{DISCLAIMER}

"This report was prepared as an account of work sponsored by an agency of the United States Government. Neither the United States Government nor any agency thereof, nor any of their employees, makes any warranty, express or implied, or assumes any legal liability or responsibility for the accuracy, completeness, or usefulness of any information, apparatus, product, or process disclosed, or represents that its use would not infringe privately owned rights. Reference herein to any specific commercial product, process, or service by trade name, trademark, manufacturer, or otherwise does not necessarily constitute or imply its endorsement, recommendation, or favoring by the United States Government or any agency thereof. The views and opinions of authors expressed herein do not necessarily state or reflect those of the United States Government or any agency thereof." 


\section{ABSTRACT}

The overarching goal of this project was to create a sustained center to support the continued development of new products and industries that manufacture construction materials from coal combustion by-products or CCB's (e.g., cements, grouts, wallboard, masonry block, fillers, roofing materials, etc). Specific objectives includes the development of a research kiln and associated system and the formulation and production of high performance low-energy, low- $\mathrm{CO}_{2}$ emitting calcium sulfoaluminate (CAS) cement that utilize coal combustion byproducts as raw materials. 


\section{Table of Contents}

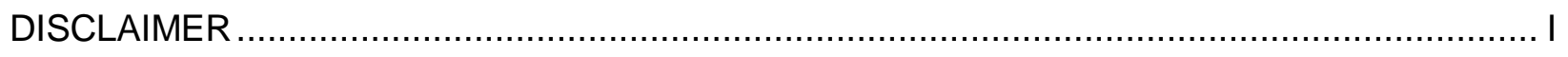

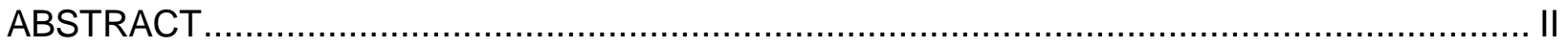

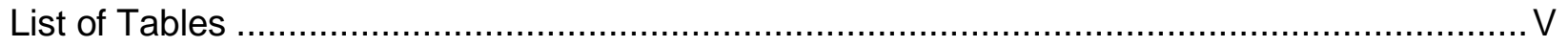

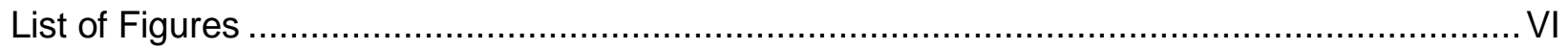

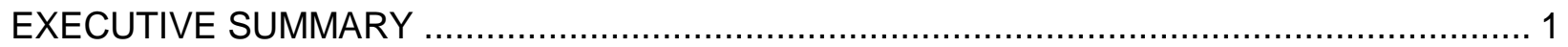

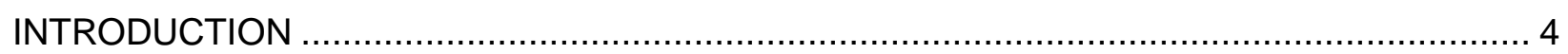

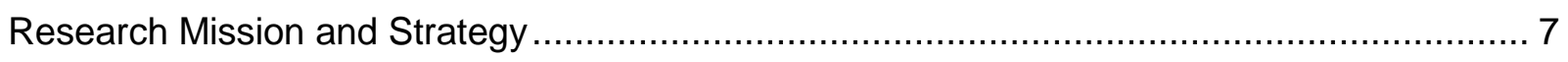

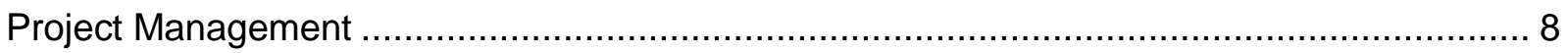

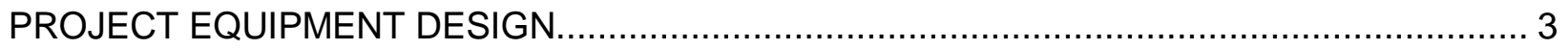

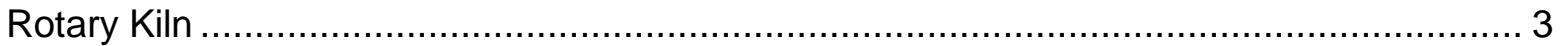

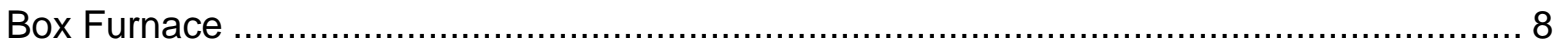

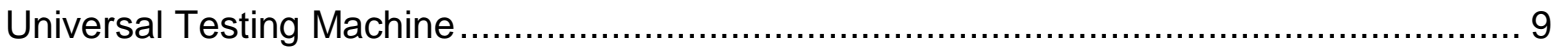

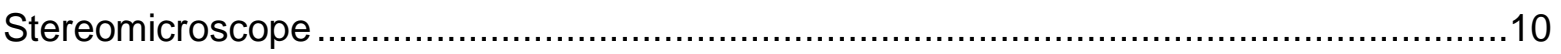

FIELD TESTING AND FINAL DESIGN OF KILN SYSTEM.......................................11

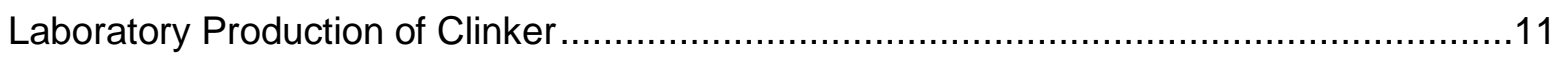

Preparation of Raw Materials for Rotary Kiln Testing ….............................................15

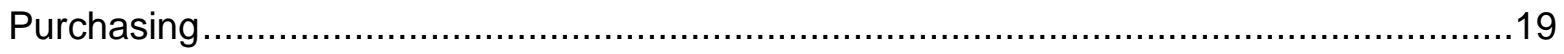

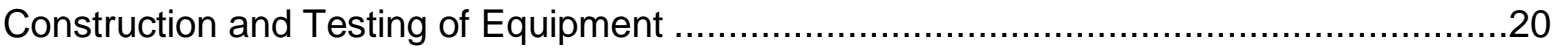

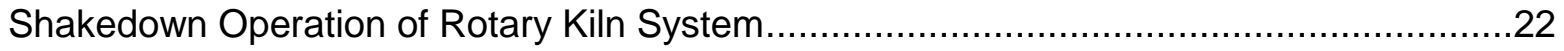

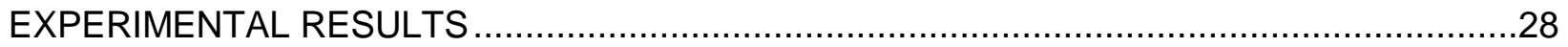

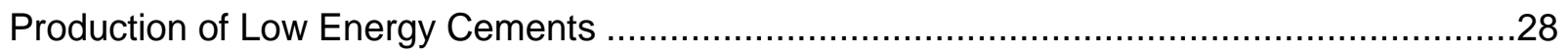

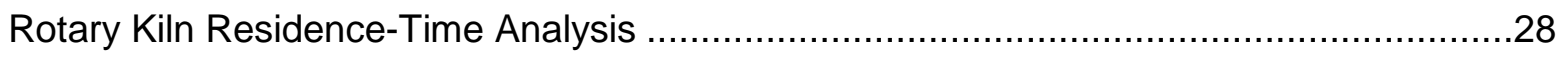

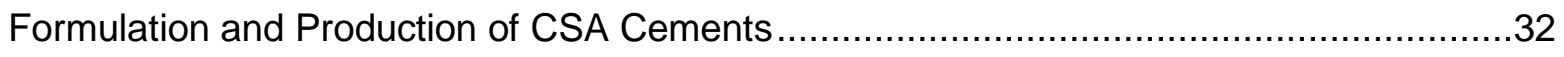

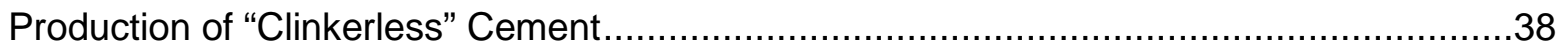

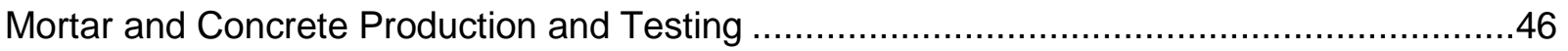

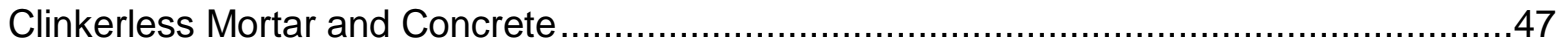

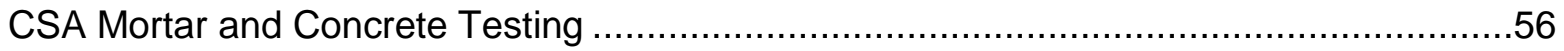

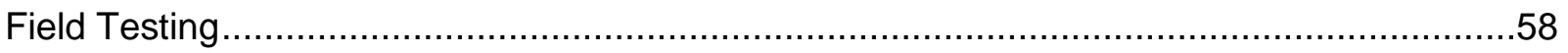

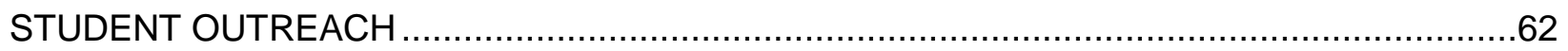

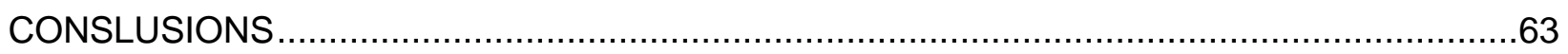




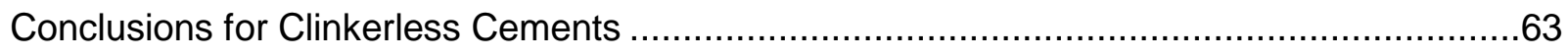

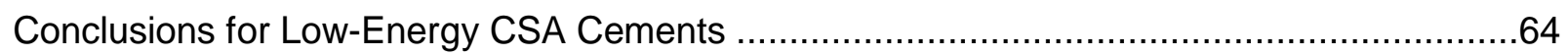

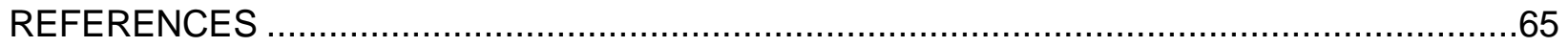




\section{List of Tables}

TAble 1. CRushing And Milling Equipment ReQuiRed for Low Energy CementS................................. 7

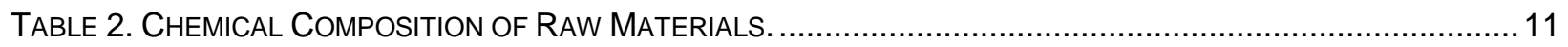

TABLE 3. Proportions OF RAW MATERIALS for CLINKER Production. ................................................ 11

Table 4. Calculated Compositions of Raw Material Mixtures. ..................................................... 12

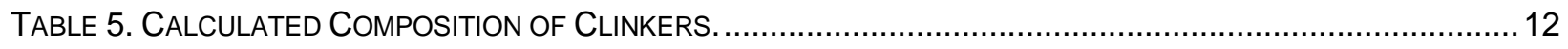

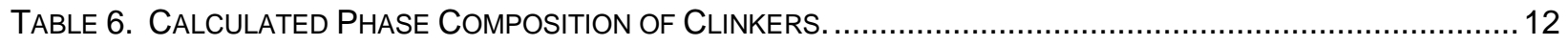

TABLE 7. FREE LIME CONTENT OF CLINKERS PRODUCED IN A LABORATORY TUBE FURNACE.............................13

TABLE 8. PROCESSING TEMPERATURES FOR ROTARY KILN CLINKERS. ...................................................... 16

TABle 9. Chemical CoMPosition Of RotARY KILN CLINKERS. .................................................................. 16

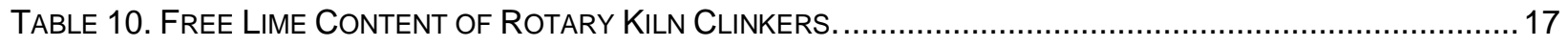

Table 11. Free Lime Content of Re-Heated Rotary Clinkers...................................................... 19

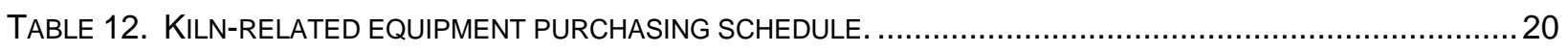

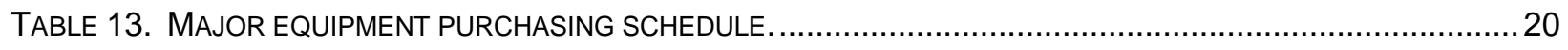

TABLE 14. ResidenCE TIME EVAluAtION FOR PELLETIZED RAW MATERIAL PASSING THROUGH THE ROtARY KILN.

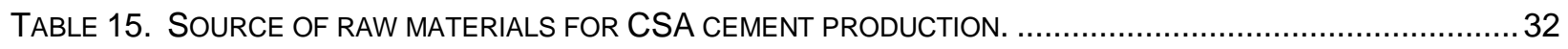

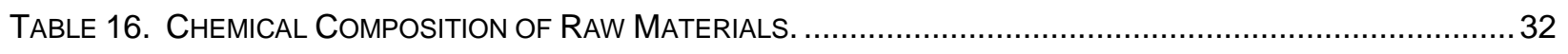

Table 17. Calculated Phase Compositions for the CSAB\#4 And CSFAB\#3 Clinkers. ....................... 34

TABLE 18. CALCULATED AND MEASURED COMPOSITION OF SELECTED ELEMENTS IN CSFAB CLINKER................36

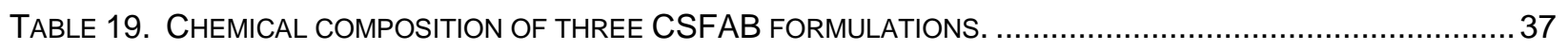

TABLE 20. PRoportion Of MATERIALS USED IN CLINKERLESS CEMENT FORMULATIONS................................. 39

TABLE 21. CheMICAL COMPOSITION OF CCPS USED IN PREVIOUS RESEARCH............................................ 40

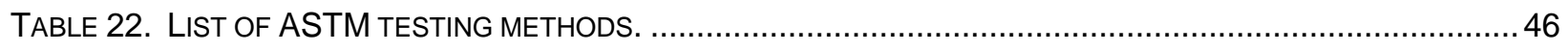

TABLE 23. PROPORTIONS OF MATERIALS FOR TWO MORTAR FORMULATIONS........................................... 47

TABLE 24. UNCONFINED COMPRESSIVE STRENGTH OF MORTAR CUBE SPECIMENS..................................... 48

TABLE 25. PROPORTIONS OF INGREDIENTS FOR HYDRATED/250C CEMENT MORTAR. ..................................54 
TABLE 26. MAJOR OXIDES IN GGBS.

TABLE 27. MIXTURE PROPORTIONS FOR GGBS MORTARS. .55

TABLE 28. MIX PROPORTIONS FOR LOW ENERGY CONCRETE SECTIONS. 59

TABLE 29. MIX FORMULATION FOR ALKALI-ACTIVATED CONCRETE. 62

\section{List of Figures}

FigURE 1. MAP SHOWING LOCATION OF UNIVERSITY OF KENTUCKY CENTER FOR APPLIED ENERGY RESEARCH. LAB IS LOCATED AT THE SMALL SQUARE, DETAILS OF WHICH ARE SHOWN IN FIGURE 2.

FIGURE 2. AERIAL PHOTO OF CAER SITE, SHOWING LOCATION OF THE PROPOSED CENTER WITHIN A LABORATORY

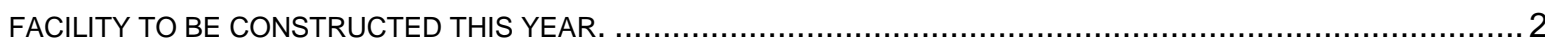

FIGURE 3. (A) SOUTH-FACING EXTERIOR OF THE LABORATORY; (B) NORTH-FACING EXTERIOR. ....................... 7

FIGURE 4. MINERALS-PROCESSING LABORATORY, LOCATED ON THE SOUTH-END OF THE LAB .......................... 7

FiguRE 5. CEMENT AND CONCRETE TESTING LABORATORY, LOCATED ON THE NORTH-END OF THE LAB. .............. 8

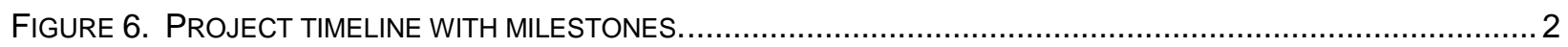

FIGURE 7. HED ROTARY KILN, USED IN THE PRODUCTION OF LOW-ENERGY CEMENTS.................................... 4

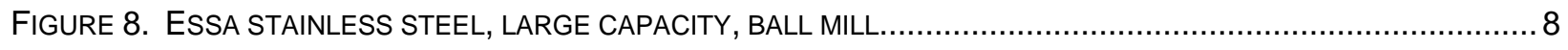

FIGURE 9. BOX FURNACE USED TO PRODUCE BATCH QUANTITIES OF CEMENT FOR TESTING. ............................. 9

FIGURE 10. INSTRON 600DX UNIVERSAL CLOSED-LOOP TESTING INSTRUMENT. ........................................... 10

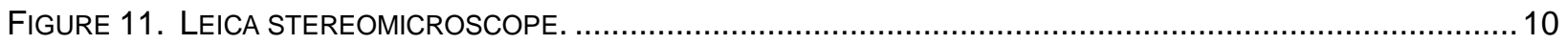

FIGURE 12. XRD ANALYSIS OF LABORATORY CSAB\#4 CLINKERS. ..................................................... 14

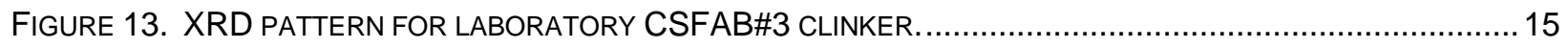

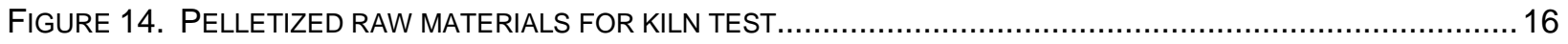

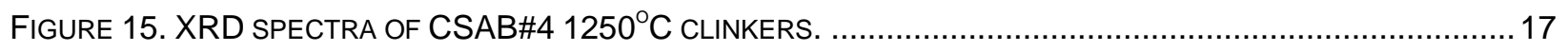

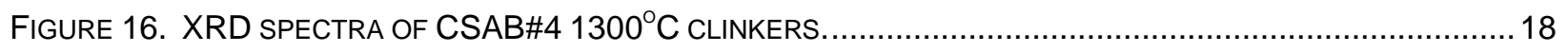

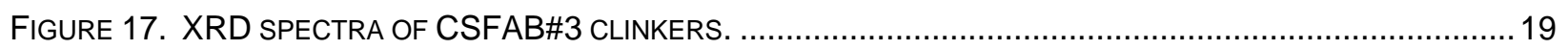

FiguRE 18. CILAS 1090 PARTICLE SIZE ANALYZER WITH ALCOHOL RECIRCULATION SYSTEM (ON THE LEFT).......21 
FIGURE 19. PHOTOGRAPH OF THE FEED-END OF THE ROTARY KILN SHOWING THE TUBE DRIVE MECHANISM. THERE IS A SIMILAR MECHANISM ON THE DISCHARGE END, AND BOTH ARE CHAIN DRIVEN BY AN ELECTRIC MOTOR THROUGH A COMMON SHAFT WHICH RUNS ALONG THE LENGTH OF THE KILN.

FIGURE 20. A) IMAGE OF ORIGINAL SCHENCK ACCURATE FEEDER WITH NARROW TUNNEL OPENING. B) IMAGE OF NEW FEEDER WITH LARGER TUNNEL OPENING TO PREVENT CRUSHING OF THE PELLETS.

FIGURE 21. SCHEMATIC OF KILN FEED END, SHOWING REQUIRED DISTANCE FROM FEEDER TO KILN TUBE (6.5 INCHES), VERSUS THE ACTUAL LENGTH OF THE FEEDER SCREW AND TUBE (3.5 INCHES).

FIGURE 22. FINALIZED FEEDER DESIGN WITH LONGER FEED BARREL AND ENCLOSED FEED SCREW 25

FIGURE 23. UPGRADED DISCONNECT BOX AND WIRING FOR THE ROTARY KILN. 26

FIGURE 24. FINALIZED ROTARY KILN CONFIGURATION (INPUT SIDE) WITH UPGRADED WIRING AND CEMENT, RAW MATERIAL, FEEDER SYSTEM.

FIGURE 25. FINALIZED ROTARY KILN CONFIGURATION (OUTPUT SIDE).

FIGURE 26. BLUE PELLETS PASSING THROUGH MATERIAL FEEDER INTO THE ROTARY KILN DURING THE RESIDENCE-TIME EVALUATION.......

FIgURE 27. CUMULATIVE \% CURVES BASED ON THE FREQUENCY DATA FOR THE RESIDENCE TIME OF THE RAWMATERIAL PELLETS PASSING THROUGH THE ROTARY KILN.

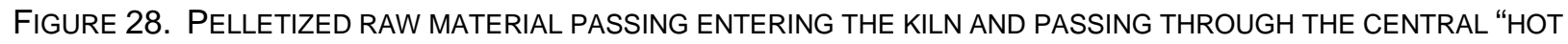
ZONE" WITHIN THE ROTARY KILN. 30

FIGURE 29. A) CSA CLINKER PRODUCT ADDED TO BALL MILL; B) ANHYDRITE ADDED TO MILLED CSA CLINKER; C)

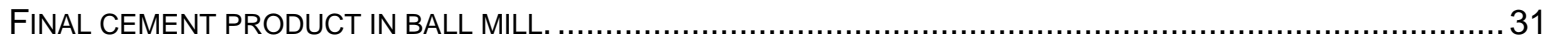

FIGURE 30. PROPORTIONS OF RAW MATERIALS FOR CSAB\#4 AND CSFAB\#3 CLINKERS. ............................... 33

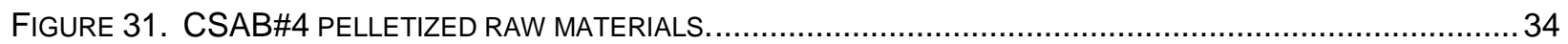

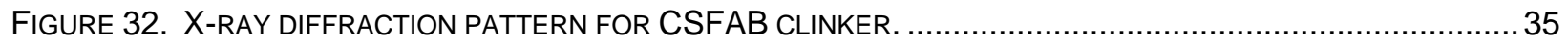

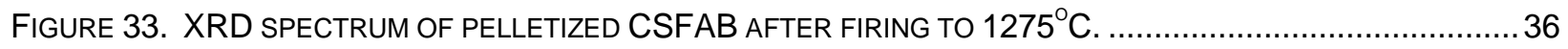

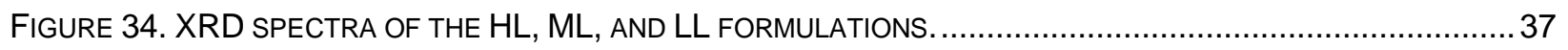

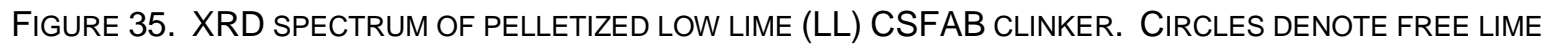
PEAKS.

FIGURE 36. XRD SPECTRUM OF FGD CALCIUM SULFATE HEMIHYDRATE. 39

FIGURE 37. COMPRESSIVE STRENGTH OF MORTAR PREPARED WITH DIFFERENT CLINKERLESS CEMENT BLENDS. 41

FIGURE 38. CALORIMETRY OF 25\% HH CLINKERLESS PASTE WITH 4 DOSAGES OF SET RETARDER................... 42

FIGURE 39. CALORIMETRY OF 50\% HH CLINKERLESS PASTE WITH 4 DOSAGES OF SET RETARDER. 42 
FIGURE 40. SPECIMEN OF CLINKERLESS CEMENT CONCRETE; AFTER 1 DAY EXPOSURE (LEFT) AND AFTER 2 YEARS EXPOSURE (RIGHT). NOTE THE EXPOSURE OF THE AGGREGATE CAUSED BY GRADUAL DISSOLUTION OF THE CEMENT COMPONENT.

FIGURE 41. XRD SPECTRUM OF HYDRATED FBC SPENT BED MATERIAL; ET=ETTRINGITE, CH=CALCIUM HYDROXIDE, GP=GYPSUM.

FIGURE 42. XRD SPECTRUM OF HYDRATED, AUTOCLAVED FBC SPENT BED; CH=CALCIUM HYDROXIDE, AN=ANHYDRITE, $\mathrm{HH}=$ CALCIUM SULFATE HEMIHYDRATE...

FIGURE 43. XRD SPECTRUM OF HYDRATED FBC SPENT BED MATERIAL THAT WAS HEATED TO 250C FOR 4 HOURS.

FIGURE 44. ISOTHERMAL CALORIMETRY DATA FOR 25\% AND 50\% HH MORTARS. 47

FIGURE 45. UNCONFINED COMPRESSIVE STRENGTH OF MORTAR CUBE SPECIMENS. 48

FiguRE 46. CLINKER CEMENT MORTAR CUBE PREPARED WITH HD45 ADMIXTURE AT 3.0\% BY MASS 49

FIGURE 47. MIX SUMMARY FOR MORTAR PREPARED WITH HYDROPHOBIC ADMIXTURES .50

FIGURE 48. UNCONFINED COMPRESSIVE STRENGTH OF MORTAR CUBE SPECIMENS 51

FIGURE 49. UNCONFINED COMPRESSIVE STRENGTH OF MORTAR CUBE SPECIMENS. 52

FIGURE 50. UNCONFINED COMPRESSIVE STRENGTH OF MORTAR CUBE SPECIMENS 52

FIGURE 51. EXPANSION OF MORTAR BAR SPECIMENS WITH HYDROPHOBIC ADMIXTURE. .53

FIGURE 52. COMPRESSIVE STRENGTH OF HYDRATED $/ 250^{\circ} \mathrm{C}$ FBC CEMENT MORTAR 54

FIGURE 53. UNCONFINED COMPRESSIVE STRENGTH OF MORTAR CUBES WITH AND WITHOUT GGBS. 56

FIGURE 54. UNCONFINED COMPRESSIVE STRENGTH OF MORTAR CUBE SPECIMENS .57

FIGURE 55. MIX SUMMARY FOR CONCRETE PREPARED WITH THE COAL COMBUSTION BYPRODUCT CEMENTS FABRICATED IN THE ROTARY KILN.

FIGURE 56. UNCONFINED COMPRESSIVE STRENGTH OF CONCRETE CYLINDER SPECIMENS WITH CEMENT FABRICATED FROM COAL COMBUSTION BYPRODUCTS.

FIGURE 57. WALKWAY LOCATION SHOWING BOTTOM ASH BASE COURSE. 60

FIGURE 58. MIXING THE CONCRETE INGREDIENTS. 60

Figure 59. Placing AND COMPACting A SECTION OF CONCRETE 


\section{EXECUTIVE SUMMARY}

The goal of this project was to create a center to support the development of new products and industries that manufacture construction materials from coal combustion by-products or CCB's. The center served three functions: 1 . facilitated the development of technology to produce new forms of non-Portland cement, pozzolanic concrete additives, and masonry from coal products; 2. provided informational transfer and technical liaison between coal combustion producers and the construction industry; 3 . supported relevant education and training via participation of graduate and co-operative students.

This center conducted research into the development of low energy, low $\mathrm{CO}_{2}$ emitting construction materials from CCB's, including calcium sulfoaluminate and plaster based cements, high performance pozzolanic cement additives and geopolymers.

The specific objectives of this project included the design, procurement, installation and finally testing of a processing system built around a research kiln. This system was installed in a new $6,400 \mathrm{ft}^{2}$ facility constructed with funds from the State of Kentucky (Figure 1 and 2). The project has four broad task components: project management and planning, design of equipment, purchasing, construction and testing of equipment, and production and performance testing of low energy cements. Important milestones and deliverables include the formation of a technical advisory board; the final design of the system; system procurement and testing; final shakedown operation and finally the production and testing of a calcium sulfoaluminate clinker.

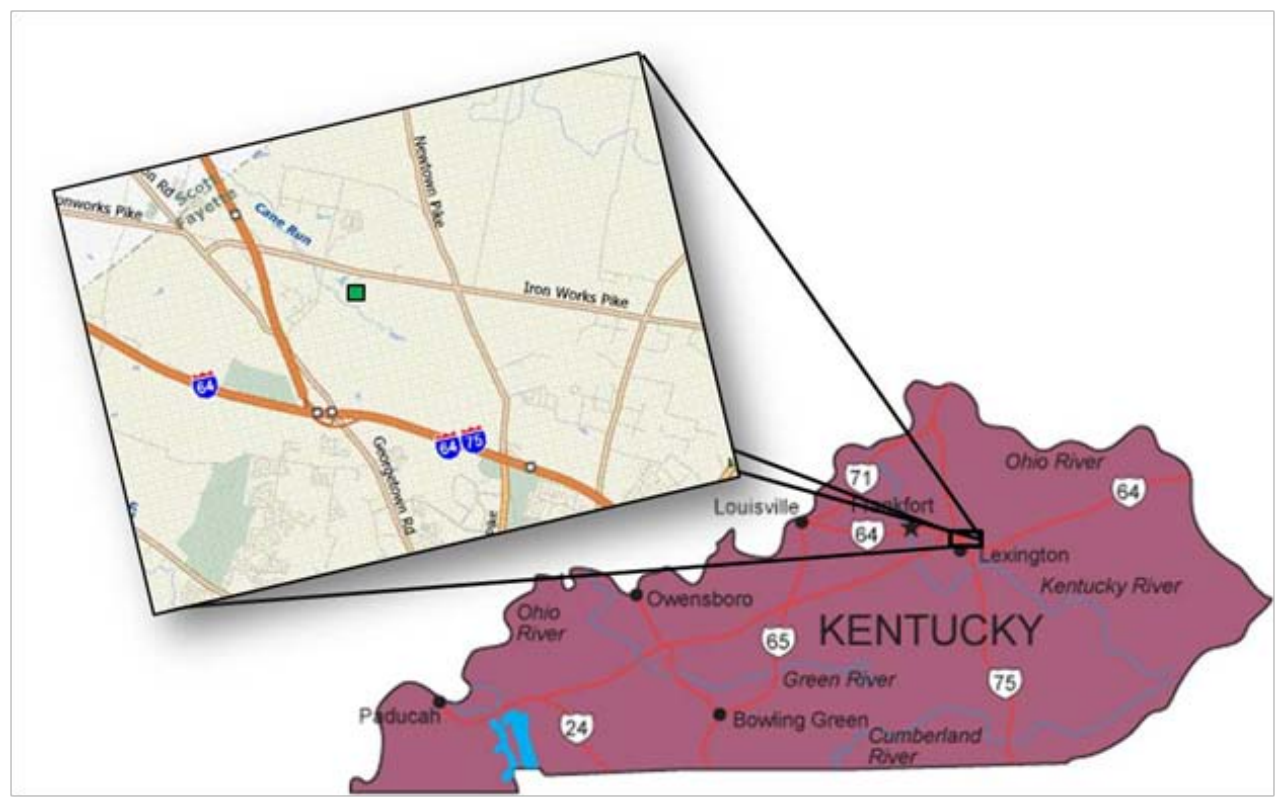

Figure 1. Map showing location of University of Kentucky Center for Applied Energy Research. Lab is located at the small square, details of which are shown in Figure 2. 


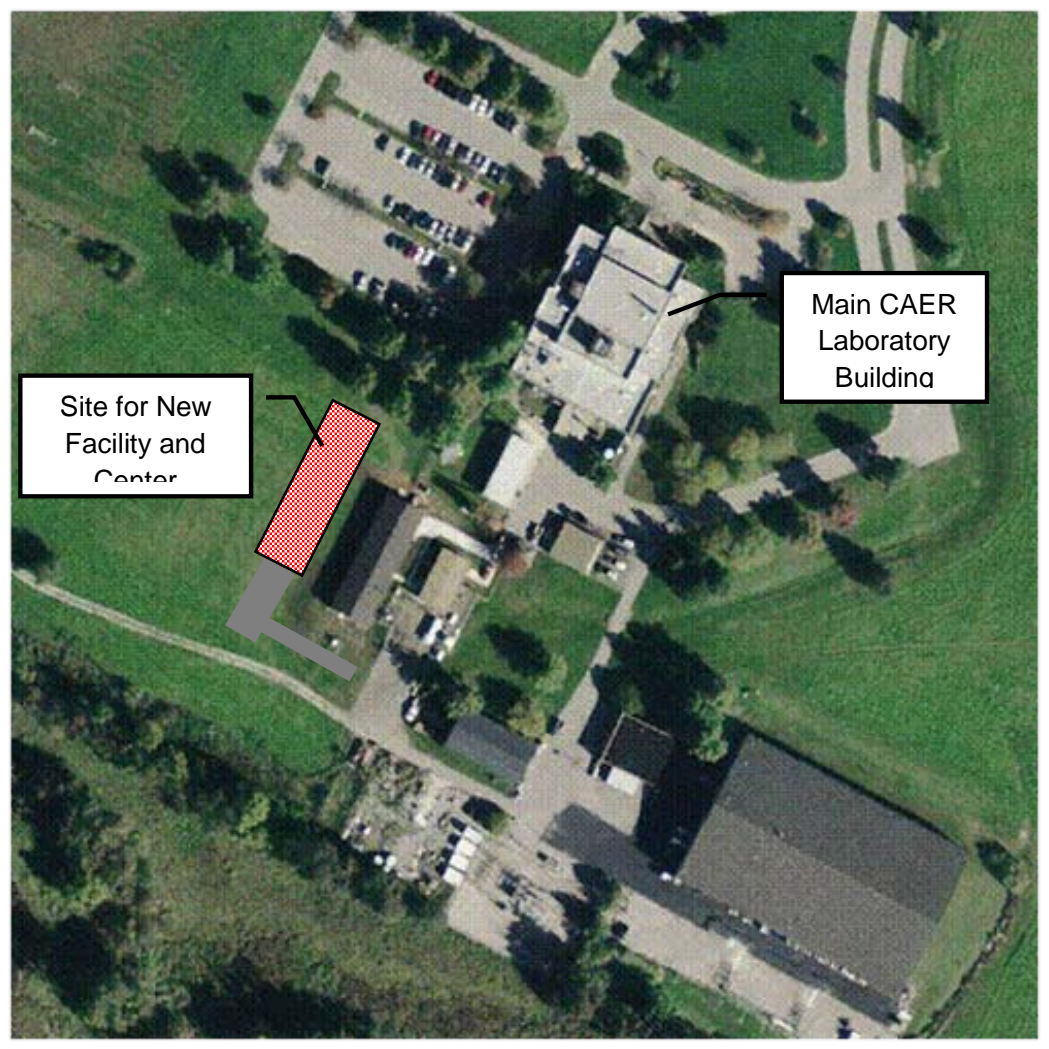

Figure 2. Aerial photo of CAER site, showing location of the proposed center within a laboratory facility to be constructed this year.

The production of Portland cement requires prodigious amounts of energy, mainly because of the high temperatures required to partially melt and fuse the raw materials into clinker. Portland cement clinker, which is comprised mainly of calcium silicates, is also very hard and requires considerable energy to grind to the final product. Furthermore, limestone is the predominant raw material used to produce Portland cement and releases large amounts of $\mathrm{CO} 2$ during the thermal processing. In order to realize substantial reductions in energy consumption and CO2 emissions, significantly lowering the clinkering temperature and the proportion of limestone in the feed is necessary. This is unfortunately not possible with Portland cement. However, energy-conserving or "low-energy" cements can be produced at lower temperatures and using much less limestone than Portland cement. They can also be much softer and easier to grind. An additional environmental benefit is that CSA cements can be prepared using substantial amounts of coal combustion wastes as the raw materials. These include FGD gypsum, pulverized coal combustion (PCC) fly ash, and fluidized bed combustion (FBC) ash.

There are several types or classes of low-energy, low-CO2 cements. This study focused on two types: calcium sulfoaluminate (CSA) cements, and FBC ash-based "clinkerless" cement. Both of these cements gain strength primarily from the formation of a calcium aluminum sulfate hydrate called ettringite. Because of the rapid rate of formation of ettringite, CSA cements gain strength very quickly. However, there remain questions around the durability of CSA cement concrete. The research described herein involved the formulation, production and evaluation of two 
classes of FBC byproduct-based products: 1) a medium strength material produced directly from the hydration of the FBC byproducts, and 2) CSAB cement produced by heating the FBC spent bed in the presence of limestone, bauxite, and PCC fly ash. The formulation, production, and performance testing of these two classes of materials are described in this report. The free lime and calcium sulfate present in the Gilbert spent bed material and fly ash imparted cementitious properties to these materials when they were mixed with water. Ettringite formation was the principal cementitious reaction. The Gilbert fly ash contained significantly more alumina than the spent bed and therefore formed more ettringite. It was possible to "activate" the Gilbert spent bed by providing an alumina source such as Class F fly ash. However, the formation of colloidal ettringite in the hydrated materials caused expansion in every formulation. Likewise, when contacted with soil and large amounts of water, the spent bed material reacted with alumina from the soil and formed expansive ettringite. Based on the data, methods to control expansive are proposed for future work. Although moist curing is required for the cementitious reactions to proceed to completion, the amount of water needs to be controlled while ettringite is forming. It is postulated here that the water ingress does not need to be controlled in perpetuity, but only during the period where there remains unreacted lime in the system. Thus, the use of water-repelling admixtures or sealants could provide a means to prevent water from entering the hydrated FBC material during the ettringite forming period. With proper proportioning of the FBC materials and Class $\mathrm{F}$ fly ash, it might be possible to complete the cementitious strength-forming reactions after which significant expansion would not occur.

Another problem with using FBC-based clinkerless cements instead of Portland cement was the slow strength gain of the former. To overcome this, addition of alkali (e.g. sodium hydroxide) to the paste could increase the dissolution rate of Class F fly ash, which would cause an increase in the rate of ettringite and calcium silicate hydrate formation, with a concomitant increase in strength. A second strategy could be to blend the clinkerless cement with rapid hardening cement (RHC) such as plaster. The RHC would provide early strength, whilst the pozzolanic reactions in the clinkerless component would provide additional longer-term strengths. The Gilbert fluidized bed combustion material has potential for use in the production of calcium sulfoaluminate belite (CSAB) cements. Production of clinker from FBC spent bed material, limestone, and bauxite produced a large quantity of Klein's compound and belite. The Gilbert FBC ash provided mainly calcium sulfate and calcium oxide, with the latter being an effective substitute for limestone that is normally required for CSAB cement clinker. The synthesized CSAB clinkers were soft and readily milled to cement fineness. Milling the clinker with FGD gypsum was effective in provide the additional calcium and sulfate required to "activate" the clinker to form ettringite. The compressive strength of the commercial and laboratory CSAB cements produced high-early strengths that exceeded those of ordinary Portland cement. Additional long-term strength was possibly provided by hydration of dicalcium silicate (C2S) within the clinker. The tests in which the CSAB cements performed well were compressive strength, drying shrinkage and expansion.

A major issue regarding the production of CSAB cement is one of cost. Because CSAB clinker production requires substantial quantities of bauxite, the cost of these cements is high. In order to minimize or eliminate bauxite, alternatives to this raw material need to be pursued. The 
replacement of some bauxite with high-iron raw materials, as presented in this report as a CSA with calcium aluminoferrite, CSFAB. This could have the net effect of replacing some of the aluminum with iron, which is considerably less expensive. Thus, the use of high-iron materials, such as certain Class F fly ashes and/or red mud, can be utilized as partial replacements for bauxite.

\section{INTRODUCTION}

\section{Center for Coal-Derived Low Energy Materials for Sustainable Construction.}

The Center, also known as the Center for Coal Combustion Derived Materials or CCDM*, has three missions:

First to facilitate the development of technology to produce new forms of non-Portland cement, advanced pozzolanic concrete additives and high performance masonry materials from coal products through research. This was the focus of this project.

The second was to provide informational transfer and technical liaison between coal combustion producing utilities and the construction industry and its trade groups. This was addressed through a technical advisory board consisting of industrial and trade group representatives including the Kentucky Department of Highways, Cemex, Inc., IMI, Inc., the Kentucky Ready Mix Association, E.ON USA LLC, TVA, and the East Kentucky Power Cooperative (EKPC).

Thirdly this project supported education via participation of graduate and co-operative students. It operated in close collaboration with the UK Department of Civil Engineering. Professor Mahboub will be a faculty associate and coordinator of this activity. Additionally the UK Department of Design has dedicated a course to the study and innovative use of CCBs in the design of innovative products from decorative art to functional furniture and housing.

The project was focused on moving existing research on energy efficient cement production beyond the workbench to the next level, that is, the manufacture of low energy cements of various types and formulations in a continuous pilot kiln in sufficient quantity to conduct realistic demonstrations of the cements and investigate their properties. The effort to accomplish this had four broad task components: project management and planning, design of equipment, purchasing, construction and testing of equipment, and production of low energy cements for use in concrete. The Center itself is housed in a new 6,400 $\mathrm{ft}^{2}$ laboratory that has been constructed on the property of the Center for Applied Energy Research Campus.

Currently in the U.S., there are approximately 60 fluidized bed combustion (FBC) boilers used to generate electricity. There are two units in Kentucky that use this technology: the Shawnee Plant, operated by TVA, and the Gilbert Unit, operated by East Kentucky Power Cooperative (EKPC). Although FBC boilers can substantially reduce SOx and NOx emissions relative to a pulverized coal combustion (PCC) boiler, they generate a much larger quantity of solid byproducts. FBC burns coal in a fluidized bed of sorbent, usually limestone, which removes 
most of the SOx emissions. The resultant byproducts are thus mainly composed of calcium sulfate, and also contain lesser amounts of unreacted sorbent i.e. lime or $\mathrm{CaO}$. There are two types of byproducts produced in an FBC boiler: spent bed material, which is a coarse sandy material, and "fly ash", which is a much finer material that is captured from the flue gas. The spent bed material generally contains a higher proportion of lime and calcium sulfate than the fly ash, whereas the latter contains more alumina and silica because of the presence of ash from the combusted coal. The lime, alumina, and calcium sulfate within FBC byproducts imparts a cementitious nature when they are mixed with water. The cementitious properties are largely the result of the formation of two hydrated phases: gypsum and ettringite. Gypsum is formed from the hydration of the anhydrous calcium sulfate (anhydrite). This reaction can be slow because of the "hard burned" nature of the FBC anhydrite, which results from the high temperatures within the boiler. Nevertheless, the hydration reaction is:

$$
\text { Equation 1: } \mathrm{CaSO}_{4}+2 \mathrm{H}_{2} \mathrm{O} \rightarrow \mathrm{CaSO}_{4} \cdot 2 \mathrm{H}_{2} \mathrm{O} \text { (gypsum) }
$$

Ettringite is a calcium aluminum sulfate hydrate that forms in a high $\mathrm{pH}$ environment (i.e. that occurring from the dissolution of lime in the FBC ash) by the following reaction:

Equation 2: $3 \mathrm{CaSO}_{4}+3 \mathrm{Ca}(\mathrm{OH})_{2}+2 \mathrm{Al}(\mathrm{OH})_{3}+26 \mathrm{H}_{2} \mathrm{O} \rightarrow \mathrm{Ca}_{6} \mathrm{Al}_{2}\left(\mathrm{SO}_{4}\right)_{3}(\mathrm{OH})_{12} \cdot 26 \mathrm{H}_{2} \mathrm{O}$

The formation of these cementitious compounds in hydrated FBC byproducts has prompted a considerable research effort over the past 25 years or so to utilize the byproducts. The material is currently used in applications such as soil stabilization, structural fills, road subbase, and various fills (ACAA, 2006; LA Ash, Inc.). No-cement concrete and synthetic aggregates, prepared with spent bed material, have also been investigated (Bland et al., 1987; EPRI, 1991) but are not produced commercially. Probably the largest drawbacks to using FBC byproducts in cement and concrete applications are their potential dimensional instability and deleterious impacts on ordinary Portland cement (OPC) concrete when placed in contact with the concrete (Hemmings, 2007). Regarding the dimensional instability, FBC byproducts have exhibited detrimental swelling when they were used for stabilization of road subgrade, even though prescribed laboratory testing indicated that swelling would not be a problem (Hopkins and Beckham, 1999). The addition of PCC fly ash has been used with some success to produce a strong, stable fill material, largely through the slow reaction of lime with the fly ash to form calcium aluminosilicate hydrate cement (Berry et al, 1991).

Another pathway to the utilization of FBC byproducts is to produce a calcium sulfoaluminatebelite (CSAB) cement via a high temperature clinkering process, similar to the production of Portland cement. In contrast to Portland cement, which derives its strength from the formation of calcium silicate hydrates, CSAB cement concrete hardens and gains strength primarily through the hydration of Klein's compound $\left(\mathrm{Ca}_{4} \mathrm{Al}_{6} \mathrm{O}_{12} \mathrm{SO}_{4}\right)$ and calcium sulfate to form ettringite: 
Equation 3: $\mathrm{Ca}_{4} \mathrm{Al}_{6} \mathrm{O}_{12} \mathrm{SO}_{4}+2 \mathrm{CaSO}_{4} \cdot 2 \mathrm{H}_{2} \mathrm{O}+34 \mathrm{H}_{2} \mathrm{O} \rightarrow \mathrm{Ca}_{6} \mathrm{Al}_{2}\left(\mathrm{SO}_{4}\right)_{3}(\mathrm{OH})_{12} \cdot 26 \mathrm{H}_{2} \mathrm{O}+4 \mathrm{Al}(\mathrm{OH})_{3}$

A compound similar to ettringite called "monosulfate" can also form under sulfate-deficient conditions (Glasser and Zhang, 2001) and its role as a cementitious component in CSA cement is not well understood. Belite is usually present in CSA cements, but its hydration is typically slow and only provides additional long-term strength. Because of the rapid rate of formation of ettringite, CSA cements gain strength very quickly. If enough lime $\left(\mathrm{Ca}(\mathrm{OH})_{2}\right)$ and calcium sulfate are present in the system, then additional ettringite is formed through reaction with the aluminum hydroxide. However, with excess lime the system can become expansive to the degree that it is destructive to the material (Mehta, 1973). In China, CSA cements have been used primarily to replace Portland cement in mortars and concrete when rapid strength gain, self stressing properties or sulfate resistance is desired. Approximately 1 million tons per year are manufactured in China (Zhang and Glasser, 1999) which has special standards for the cements (Zhang et al, 1999). CSA-type cements have a long history of use in the United Kingdom for specialty applications such as in the mining industry. Brown (1993) described a wide range of formulations for products used in construction, for example, general purpose low shrinkage cement, shrinkage compensated concrete slabs, mortar coatings for concrete pipes, rapid repair and setting mortars, anchor bolt grouts and glass fiber reinforced cement products.

An issue regarding the widespread use of CSA cements involves cost. Because of the high alumina content of Klein's compound, production of CSA cement requires a high alumina feedstock, which is traditionally bauxite. There are ostensibly no reserves of bauxite remaining in the U.S., which means that it must be imported from other countries such as Jamaica (USGS, 2006). This can make the cost of manufacturing CSA cement for widespread general use prohibitively expensive. Because of their cost, as well as the durability questions, CSA cements in the U.S. (e.g. CTS RapidSet ${ }^{\circledR}$ ) have historically been used as minor additives to Portland cement concrete to compensate for shrinkage, and for self leveling screeds and rapid repair materials. In summary, CSA cements can potentially present considerable environmental advantages compared to Portland cement because of the lower energy use, lower $\mathrm{CO}_{2}$ emissions, and use of coal combustion wastes as raw materials. In order to support widespread introduction of the cements in the marketplace there are several issues that must be addressed, namely, high cost, durability issues, and appropriate applications. As was discussed above, although only a limited amount of research has been conducted on the durability of CSA cements, there is sufficient information indicating that the cements can be quite durable in certain environments. The research described herein has focused on the production of two classes of FBC byproduct-based products: 1) a low, medium and high strength material produced directly from the hydration of the FBC byproducts, and 2) two formulations of CSAB cement produced by heating the FBC spent bed in the presence of limestone, bauxite, and with/without red mud. The formulation, production, and performance testing of these two classes of materials are described. 


\section{Research Mission and Strategy}

The primary research focus of this Center is the creation of new construction products and materials from coal by-products that require lower energy to produce and emit less carbon dioxide. These include: cold bonded geopolymers, plaster-based cement, and calcium sulfoaluminate (CSA) cement. CSA cement in particular has the potential to be a direct replacement for Portland cement and can be fabricated using substantial amounts of CCBs. The production of low energy cements and other green construction materials from coal combustion products is the primary near-term focus of this center and this agreement. Photos of the Center are shown in Figures $3-5$.
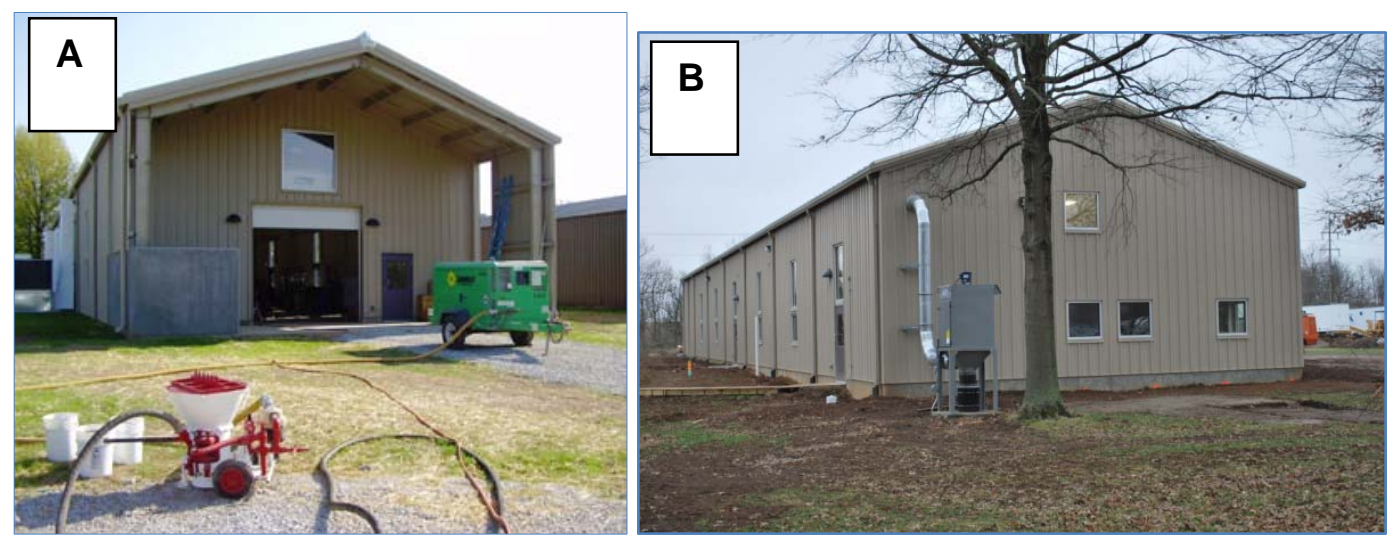

Figure 3. (A) South-facing exterior of the laboratory; (B) North-facing exterior.

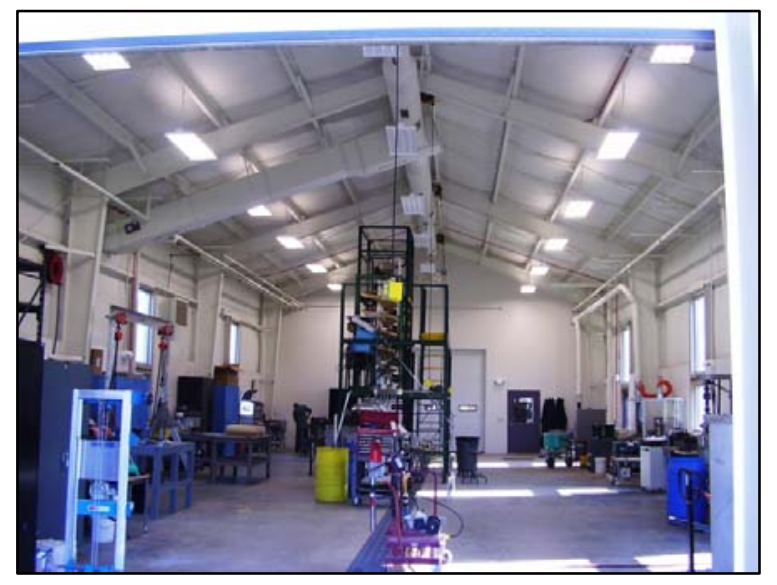

Figure 4. Minerals-processing laboratory, located on the south-end of the lab. 


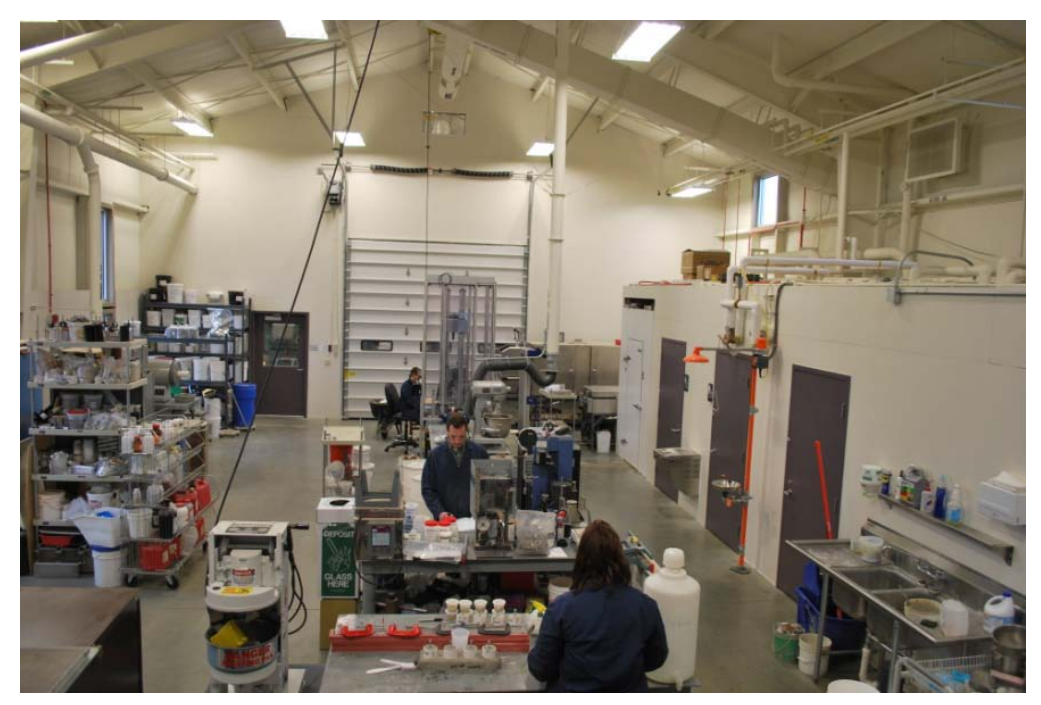

Figure 5. Cement and concrete testing laboratory, located on the north-end of the lab.

\section{Project Management}

A technical advisory board was assembled that consists of industrial and trade group representatives including the Kentucky Department of Highways, Cemex, Inc., IMI, Inc., the Kentucky Ready Mix Association, E.ON USA LLC, TVA, and the East Kentucky Power Cooperative (EKPC). Based on input from the advisory board, a strategic plan for the center will be drafted. The plan was to identify focus areas of research for the center and addressed not only low energy cements, but also other "green" construction materials such as pervious concrete, coal bottom ash (i.e. as a lightweight aggregate), and geopolymers. The project timeline and milestones are shown in Figure 6. The advisory board comprises representatives from academia, government, and industry:

- Mr. Morgan H. Mosser: U.S. DoE NETL, program manager on the project

- Dr. Rodney Andrews: Director, Univ. of Kentucky Center for Applied Energy Research

- Mr. John Vaughan, Irving Materials Inc.

- Mr. Peter S. Mills, Minova Inc.

- Dr. M. Roderick Jones, University of Dundee, Scotland

- Mr. Stephen Bryan, Ecocem Materials Ltd. 


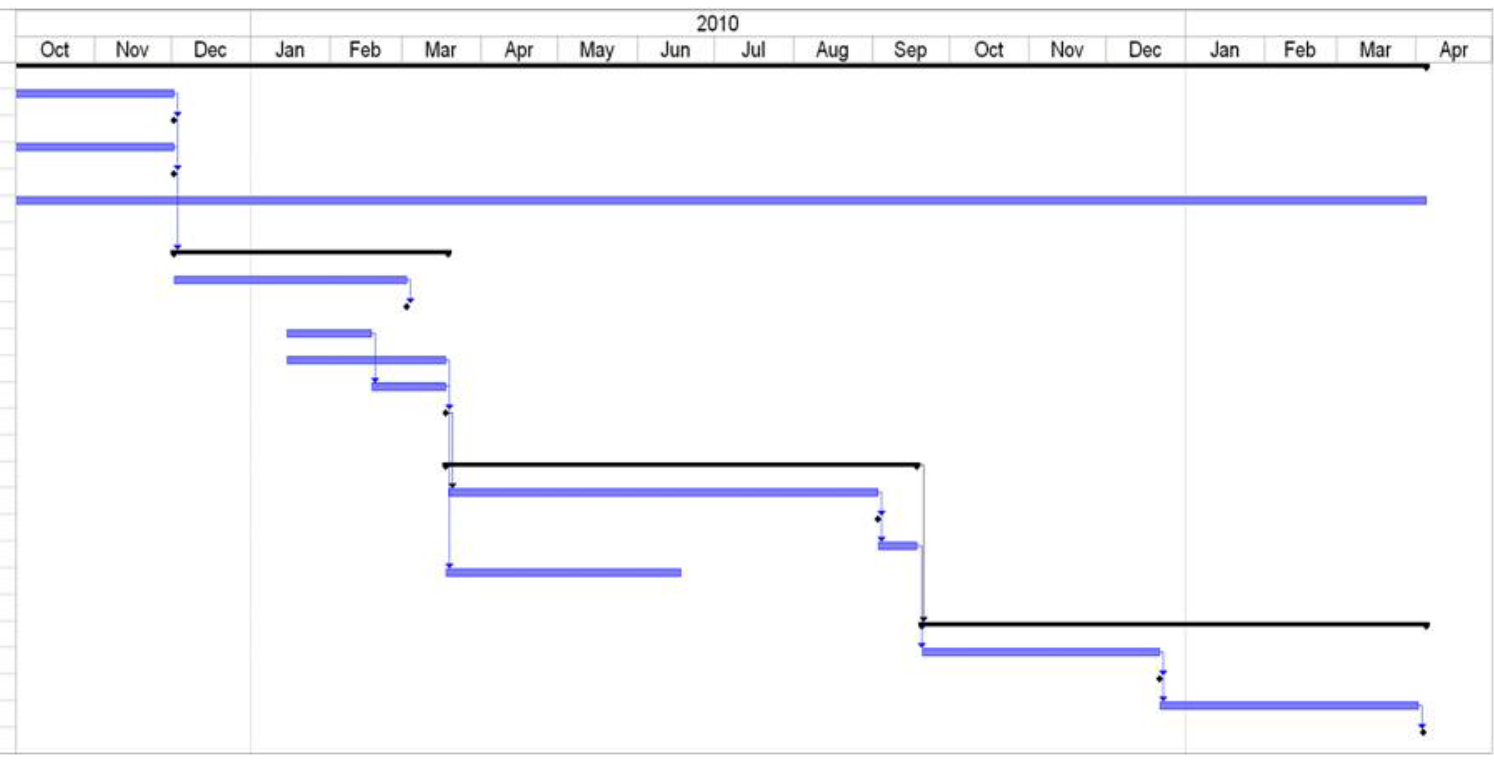

Figure 6. Project timeline with milestones. 


\section{PROJECT EQUIPMENT DESIGN}

The design of equipment systems focused on a rotary kiln (Figure 7), for cement production, and on a closed-loop universal tester, for mortar and concrete strength testing. These items were prioritized because of the length of time required for evaluation, purchase and delivery of the equipment.

\section{Rotary Kiln}

The primary advantage of a rotary kiln is that raw materials in the kiln can be tumbled constantly and heated uniformly, and can process a large amount of material on a continuous basis. The steps involved in the rotary kiln design and purchase are:

1. Determine quantity of clinker to be produced per day

2. Identification of kiln manufacturers

3. Obtain kiln specifications and price quotes

4. Prepare raw materials for kiln testing

5. Process the raw materials in the kiln to produce clinker

6. Analyze the clinker

7. Decide if rotary kiln has effectively produced high-quality clinker and, if so

8. Purchase kiln

It was calculated that a kiln should be able to produce a minimum of $15 \mathrm{~kg}$ per day of clinker, which equates to a feed rate of approximately $1.5 \mathrm{~kg} / \mathrm{hr}$ of calcined material or $2 \mathrm{~kg} / \mathrm{hr}$ of uncalcined material. The power available is $208 \mathrm{~V}$, 3-phase and is estimated to require a minimum of 104 amps. Two manufacturers were identified: Harper International and HED International. Both companies manufacture a rotary kiln that met the required feed rates and were therefore contacted to provide detailed information and price quotes. The following two pages provide the finalized requirements determined for the kiln: 

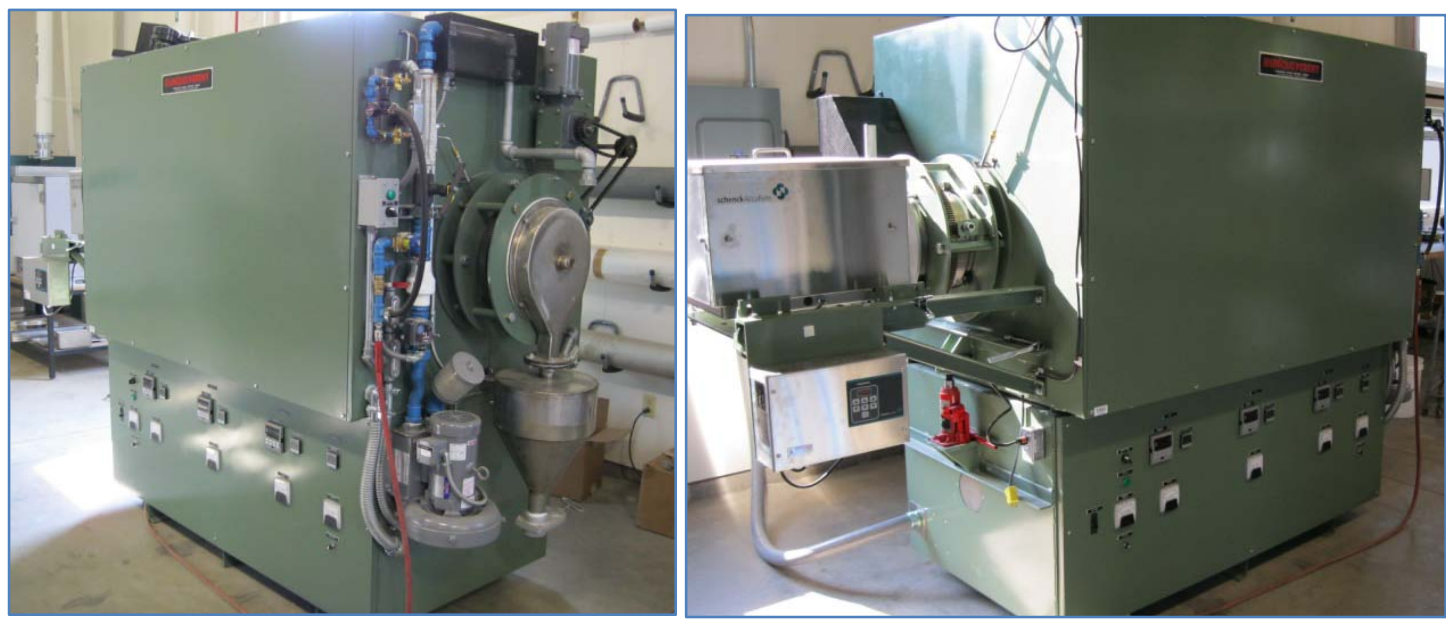

Figure 7. HED rotary kiln, used in the production of low-energy cements. 


\section{University of Kentucky Center for Applied Energy Research}

The raw materials to be processed in the kiln will have a range of compositions, but the following mixtures are representative examples of "typical" material composition:

\begin{tabular}{|c|c|c|c|c|c|c|c|c|c|c|}
\hline \multicolumn{11}{|c|}{ Chemical compositions of raw meal calculated according to mixture } \\
\hline \multirow{2}{*}{ Mixture } & \multicolumn{10}{|c|}{ Chemical compositions $/ \%$} \\
\hline & $\mathrm{CaO}$ & $\mathrm{SiO}_{2}$ & $\mathrm{Al}_{2} \mathrm{O}_{3}$ & $\mathrm{Fe}_{2} \mathrm{O}_{3}$ & $\mathrm{SO}_{3}$ & $\mathrm{MgO}$ & $\mathrm{K}_{2} \mathrm{O}$ & $\mathrm{Na}_{2} \mathrm{O}$ & LOI & $\Sigma$ \\
\hline$\# 1$ & 35.14 & 7.01 & 24.11 & 3.38 & 7.47 & 1.43 & 0.13 & 0.01 & 20.68 & 99.37 \\
\hline \#2 & 35.83 & 6.63 & 19.20 & 8.60 & 4.54 & 1.30 & 0.13 & 0.31 & 21.71 & 100.00 \\
\hline
\end{tabular}

The physical properties of the raw materials are as follows:

\begin{tabular}{|l|c|}
\hline Particle size of powdered feed & -200 mesh (75 microns) \\
\hline Particle size of pelletized feed & $5-7 \mathrm{~mm}$ approximate \\
\hline Bulk density & $85-90 \mathrm{lbs} / \mathrm{ft}^{3}(1.36 \mathrm{~kg} / \mathrm{L})$ \\
\hline True density & $2.8-2.9 \mathrm{~g} / \mathrm{cm}^{3}$ \\
\hline Volatiles evolved during processing & Water vapor, $\mathrm{SO}_{2}$ \\
\hline
\end{tabular}

The minimum raw material feed rate is estimated to be $5-6 \mathrm{lbs} / \mathrm{hr}(2.5-2.7 \mathrm{~kg} / \mathrm{hr})$, with a residence time in the heated zone between 15 minutes and 1 hour.

\section{General Requirements}

- The kiln must be capable of achieving a working temperature of up to $1350^{\circ} \mathrm{C}$

- The kiln must be fully integrated complete with power supply, temperature and material handling control instrumentation and atmosphere flow control panel

- 3 independent zones of temperature control must be provided

- Temperature control system must be mounted in the base

- Low thermal mass ceramic insulation

- Power supply must be contained in the kiln stand

- Tube and heating elements must be easily accessible

\section{Feed System}

- Volumetric, adjustable speed feeder(s) must be capable of feeding powdered and pelletized raw materials

- Feed hopper should have a minimum of $0.33 \mathrm{ft}^{3}(9.3 \mathrm{~L})$ capacity

- Feeder discharge needs to be shielded from furnace heat

\section{Process Tube}

- Kiln must be capable of using different tube materials including nickel alloy, fused quartz, ceramic mullite and recrystallized silicon carbide 
- Price of different tube materials must be included

- Site port to view inside of kiln during operation is required

- Tube must have a variable speed drive

\section{Product Discharge}

- Discharge needs to be capable of rapidly cooling the product

- Any required fittings for air- or water-cooling must be included with discharge apparatus

\section{Furnace Stand Must Contain:}

- Hydraulic or screw jack to provide variable tube inclination from horizontal

- Mechanism to remove loosely bound deposits from tube during operation

- Power supply and temperature control systems integrated into base of unit

- Indicator mounted on upper stand to indicate tube inclination

\section{Guarding}

- Guarding around electrical and pinch-point areas needs to be provided

- Guards should be readily removable for servicing

\section{Power Control System}

- Kiln must be capable of operating on 220V ( $\pm 10 \%)$ 3-phase power, $60 \mathrm{hz}$

- Control system components must be completely mounted and wired in enclosures that are integral to the furnace's main body

- The University of Kentucky will provide a single power drop to the kiln

- All temperature, power and other controls must be mounted on the kiln and be interconnected within the kiln

- Any additional 110 VAC circuits required for operating ancillary equipment such as materials feeders must be provided and mounted on kiln

\section{Temperature Control}

- Controllers must be mounted to the kiln base

- One digital controller per zone must be provided

- One over-temperature controllers per zone must be provided

- Thermocouples must be capable of accurately measuring temperatures in the range of $200^{\circ} \mathrm{C}$ to $1350^{\circ} \mathrm{C}$

\section{Delivery to University of Kentucky}

Due to project scheduling demands, the kiln must be ready for shipment within 6 months of the receipt of a purchase order from the University of Kentucky.

It is required that the kiln be manufactured in the U.S. Furthermore, it is preferred that, to the extent possible, the materials used to construct the reactor/kiln be produced in the U.S. 
The most critical factors specified for the rotary kiln were maximum operating temperature $\left(1350^{\circ} \mathrm{C}\right)$, residence time in the heated zone (15-60 minutes), throughput (5-6 lbs/hr or 2.5-2.7 $\mathrm{kg} / \mathrm{hr}$ minimum), and ability to use different tube materials (e.g. steel, mullite). Other specific properties specified were a feeder capable of delivering powders and pellets to the kiln, a clinker discharge capable of rapid cooling of the product, and the ability to purge air through the kiln tube in order to remove volatiles during processing.

The milling equipment required to process coal combustion byproducts, raw materials for cement production and clinker were specifically designed for this project. The equipment required is identified in Table 1 , along with the function and status of the equipment at the CAER laboratory.

Table 1. Crushing and Milling Equipment Required for Low Energy Cements.

\begin{tabular}{|c|l|c|}
\hline Equipment & \multicolumn{1}{|c|}{ Function } & Status \\
\hline Jaw Crusher & Crushing to $-2 \mathrm{~mm}$ particle size & Need \\
\hline Disk Mill & Milling to -850 microns & On-site \\
\hline Ring Mill & Milling to -100 to 150 microns & Need \\
\hline Ball Mill & Milling to -80 microns & Need \\
\hline
\end{tabular}

The CAER already operates a jaw crusher for pulverizing a variety of materials, but it is for very large samples and reduces the particles to about $-1 / 4$ inch in size. For the production of low energy cements, the laboratory required a smaller jaw crusher that can effectively process smaller batches of raw materials and clinker and reduce the particle size distribution to $<2 \mathrm{~mm}$. Based on these requirements, a Braun "Chipmunk" Jaw Crusher was specified. It has a maximum throughput of $182 \mathrm{~kg} / \mathrm{hr}$ and has adjustable discharge size of 1.6 to $9.5 \mathrm{~mm}$.

The ball mills used at the CAER, prior to the project, are capable of milling approximately $4 \mathrm{~kg}$ per day, which was not sufficient for larger-scale production of low energy cement. Therefore, a larger ball mill was needed that can mill $15-20 \mathrm{~kg}$ per day of material to -200 mesh (75 microns), without the need for lifting the mill assembly to empty the milling media and product. The Essa $\mathrm{R} / \mathrm{M} 300 \times 360 S S$ ball mill meets these requirements, and was estimated to have a throughput of $16-20 \mathrm{~kg}$ per 8-hour day (Figure 8).

The final milling equipment that was designed will be used to process samples of raw materials, clinker and cement that will be periodically sampled during the production of the low energy cements. These small mills will rapidly reduce the particle size of 10-100 g samples for chemical and XRD analysis and for small-scale paste studies. 

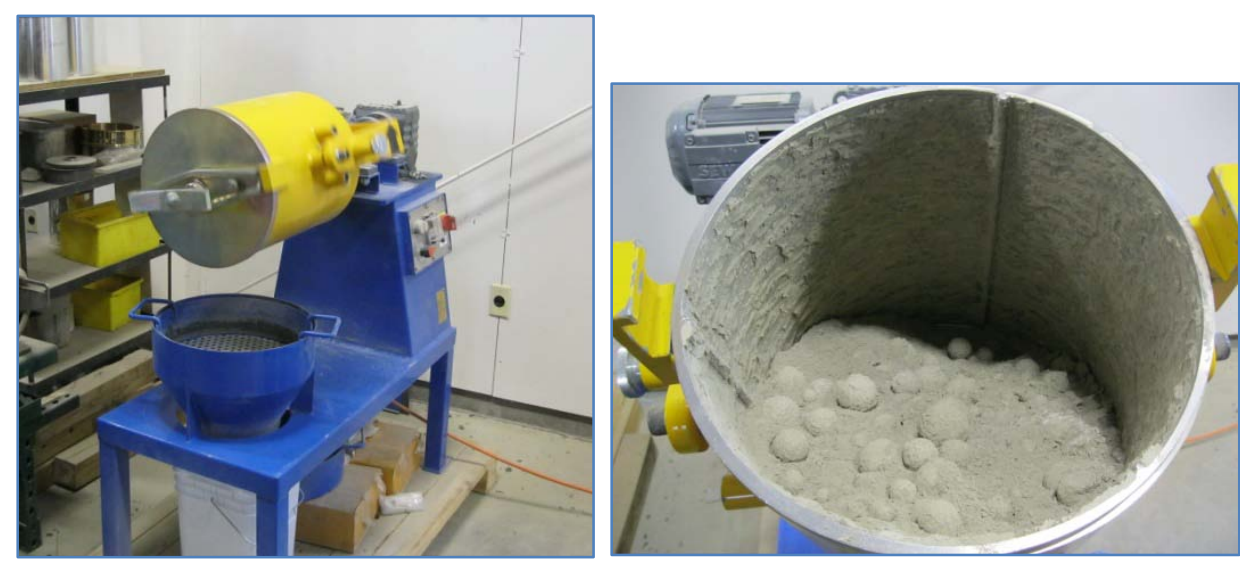

Figure 8. Essa stainless steel, large capacity, ball mill.

During the preliminary design of the rotary kiln, potential risks that were identified were that the raw materials may not properly fuse in the kiln, and could also form deposits on the kiln tube which would cause it to crack when cooled. This would substantially increase the operating costs of the kiln, since each tube is expensive. To minimize these risks, it was decided to pelletize the raw materials in advance of the kiln testing. It is hoped that pelletizing will reduce the surface area of the material in contact with the kiln tube and, combined with the constant rotation of the tube, minimize the deposit of material on the tube. To accomplish the pelletization step, a laboratory pelletizer was purchased and installed at the CAER. Several small batches of pellets were produced to optimize the pelletizer settings to produce hard, uniform pellets.

\section{Box Furnace}

A batch kiln was specified for the production of several kilograms of cement clinker per batch. The kiln selected was a Carbolite RHF $16 / 351600^{\circ} \mathrm{C}$ box furnace with a capacity of approximately $35 \mathrm{~L}$. This kiln is capable of achieving temperatures required for production of all phases in CSA cement, in addition to the higher temperatures required to make batches of Portland cement. 


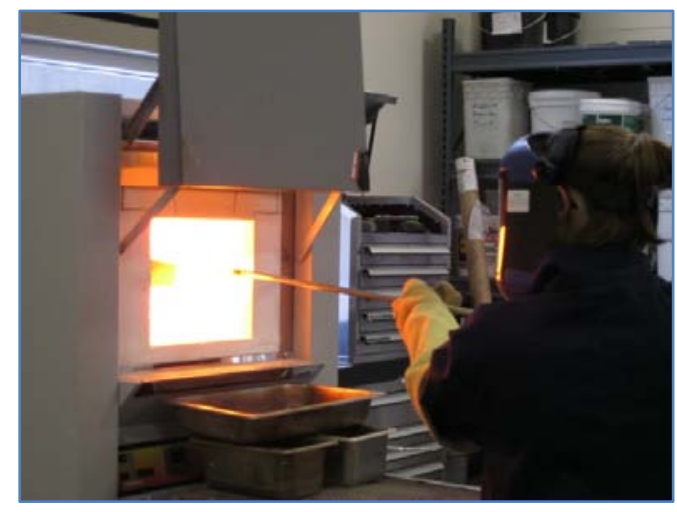

Figure 9. Box furnace used to produce batch quantities of cement for testing.

\section{Universal Testing Machine}

The CAER has an instrument for measurement of compressive and flexural strength of concrete and mortar specimens. Although the instrument is well-suited for basic testing, it has not been adequate for comprehensive characterization of mortar and concrete prepared with the lowenergy, low- $\mathrm{CO}_{2}$ cements produced at the CAER. One major drawback is that, because of the limited quantities of cement that can be produced in the batch furnaces currently used, small specimens of mortar and concrete are necessary. Thus, an instrument needs to be able to accurately and precisely measure strengths in the range of several hundred to several thousand pounds force for smaller, early age specimens, but also be capable of measuring high strength larger specimens. Compressive strength testers, such as the one currently at CAER, are capable of accurately measuring very high strengths (typically 250,000 to 400,000 lbs-force), but are inaccurate in the lower strength ranges. They are also very limited as regards the range of materials testing.

The universal closed-loop testing instrument, Instron 600DX, will be used for tensile, compressive, and flexural strength measurements (Figure 10). Two manufacturers were contacted: Instron and MTS. CAER staff met with representatives from each company to design the appropriate system for concrete and mortar testing. Price quotes were then obtained from each manufacturer and were reviewed. These instruments are capable of a wide range of testing and provide the forces necessary for static tension, compression, bend and shear testing. Although a UTS is capable of measuring very high strength specimens $(110,000$ to $135,000 \mathrm{lb}-\mathrm{f}$ ) it can be fitted with a lower-capacity load cell for measurement of low strength and/or smaller specimens. The overall dimensions of the Instron were also consistent with the space available in the Sustainable Construction Materials Center laboratory building. 


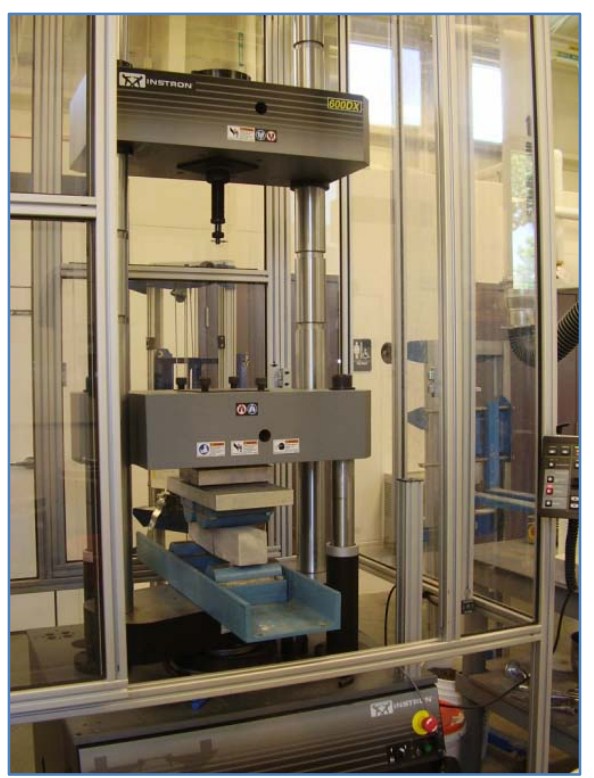

Figure 10. Instron 600DX universal closed-loop testing instrument.

\section{Stereomicroscope}

A stereomicroscope to be used for studying the microstructure of coal combustion byproducts, cements, mortar and concrete was researched and specified for this project. The microscope chosen is a Leica M205C, which has a maximum 20.5:1 zoom, 1280X magnification, and a resolution of $476 \mathrm{~nm}$ (Figure 11). The advantage of acquiring this microscope is that it can be used to acquire 3-dimensional information on the microstructure of the materials listed above, with minimal sample preparation time. To view very fine microstructure and crystallinity a scanning electron microscope was still necessary, although it involves considerable sample preparation and only a very small sample can be observed.

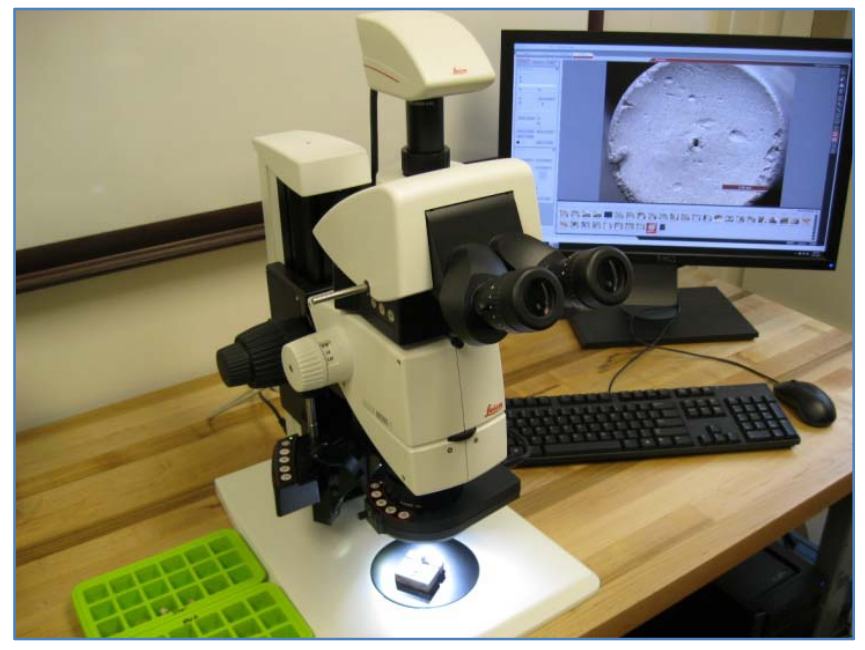

Figure 11. Leica stereomicroscope. 


\section{FIELD TESTING AND FINAL DESIGN OF KILN SYSTEM}

\section{Laboratory Production of Clinker}

Raw materials for low energy cement clinker production were acquired, including fluidized bed combustion (FBC) bottom ash, red mud (a byproduct of aluminum ore processing), hydrated lime and bauxite. These materials were milled to a fine powder and blended in different proportions for the production of two types of cement clinker: a low-iron calcium sulfoaluminatebelite (CSAB) clinker, and a high-iron calcium sulfo-ferroaluminate-belite (CSFAB) clinker. The chemical composition of the raw materials and the mixture proportions are shown in Tables $2 \&$ 3.

Table 2. Chemical Composition of Raw Materials.

\begin{tabular}{|c|c|c|c|c|c|c|c|c|c|c|c|}
\hline \multirow{2}{*}{ Materials } & \multicolumn{11}{|c|}{ Chemical Composition (wt. \%) } \\
\hline & $\mathrm{CaO}$ & $\mathrm{SiO}_{2}$ & $\mathrm{Al}_{2} \mathrm{O}_{3}$ & $\mathrm{Fe}_{2} \mathrm{O}_{3}$ & $\mathrm{SO}_{3}$ & LOI & $\mathrm{MgO}$ & $\mathrm{K}_{2} \mathrm{O}$ & $\mathrm{Na}_{2} \mathrm{O}$ & $\mathrm{CaF}_{2}$ & $\Sigma$ \\
\hline $\begin{array}{l}\text { Hydrated } \\
\text { Lime }\end{array}$ & 69.29 & 3.74 & 1.58 & 0.45 & 0.14 & 24.69 & 2.08 & 0.11 & 0.01 & 0.00 & 102.08 \\
\hline Bauxite & 0.16 & 6.58 & 54.75 & 6.08 & 0.29 & 29.86 & 0.16 & 0.01 & 0.01 & 0.00 & 97.90 \\
\hline $\begin{array}{l}\text { FBC } \\
\text { Bottom } \\
\text { Ash }\end{array}$ & 47.21 & 11.62 & 4.67 & 2.81 & 27.22 & 1.90 & 2.59 & 0.32 & 0.01 & 0.00 & 98.34 \\
\hline Red Mud & 6.76 & 9.89 & 15.03 & 40.49 & 0.38 & 14.43 & 0.22 & 0.20 & 1.65 & 0.0 & 95.49 \\
\hline
\end{tabular}

Table 3. Proportions of Raw Materials for Clinker Production.

\begin{tabular}{|c|c|c|c|c|}
\hline \multirow{2}{*}{ Clinker ID } & \multicolumn{4}{|c|}{ Mixture Ratio (wt. \%) } \\
\cline { 2 - 5 } & $\begin{array}{c}\text { FBC Bottom } \\
\text { Ash }\end{array}$ & Bauxite & $\begin{array}{c}\text { Hydrated } \\
\text { Lime }\end{array}$ & Red Mud \\
\hline CSAB\#4 & 26.85 & 40.82 & 32.33 & 0 \\
\hline CSFAB\#3 & 17.50 & 28.10 & 39.40 & 15.0 \\
\hline
\end{tabular}

Based on the chemical analyses of the individual components, the chemical composition of the raw material mixtures and their resulting clinkers were calculated. These are presented in Tables 4 \& 5. The column denoted "LOI" is loss on ignition, which provides the mass loss that will occur during the clinkering process. 
Table 4. Calculated Compositions of Raw Material Mixtures.

\begin{tabular}{|c|c|c|c|c|c|c|c|c|c|c|}
\hline \multirow{2}{*}{$\begin{array}{c}\text { Clinker } \\
\text { ID }\end{array}$} & \multicolumn{10}{|c|}{ Chemical composition (wt. \%) } \\
\cline { 2 - 13 } & $\mathrm{CaO}$ & $\mathrm{SiO}_{2}$ & $\mathrm{Al}_{2} \mathrm{O}_{3}$ & $\mathrm{Fe}_{2} \mathrm{O}_{3}$ & $\mathrm{SO}_{3}$ & $\mathrm{LOI}$ & $\mathrm{MgO}$ & $\mathrm{K}_{2} \mathrm{O}$ & $\mathrm{Na}_{2} \mathrm{O}$ & $\Sigma$ \\
\hline CSAB\#4 & 35.14 & 7.01 & 24.11 & 3.38 & 7.47 & 20.68 & 1.43 & 0.13 & 0.01 & 99.37 \\
\hline CSFAB\#3 & 35.83 & 6.63 & 19.20 & 8.60 & 4.54 & 21.71 & 1.30 & 0.13 & 0.31 & 100.00 \\
\hline
\end{tabular}

Table 5. Calculated Composition of Clinkers.

\begin{tabular}{|c|c|c|c|c|c|c|c|c|c|c|}
\hline $\begin{array}{c}\text { Clinker } \\
\text { ID }\end{array}$ & \multicolumn{8}{|c|}{ Chemical composition (wt. \%) } \\
\cline { 2 - 14 } & $\mathrm{CaO}$ & $\mathrm{SiO}_{2}$ & $\mathrm{Al}_{2} \mathrm{O}_{3}$ & $\mathrm{Fe}_{2} \mathrm{O}_{3}$ & $\mathrm{SO}_{3}$ & $\mathrm{LOI}$ & $\mathrm{MgO}$ & $\mathrm{K}_{2} \mathrm{O}$ & $\mathrm{Na}_{2} \mathrm{O}$ & $\Sigma$ \\
\hline CSAB\#4 & 44.31 & 8.84 & 30.40 & 4.26 & 9.42 & 0.00 & 1.81 & 0.16 & 0.01 & 99.21 \\
\hline CSFAB\#3 & 45.77 & 8.47 & 24.53 & 10.98 & 5.80 & 0.00 & 1.66 & 0.16 & 0.39 & 100.00 \\
\hline
\end{tabular}

The final step in proportioning the raw materials was to calculate the cementitious phase composition of the two clinker formulations. The calculations are based on stoichiometry of the different phases and take into account the loss on ignition of the raw materials. The phases assumed to be present are calcium sulfoaluminate $\left(\mathrm{C}_{4} \mathrm{~A}_{3} \mathrm{~S}^{\prime}\right)$, which provides the majority of short-term strength in CSA cements, belite $\left(\mathrm{C}_{2} \mathrm{~S}\right)$, which provides long-term strength, calcium ferrite $\left(\mathrm{C}_{4} \mathrm{AF}\right)$, calcium sulfate $\left(\mathrm{CaSO}_{4}\right)$, and lime $(\mathrm{CaO})$. The calculated phase compositions are provided in Table 6.

Table 6. Calculated Phase Composition of Clinkers.

\begin{tabular}{|c|c|c|c|c|c|c|c|c|c|}
\hline \multirow{2}{*}{$\begin{array}{c}\text { Clinker } \\
\text { ID }\end{array}$} & \multicolumn{7}{|c|}{ Phase Composition (wt. \%) } \\
\cline { 2 - 12 } & $\mathrm{C}_{2} \mathrm{~S}$ & $\mathrm{C}_{4} \mathrm{~A}_{3} \mathrm{~S}^{\prime}$ & $\mathrm{C}_{4} \mathrm{AF}$ & $\mathrm{CaSO}_{4}$ & $\begin{array}{c}\text { Assumed } \\
\mathrm{CaO}\end{array}$ & $\mathrm{MgO}$ & $\mathrm{K}_{2} \mathrm{O}$ & $\mathrm{Na}_{2} \mathrm{O}$ & $\Sigma$ \\
\hline CSAB\#4 & $\begin{array}{c}25.3 \\
6\end{array}$ & 55.23 & 12.97 & 3.69 & 0.00 & 1.81 & 0.16 & 0.01 & 99.56 \\
\hline $\begin{array}{c}\text { CSFAB\# } \\
\mathbf{3}\end{array}$ & $\begin{array}{c}21.7 \\
2\end{array}$ & 34.95 & 33.41 & 2.07 & 0.00 & 1.66 & 0.16 & 0.39 & 97.77 \\
\hline
\end{tabular}

A study of the temperature and residence time in the heated zone required to produce highquality CSA clinker from these blends was evaluated in a bench-scale tube furnace in advance of the research kiln evaluation. This is referred to as "burnability" testing, which was conducted at different temperatures and residence times. The materials were prepared by milling in a ball 
mill, followed by pressing into 1 inch diameter $\times 0.25$ inch thick disks. These raw materials were then placed in a furnace and heated to $950^{\circ} \mathrm{C}$ for 30 minutes, followed by 30 minutes at the final reaction temperature. The extent of reaction of free lime with the other components to form the cementitious phases was examined by free lime analysis (ASTM C 114) and X-ray diffraction (XRD) analysis. In general, assuming that the raw material proportions are correct, the lower the free lime content in a clinker the higher the quality. For the clinkers produced here the targeted free lime content was $<1.0 \%$. Table 7 provides the free lime content for CSAB\#4 as a function of reaction temperature. From these data, it was concluded that a temperature of at least $1300^{\circ} \mathrm{C}$ would produce a well-reacted clinker.

Table 7. Free lime content of clinkers produced in a laboratory tube furnace.

\begin{tabular}{|l|c|c|c|}
\hline \multirow{2}{*}{$\begin{array}{l}\text { Formula } \\
\text { Number }\end{array}$} & \multicolumn{3}{|c|}{ Free Lime \% } \\
\cline { 2 - 4 } & $1250^{\circ} \mathrm{C}$ & $1300^{\circ} \mathrm{C}$ & $1350^{\circ} \mathrm{C}$ \\
\hline CSAB-04 & 2.74 & 0.62 & 0.37 \\
\hline
\end{tabular}

XRD analysis of the clinkers is provided in Figure 12 below, with several peaks labeled with the phase that they indicate. These data are consistent with the free lime analysis: there was significant free lime in the clinker produced at $1250^{\circ} \mathrm{C}$, but was below detection limits in the 1300 and $1350^{\circ} \mathrm{C}$ clinkers. The XRD analysis also indicated that tricalcium aluminate, which is not a desired phase, formed in the $1350^{\circ} \mathrm{C}$ clinker. This is known to form if CSA clinkers are produced at too high a temperature. 


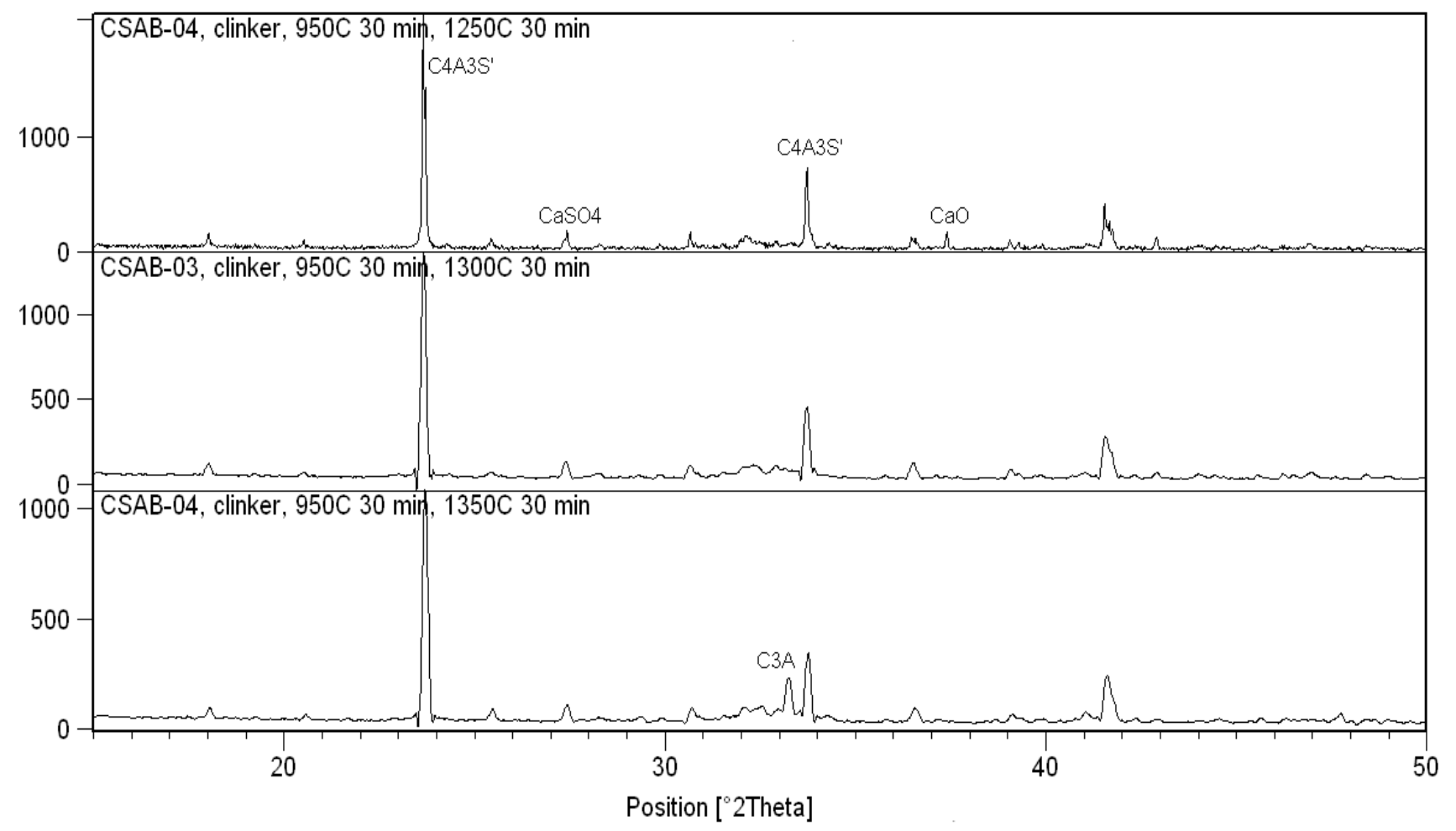

Figure 12. XRD analysis of laboratory CSAB\#4 clinkers.

Thus, from the free lime and XRD data, it was concluded that $1300^{\circ} \mathrm{C}$ would likely be the optimum temperature for the rotary kiln test. It was also decided that $1250^{\circ} \mathrm{C}$ would be tested for the CSAB\#4 clinker as well.

The high iron CSFAB\#3 clinker was produced using the same residence times as the CSAB\#4 clinker, but only at a temperature of $1250^{\circ} \mathrm{C}$. Despite this relatively low clinkering temperature, the free lime content was only about $1 \%$. The XRD pattern for the laboratory-produced clinker is provided in Figure 13. 


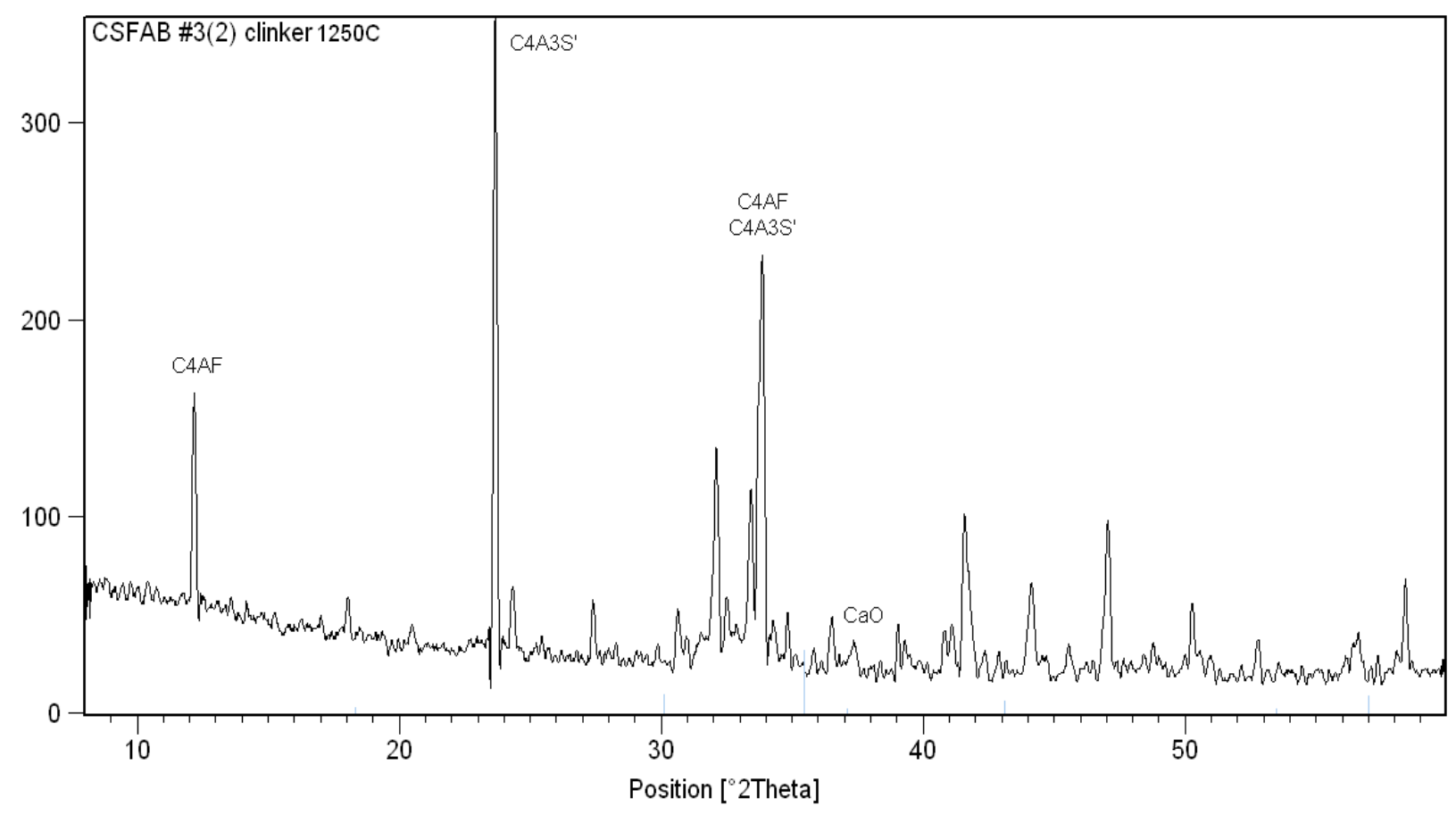

Figure 13. XRD pattern for laboratory CSFAB\#3 clinker.

The XRD data are consistent with the free lime analysis and indicate only a small amount of free lime existed in the clinker.

\section{Preparation of Raw Materials for Rotary Kiln Testing}

After completing the bench-scale burnability study, the two formulations of raw materials were prepared as described above. However, instead of pressing the materials into disks, the raw materials were pelletized in a pan pelletizer (Figure 14).

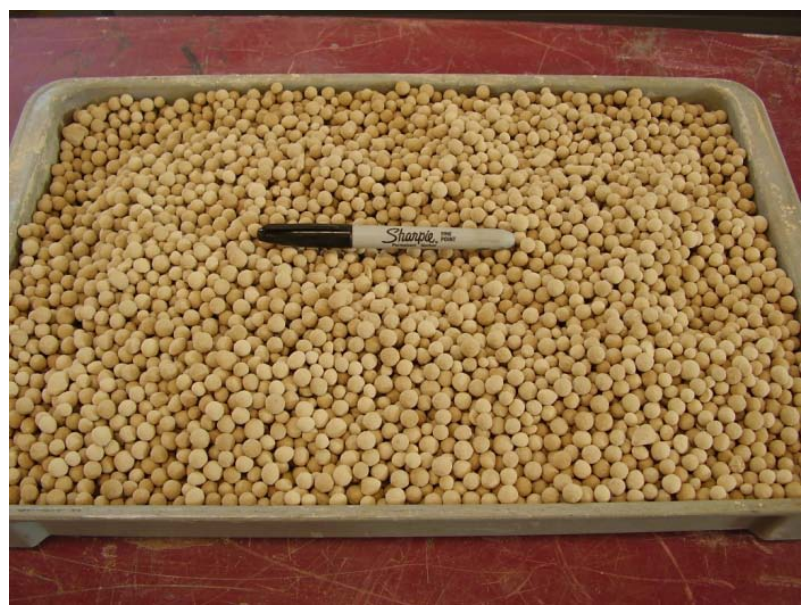


Figure 14. Pelletized raw materials for kiln test.

The pellets were oven-dried at $65^{\circ} \mathrm{C}$ and shipped to HED International for the rotary kiln testing/evaluation.

\section{Rotary Kiln Testing}

On February 17 \& 18 2010, CAER personnel travelled to HED in Ringoes, NJ to conduct the testing. The raw materials were clinkered using a Unique/Pereny RTC-3/72 rotary tube furnace equipped with a 3 inch diameter $X 6 \mathrm{ft}$. long mullite tube. The raw materials were heated in the rotary tube furnace at three temperatures which are listed in Table 8 . The kiln rotational speed and angle was adjusted to obtain the desired residence time. However, in initial tests the residence time of the pellets in the kiln varied from 15 minutes to 45 minutes, which is an unacceptable residence time distribution. It was determined that there was not enough material being fed to the kiln to achieve steady state conditions. Thus, the feed rate of the pellets into the kiln was increased in order to fill the kiln tube to approximately $1 / 8$ full along the entire length of the tube. The mean residence time was then determined to be approximately 30-45 minutes.

Table 8. Processing temperatures for rotary kiln clinkers.

\begin{tabular}{|c|c|c|c|}
\hline \multirow{2}{*}{ Clinker ID } & \multicolumn{3}{|c|}{ Clinkering Temperature } \\
\cline { 2 - 4 } & $1250^{\circ} \mathrm{C}$ & $1275^{\circ} \mathrm{C}$ & $1300^{\circ} \mathrm{C}$ \\
\hline CSAB\#4 & $\sqrt{ }$ & & $\sqrt{ }$ \\
\hline CSFAB\#3 & & $\sqrt{ }$ \\
\hline
\end{tabular}

\section{Analysis of Rotary Kiln Clinkers}

After conducting the testing, the rotary kiln clinkers were shipped to the CAER for analysis. The clinkers were analyzed for chemical composition free lime content, and phase composition by XRD. The chemical composition of the clinkers is provided in Table 9, and compared to their calculated composition.

Table 9. Chemical Composition of Rotary Kiln Clinkers.

\begin{tabular}{|c|c|c|c|c|c|}
\hline \multirow{2}{*}{$\begin{array}{c}\text { Elemental } \\
\text { Oxide }\end{array}$} & \multicolumn{3}{|c|}{ CSAB\#4 } & \multicolumn{2}{c|}{ CSFAB\#3 } \\
\hline $\mathbf{S i O}_{\mathbf{2}} \mathbf{( \% )}$ & Calculated & Rotary 1250 & Rotary 1300 & Calculated & Rotary 1275 \\
\hline $\mathrm{Al}_{\mathbf{2}} \mathbf{O}_{\mathbf{3}} \mathbf{( \% )}$ & 8.84 & 9.97 & 10.06 & 8.47 & 8.26 \\
\hline $\mathrm{Fe}_{\mathbf{2}} \mathbf{O}_{\mathbf{3}} \mathbf{( \% )}$ & 30.40 & 29.32 & 29.33 & 24.53 & 23.52 \\
\hline $\mathbf{C a O}(\%)$ & 4.26 & 3.51 & 3.53 & 10.98 & 8.66 \\
\hline $\mathbf{M g O}(\%)$ & 44.31 & 45.39 & 45.81 & 45.77 & 48.05 \\
\hline $\mathrm{Na}_{\mathbf{2}} \mathbf{O}(\%)$ & 1.81 & 1.86 & 1.86 & 1.66 & 1.71 \\
\hline $\mathbf{K}_{\mathbf{2}} \mathbf{O}(\%)$ & 0.01 & $<0.01$ & $<0.01$ & 0.39 & 0.06 \\
\hline $\mathbf{S O}_{\mathbf{3}} \mathbf{( \% )}$ & 0.16 & 0.04 & 0.05 & 0.16 & 0.21 \\
\hline & 9.42 & 10.41 & 9.73 & 5.80 & 8.00 \\
\hline
\end{tabular}


The free lime content of the rotary kiln clinkers was higher than that of the laboratory clinkers (Table 10). This suggests that, although the rotary kiln effectively clinkered the raw materials, the materials would likely need a longer residence time.

Table 10. Free Lime Content of Rotary Kiln Clinkers.

\begin{tabular}{|c|c|c|}
\hline \multirow{2}{*}{ Clinker ID } & \multicolumn{2}{|c|}{ Free Lime (\%) } \\
\cline { 2 - 3 } & Laboratory & Rotary Kiln \\
\hline CSAB\#4 $1250^{\circ} \mathrm{C}$ & 2.74 & 3.58 \\
\hline CSAB\#4 $1300^{\circ} \mathrm{C}$ & 0.62 & 2.25 \\
\hline CSFAB\#3 $1275^{\circ} \mathrm{C}$ & 1.0 & 0.83 \\
\hline
\end{tabular}

The XRD spectra for the rotary clinkers are shown in Figures 15, 16 \& 17, and are compared with the laboratory equivalents. These data support the free lime analysis; the rotary kiln CSAB\#4 clinkers had a greater quantity of unreacted lime than the laboratory clinkers and would probably require a greater residence time in the kiln. However, the quality of the high-iron CSFAB\#3 rotary kiln clinker was similar to the laboratory clinker.

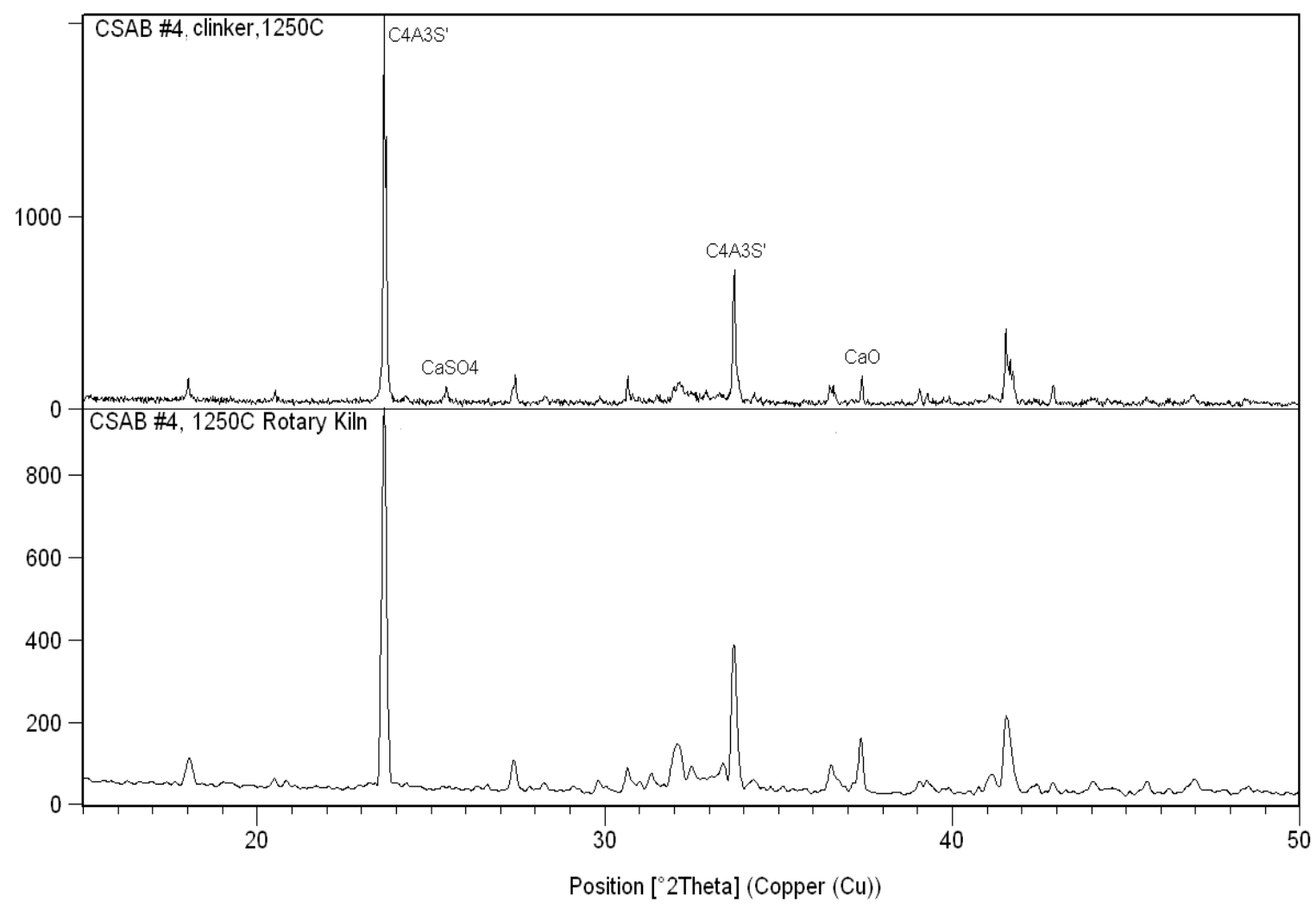

Figure 15. XRD spectra of CSAB\#4 $1250^{\circ} \mathrm{C}$ clinkers. 


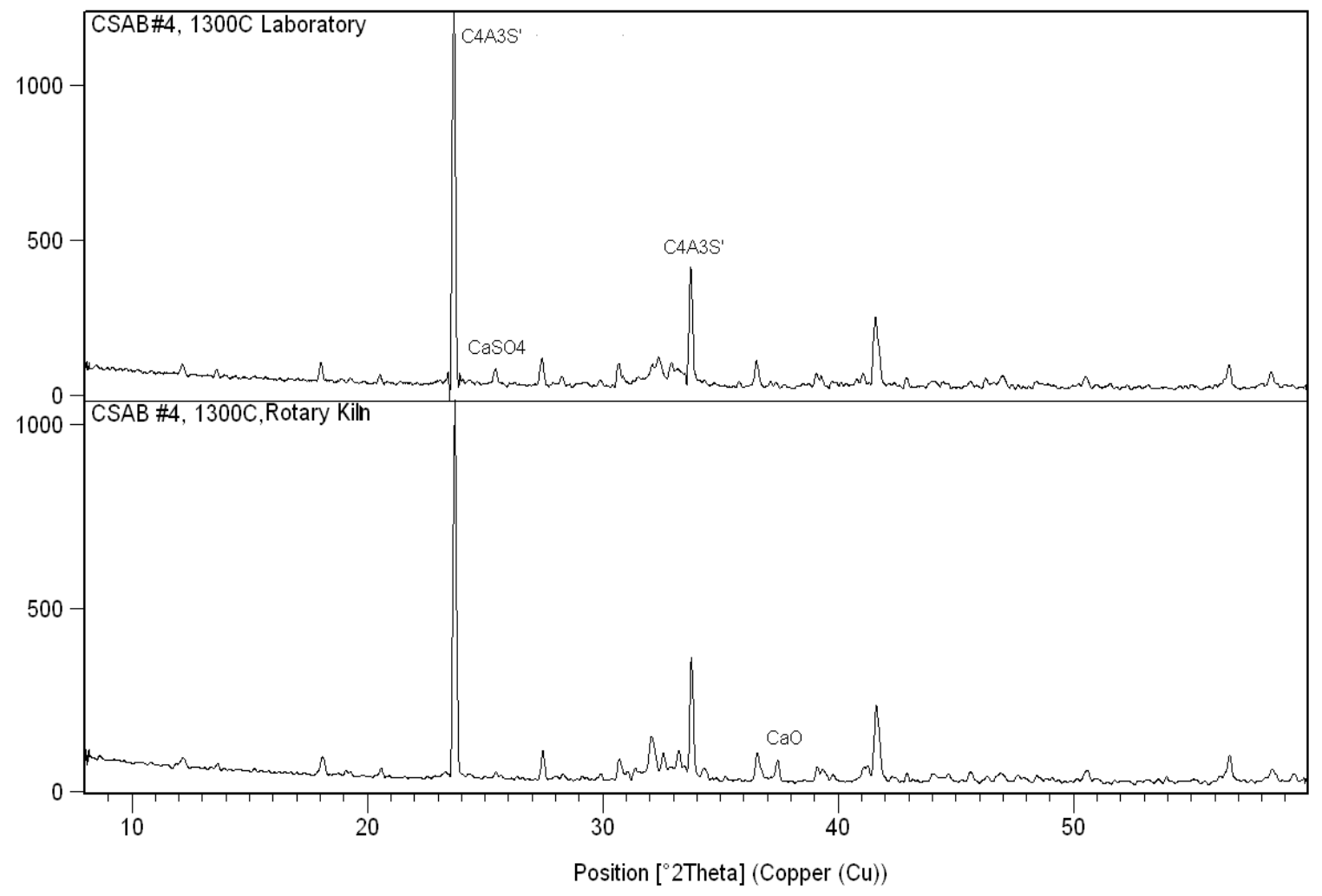

Figure 16. XRD spectra of CSAB\#4 $1300^{\circ} \mathrm{C}$ clinkers. 


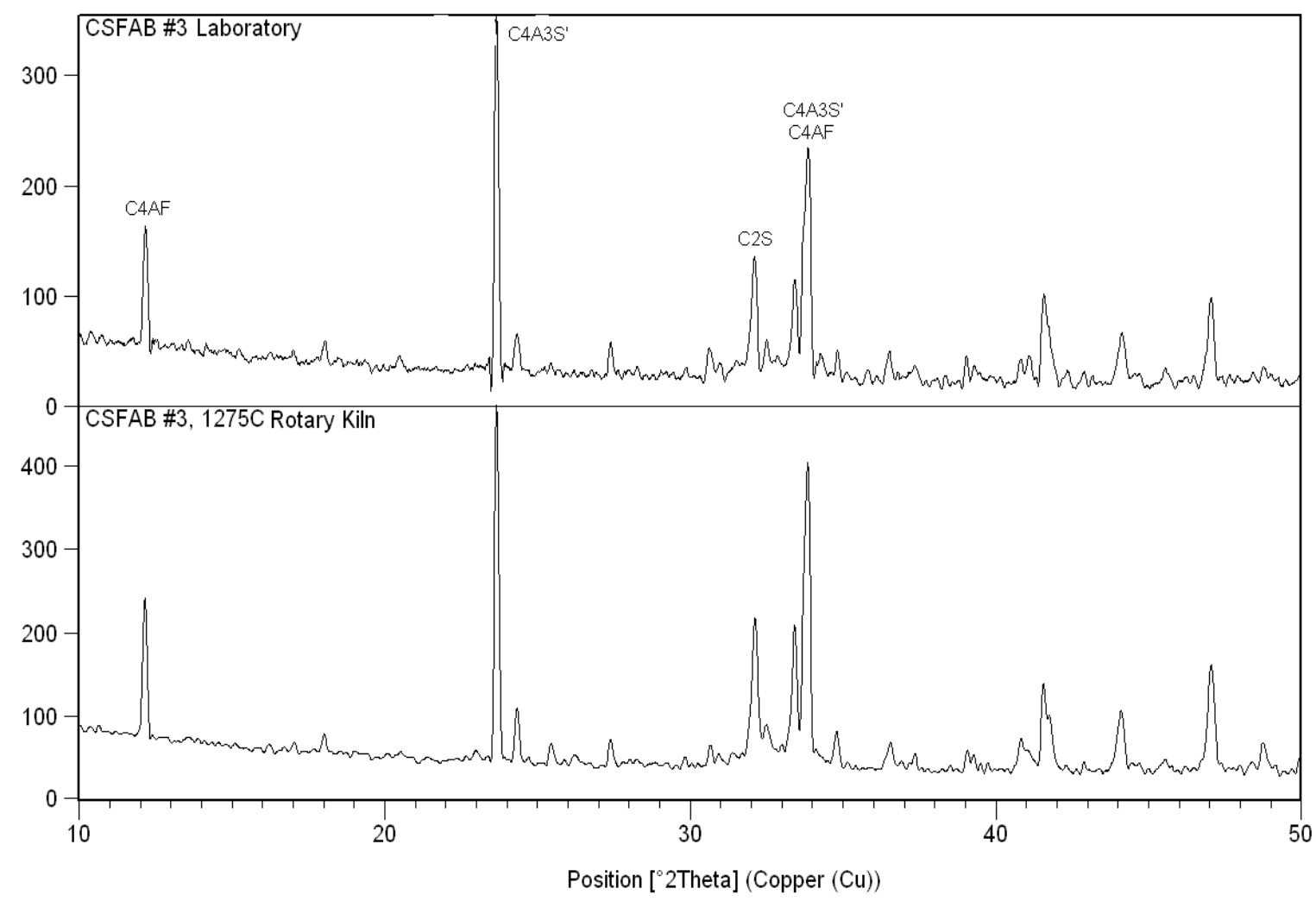

Figure 17. XRD spectra of CSFAB\#3 clinkers.

In order to investigate if a longer residence time in the rotary kiln would improve the clinker quality, the CSAB\#4 $1250^{\circ} \mathrm{C}$ and $1300^{\circ} \mathrm{C}$ rotary clinkers were re-heated in a tube furnace at the CAER for an additional 15 and 30 minutes. The re-heated clinkers were then analyzed for free lime content (Table 11).

Table 11. Free Lime Content of Re-Heated Rotary Clinkers.

\begin{tabular}{|c|c|c|c|}
\hline \multirow{2}{*}{ Clinker ID } & \multicolumn{3}{|c|}{ Re-Heat Time in the Laboratory Tube Furnace } \\
\cline { 2 - 4 } & $+0 \mathrm{~min}$ & $+15 \mathrm{~min}$ & $+30 \mathrm{~min}$ \\
\hline CSAB\#4 $1250^{\circ} \mathbf{C}$ & 3.58 & 0.98 & 1.13 \\
\hline $\mathbf{C S A B \# 4 ~} 1300^{\circ} \mathrm{C}$ & 2.25 & 0.65 & 0.54 \\
\hline
\end{tabular}

Based on these analyses, it was concluded that an additional 15 minute residence time for the CSAB\#4 pellets in the rotary kiln would produce a high-quality clinker

\section{Purchasing}

Table 12 provides a list of the kiln-related equipment, lead times for delivery, project deadline, and calculated ordering deadline i.e. the latest possible date for ordering an item to keep the project on-schedule. The table assumes that a rotary kiln will be purchased and thus provides a 
conservative time estimate because of the long lead-time for the kiln delivery. If other kilns are purchased, such as box kilns, the lead times will be much shorter.

Table 12. Kiln-related equipment purchasing schedule.

\begin{tabular}{|c|c|c|c|}
\hline Equipment Item & Lead time (days) & Project Deadline & Ordering Deadline \\
\hline Rotary kiln & 168 & $9 / 03 / 2010$ & $3 / 01 / 2010$ \\
\hline Solids feeder & 45 & $9 / 03 / 2010$ & $7 / 01 / 2010$ \\
\hline Large ball mills & 90 & $9 / 03 / 2010$ & $6 / 01 / 2010$ \\
\hline Ring mill & 30 & $9 / 03 / 2010$ & $8 / 01 / 2010$ \\
\hline Small ball mill & 30 & $9 / 03 / 2010$ & $8 / 01 / 2010$ \\
\hline
\end{tabular}

After ordering the kiln and milling equipment, the laboratory facility was prepared for the equipment. The electrical service requirement for the rotary kiln was $208 \mathrm{~V} 3$ phase, $60 \mathrm{~Hz}$ power with a connected load of 30-45 kW. The laboratory infrastructure was updated to accommodate the necessary power requirements the continuous kiln.

Table 13 provides a list of major equipment related to analytical and concrete testing that will be designed for the Center. Included are milestone deadlines for purchasing and installation, anticipated lead-times for delivery, and estimated deadlines for manufacturer selection and ordering. Major equipment is generally that which costs greater than $\$ 5,000$.

Table 13. Major equipment purchasing schedule.

\begin{tabular}{|c|c|c|c|}
\hline Equipment Item & Lead time (days) & Project Deadline & Ordering Deadline \\
\hline Universal testing machine & 90 & $6 / 15 / 2010$ & $3 / 15 / 2010$ \\
\hline Particle size analyzer & 60 & $6 / 15 / 2010$ & $4 / 12 / 2010$ \\
\hline Stereo microscope & 45 & $6 / 15 / 2010$ & $4 / 26 / 2010$ \\
\hline Autoclave & 30 & $6 / 15 / 2010$ & $5 / 07 / 2010$ \\
\hline Misc. small equipment & $\mathrm{Na}$ & $6 / 15 / 2010$ & na \\
\hline
\end{tabular}

\section{Construction and Testing of Equipment}

While the kiln is the heart of the clinker production effort, successful operation of this unit process required extensive ancillary equipment to both prepare kiln feed and kiln products. Specific feed preparation unit operations included milling, grinding, blending and pelletizing. In order to conduct these unit operations at the scale anticipated, it was necessary to design adequate solids handling systems that provide a safe, efficient working environment. The solids handling system included mechanized hoisting and loading wherever possible with particular attention to minimizing dust generation with dust control and ventilation.

Feed material grinding was accomplished with batch rotary ball mills equipped with noise abatement enclosures to provide a safe working environment (Figure 10). Pelletization was conducted with a continuous rotary pan, or cone pelletizer, fed from a hopper with a vibratory feeder. Clinker grinding was completed with the same ball mills used for feed material. 
Grinding studies were conducted on the raw materials (i.e. bed ash, bauxite and limestone) identifying the proper grinding charge, rotation speed and residence time to identify proper grinding parameters. Samples were collected under various operating conditions and analyzed for size distribution using laser diffraction. All materials for the production of the low-energy cements were ground to an average particle size $\left(d_{50}\right)$ of $10 \mu \mathrm{m}$. Once the desired grinding conditions were identified, an appropriate quantity of each feed component was generated (approximately $100 \mathrm{lbs}$ each) to facilitate pelletization studies.

In November 2010 a technician from Cilas installed the 1090 laser diffraction particle size analyzer. The analyzer is capable of measuring the particle size distribution of powders in a dry form or pre-dispersed in solution. It also contains a system for the recirculation of alcohol to aid in the analysis of cement and clinker. Figure 18 shows the analyzer in the laboratory.

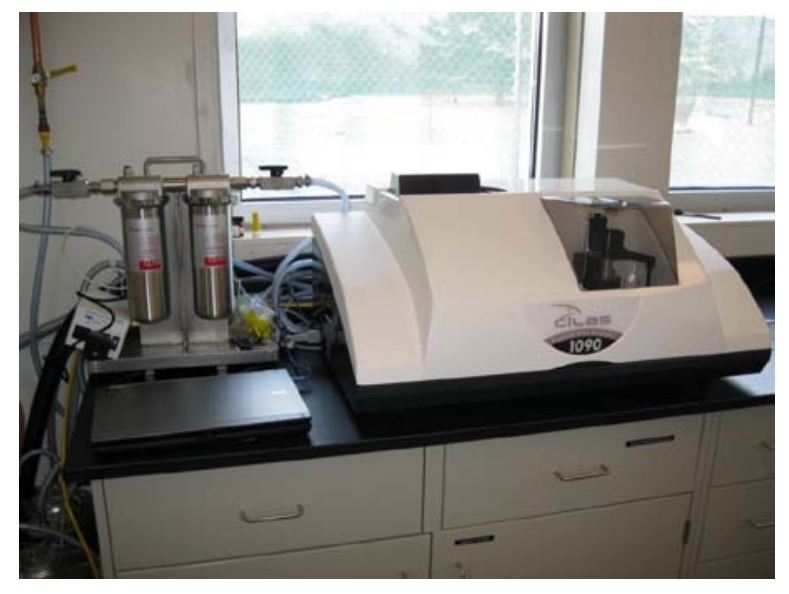

Figure 18. Cilas 1090 particle size analyzer with alcohol recirculation system (on the left).

The ground feed materials were thoroughly blended and transferred to a feed hopper for pelletization studies. Pelletization parameters that were investigated include feed rate, rotation speed, inclination angle, scraper location and discharge height. Once the desired pelletizing conditions were identified, the pelletizer was operated to produce a sufficient quantity of pelletized feed to initiate kiln operation studies.

Pelletized feed will be transferred to a hopper and fed into the pre-heated kiln to produce CSA clinker. Primary operating variables that were investigated include feed rate, temperature, and rotation speed. Clinker produced under each condition were sampled and evaluated for chemical phase composition using XRD. Once the desired kiln operating conditions were identified to produce the desired clinker composition, the kiln was operated continuously to produce a sufficient quantity of clinker (approximately $50 \mathrm{lbs}$ ) to conduct clinker grinding studies with the ball mills used for feed preparation. As with feed grinding studies, the clinker was crushed and transferred to the ball mill where grind charge, rotation speed and residence time were investigated to produce the desired product size distribution (i.e. $d_{50}<10 \mu \mathrm{m}$ ) as verified by laser diffraction particle size analysis. 
The equipment described above was acquired and installed in the laboratory facility during this project. CAER already has a variety of conventional mortar and concrete testing equipment which was an important component of evaluating CSA performance. However, additional testing equipment was necessary to develop a comprehensive performance testing program, with an emphasis on long-term durability. Identification of specific testing requirements is as ongoing effort at CAER and continued throughout the duration of the project. Since much of this type such testing is not routinely conducted at testing facilities, it was necessary to fabricate some of the necessary equipment.

\section{Shakedown Operation of Rotary Kiln System}

On December 20-21 2010, an engineer from the kiln manufacturer (HED International) visited the laboratory to assist with kiln start-up and "dry out". This latter step must be accomplished gradually to prevent cracking of the refractory and was completed by slowly heating the kiln to $500^{\circ} \mathrm{C}$ and soaking it at that temperature for 6 hours. Although this step was accomplished without any problems, there were subsequent problems encountered with the tube drive mechanism. The main issue involved the insulation tending to slip out of the shoes that hold the tube in-place on each end of the kiln (Figure 3). It is believed that this problem was primarily caused by the large weight of the rotating stainless steel tube compressing the insulation on the lower shoes as the tube rotated, thus causing the insulation to migrate out of the shoes. This was solved by running the kiln slowly at room temperature for several hours whilst tightening down the shoes periodically against the compressed insulation (Figure 19). After a while, the insulation stabilized and remained in-place. 


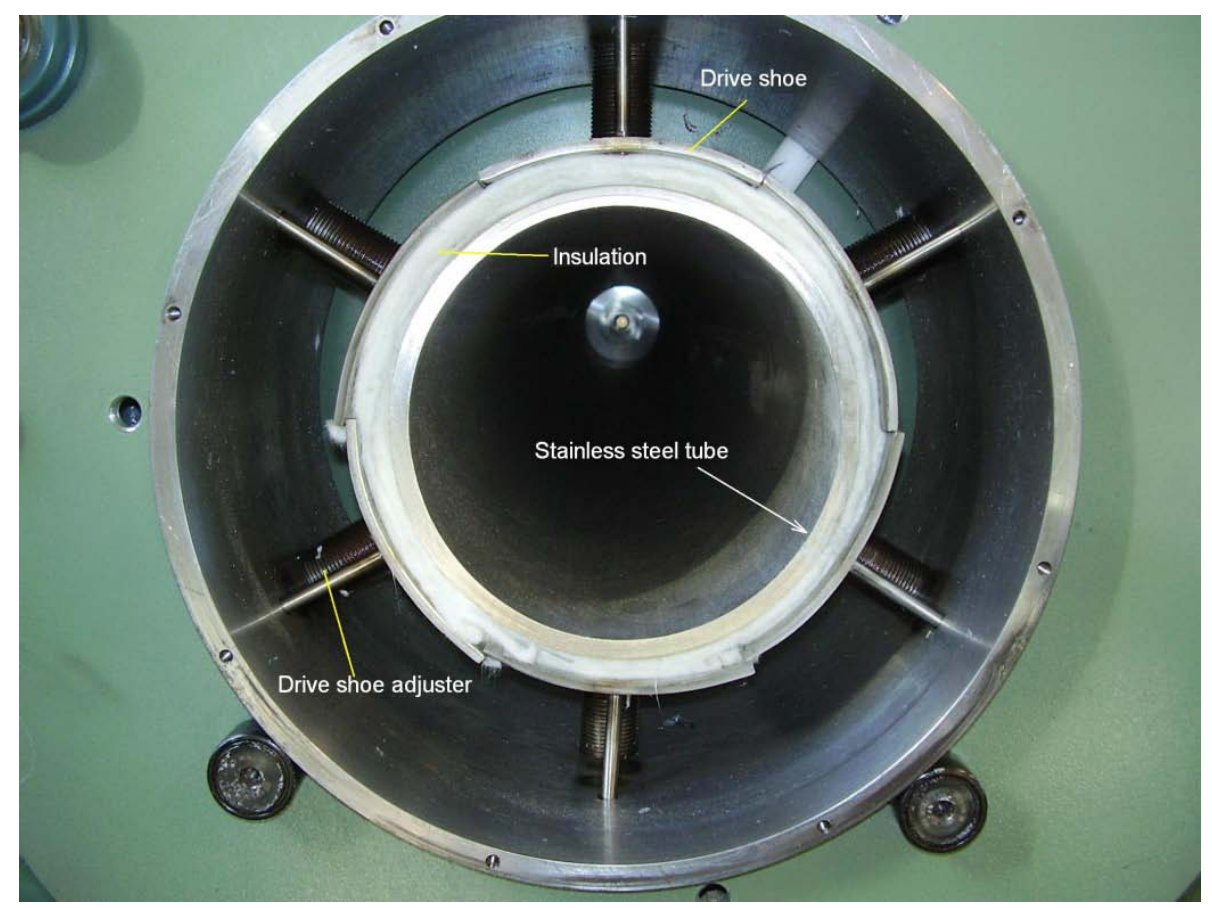

Figure 19. Photograph of the feed-end of the rotary kiln showing the tube drive mechanism. There is a similar mechanism on the discharge end, and both are chain driven by an electric motor through a common shaft which runs along the length of the kiln.

After the issue with the insulation was solved, the stainless steel tube was removed and a mullite tube was inserted. The stainless steel tube will be suitable for processing materials at relatively low temperatures, such as the FGD gypsum conversion to anhydrite at $500-600^{\circ} \mathrm{C}$, whereas the mullite tube will be used to produce cement clinker at $1250-1300^{\circ} \mathrm{C}$.

A more significant problem was encountered with the raw material feeder that was supplied as part of the kiln system. The feeder is a Schenk AccuRate volumetric feeder with a screw mechanism to feed material into the kiln (Figure 20A). It was found that the screw feeder crushed the pelletized feed instead of discharging it intact from the end of the feeder tube, although the ability to feed pelletized material was specified by CAER as a requirement for the kiln. A solution to this problem was pursued by Schenk Accurate and HED International. A smaller diameter screw was used with a wider barrel (Figure 20B). This greatly reduced the number of pellets that were crushed within the feed system. In June 2011, HED International sent an employee to fabricate a new base to support the new feeder from Schenck AccuRate. The new feeder design was passed on the material that was shipped to AccuRate in late January 2011. The new feeder has a larger volume holding capacity in order to accommodate a larger feed tunnel with a helix shaft. The larger feed tunnel prevents allows the pellets to move freely from the feeder into the kiln with no signs of crushing (Figure 20B). 

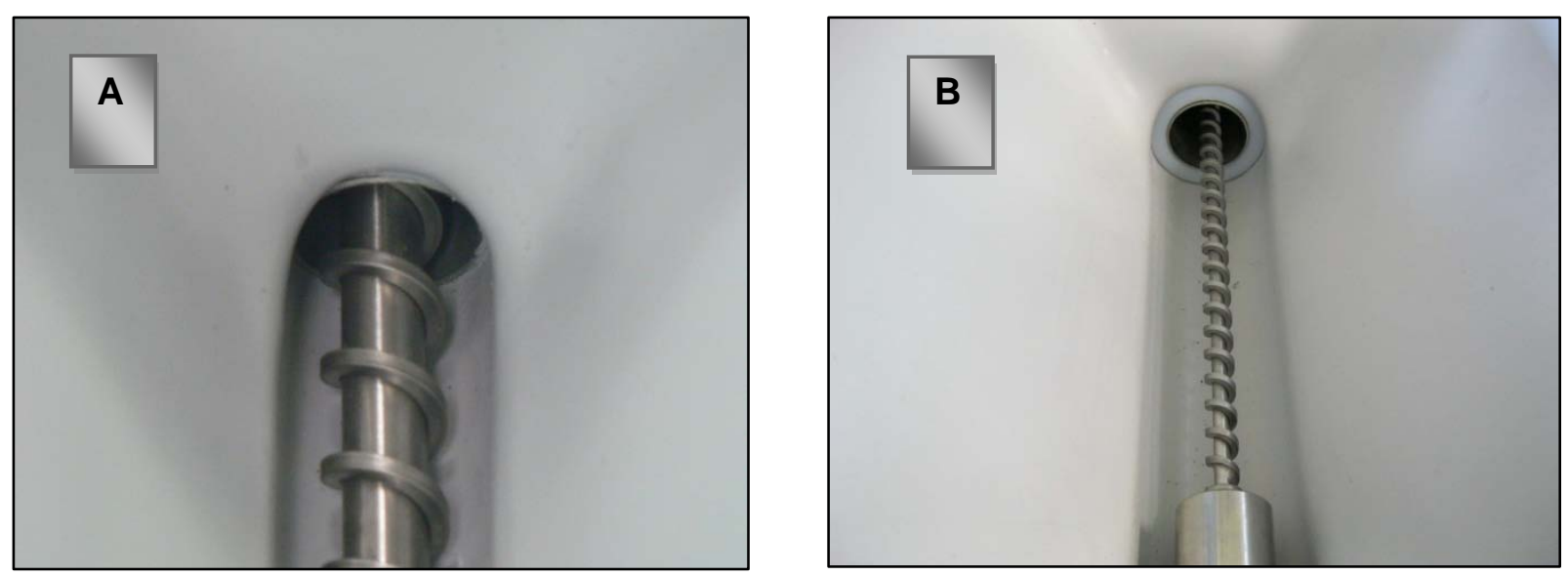

Figure 20. A) Image of original Schenck AccuRate feeder with narrow tunnel opening. B) Image of new feeder with larger tunnel opening to prevent crushing of the pellets.

A second problem with the feeder concerned the length of the stainless steel feed tube (Figure 21), which is not long enough to actually deliver material into the rotating kiln tube. The solution to the feeder was corrected by Schenck AccuRate as shown in Figure 22.

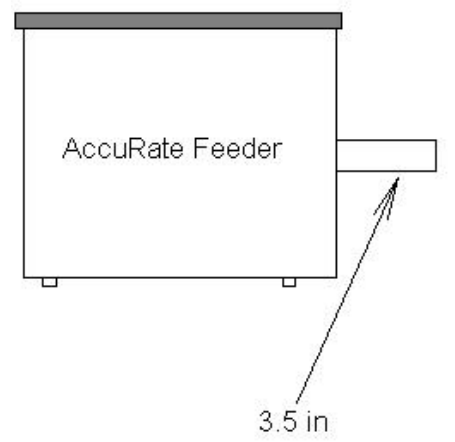

\section{Feed End of Kiln}

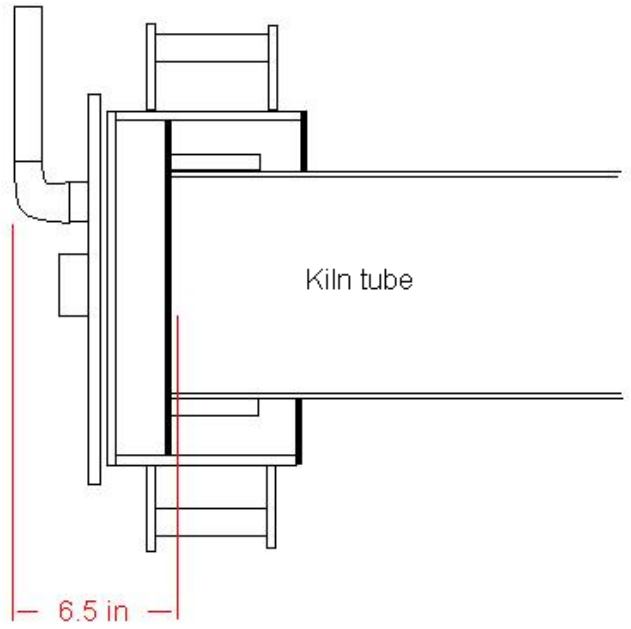

Figure 21. Schematic of kiln feed end, showing required distance from feeder to kiln tube (6.5 inches), versus the actual length of the feeder screw and tube (3.5 inches). 


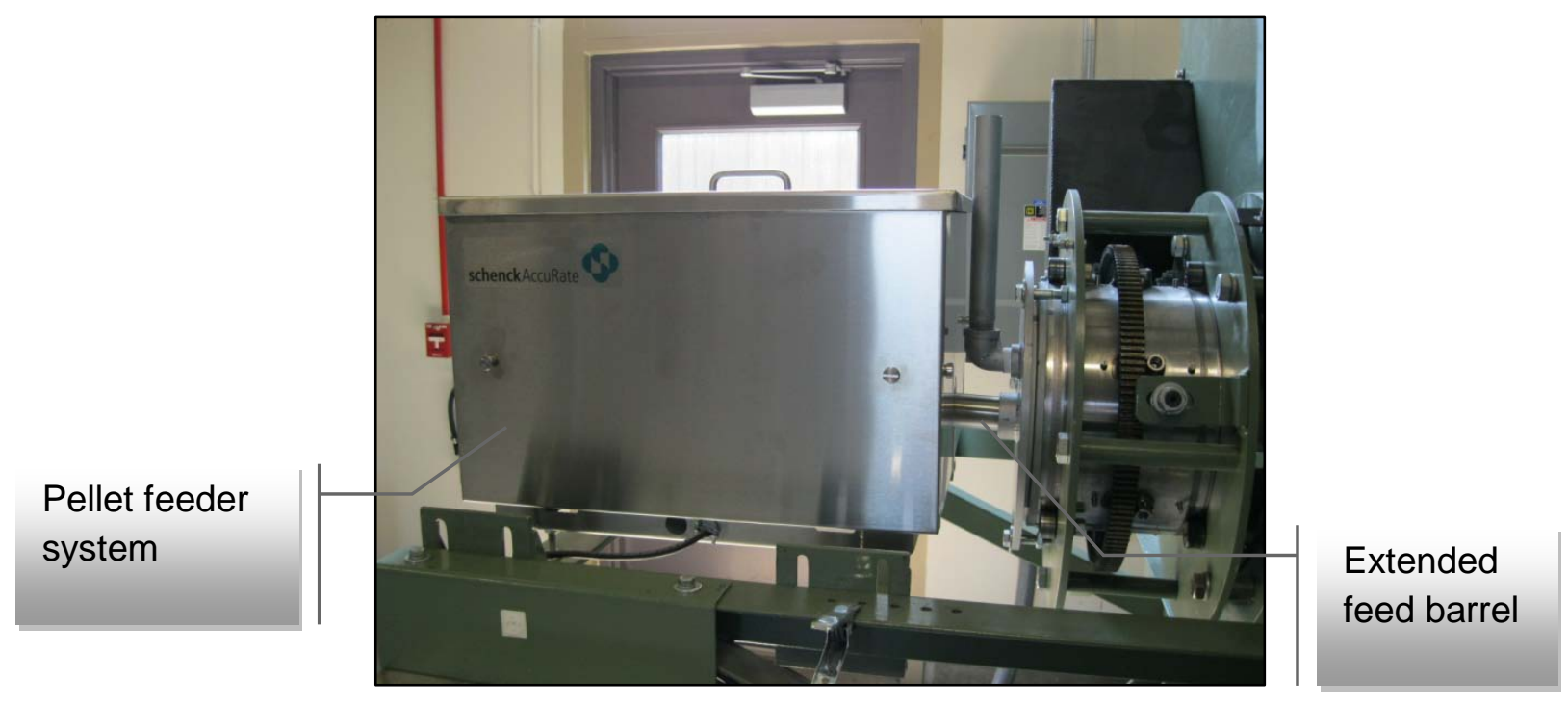

Figure 22. Finalized feeder design with longer feed barrel and enclosed feed screw.

After installation of the new feeder system, the kiln was then programmed for a test run to evaluate if the target temperature $\left(1250^{\circ} \mathrm{C}\right)$ would be attained and in what amount of time. Unfortunately after 28 hours of operation the kiln only reached a temperature of $930^{\circ} \mathrm{C}$. Of greater concern was that the supply line, encased in conduit, was overheating to the point of possibly starting a fire.

One solution, which was completed on July $28^{\text {th }}$, was to upgrade the power supply wiring to a 150 amp circuit. The original circuit was rated for $208 \mathrm{~V} / 100$ amps which was creating too much resistance in the wiring, and therefore was not sufficient to operate the kiln. The kiln was designed for 127 amps, so the new 150 amp circuit should provide adequate power to the kiln. In order to upgrade the wiring, new conduit, fuse panel, 10 gauge wiring, new disconnect box, and wire tail from the disconnect box to the kiln had to be installed (Figure 23). This upgrade has resolved the extremely slow heating problem; the $1250^{\circ} \mathrm{C}$ operating temperature was attainable after eight hours of heating. The finalized rotary kiln configuration can be seen with all necessary components attached in figure 24 and figure 25. 


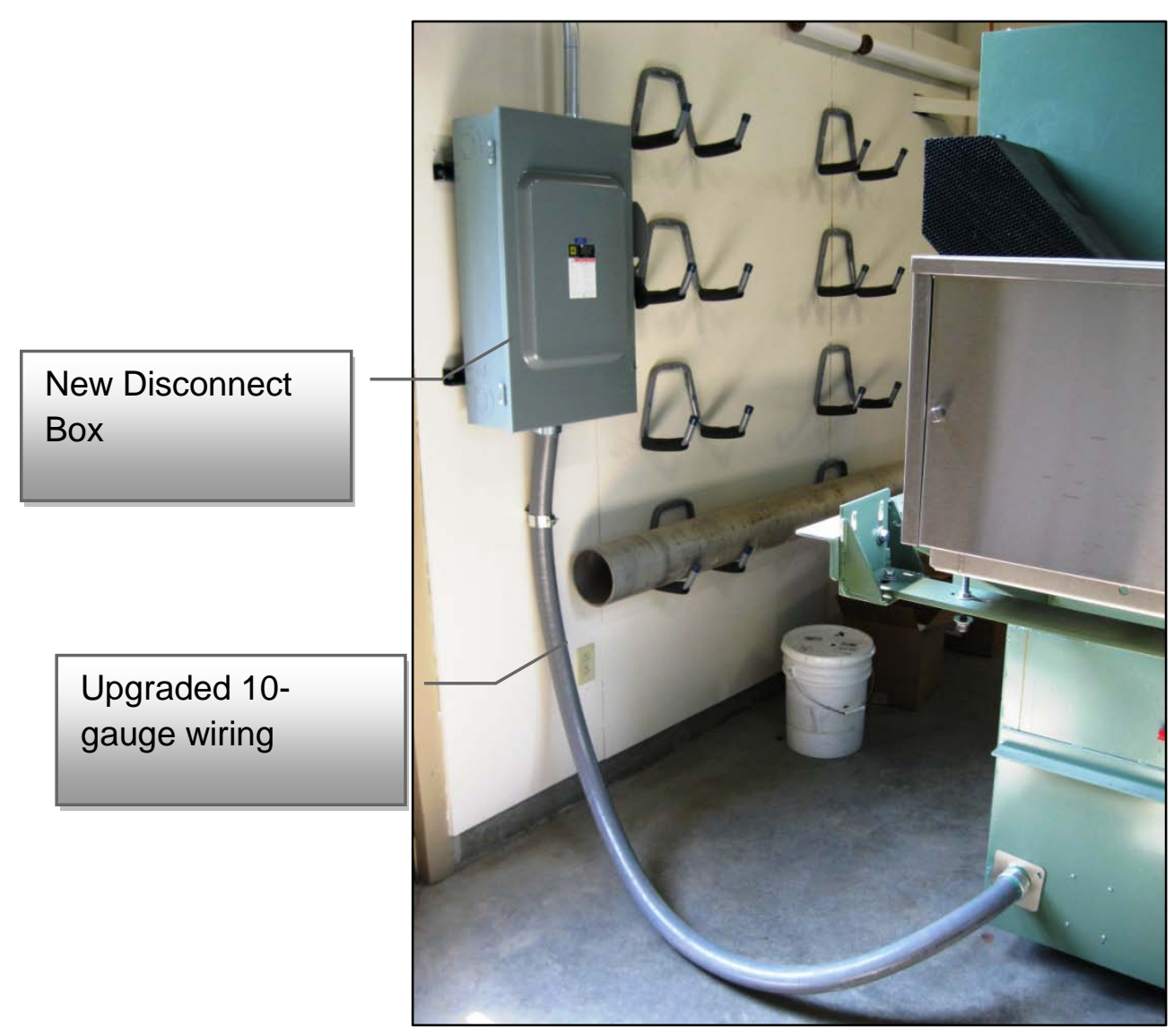

Figure 23. Upgraded disconnect box and wiring for the rotary kiln. 


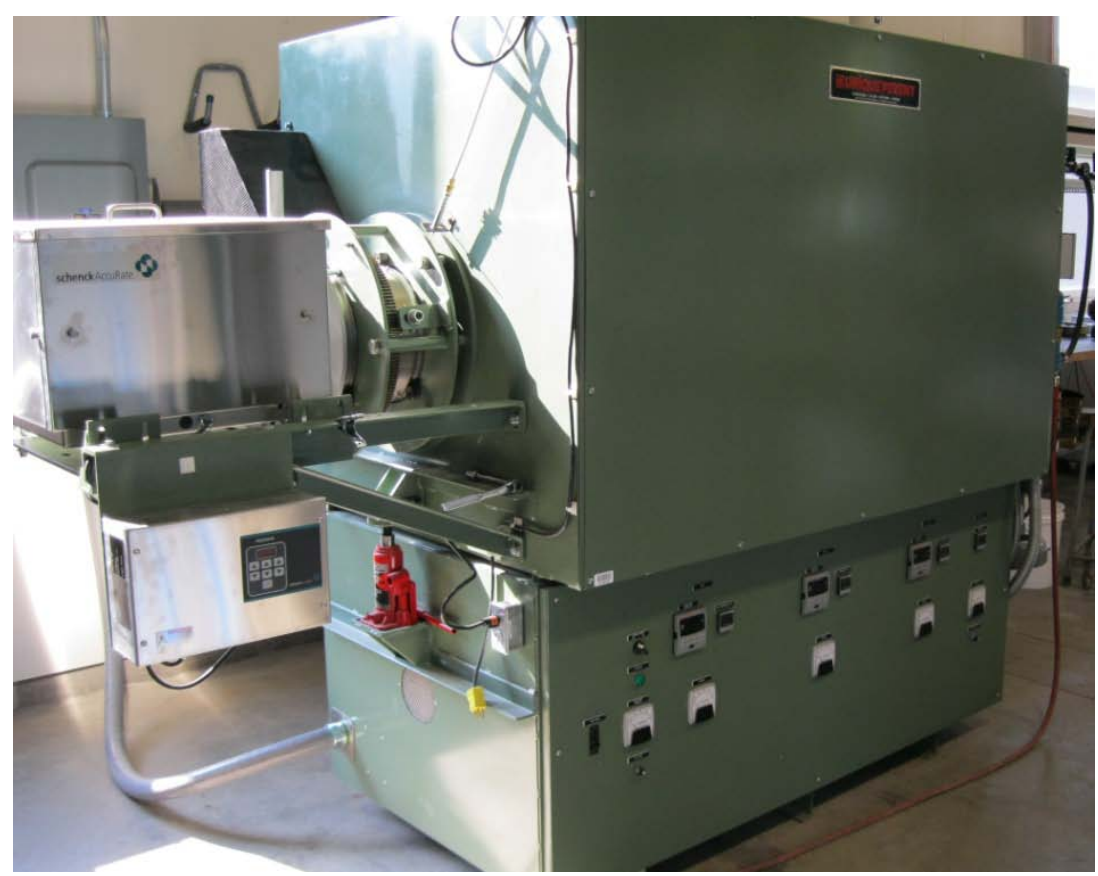

Figure 24. Finalized rotary kiln configuration (input side) with upgraded wiring and cement, raw material, feeder system.

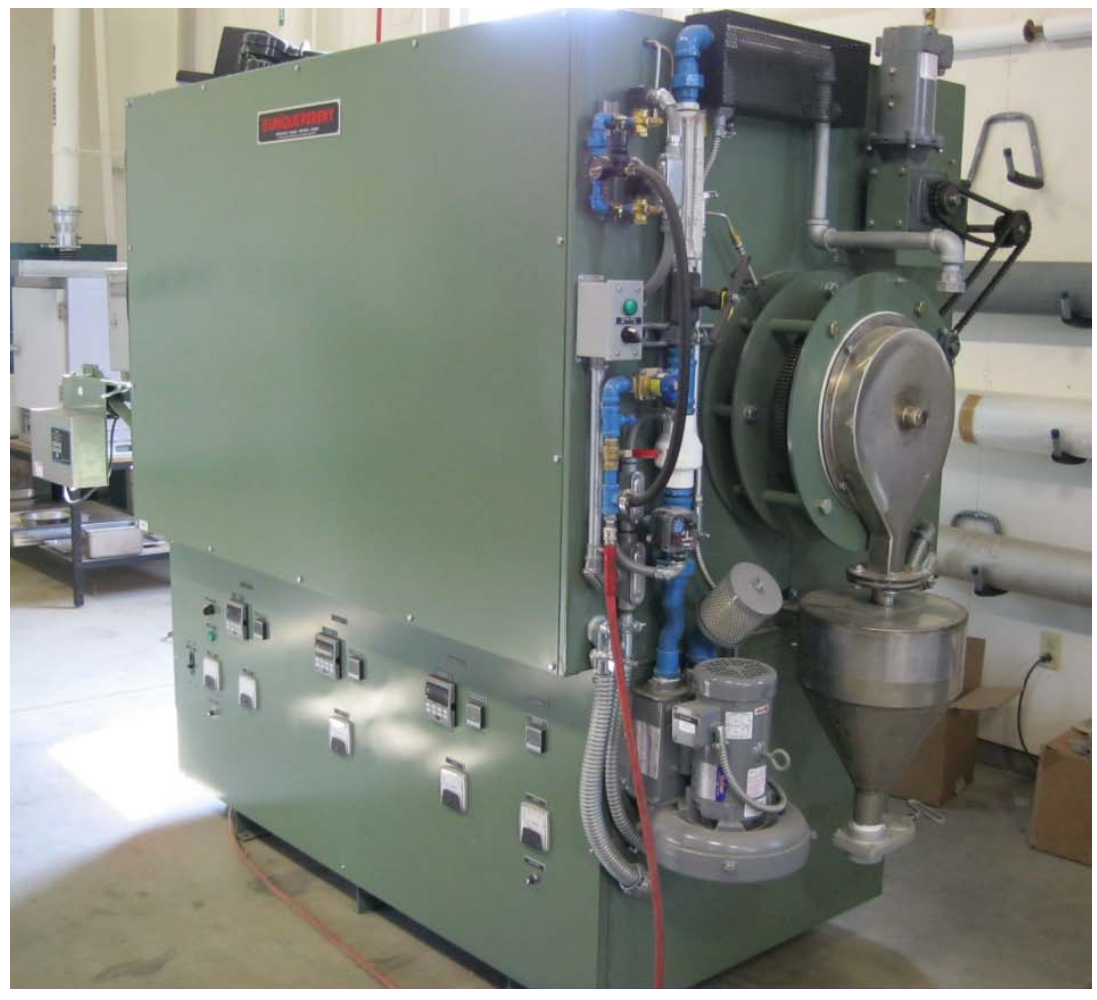

Figure 25. Finalized rotary kiln configuration (output side). 


\section{EXPERIMENTAL RESULTS}

\section{Production of Low Energy Cements}

\section{Rotary Kiln Residence-Time Analysis}

The residence time in the kiln for the two cement formulations (CSAB\#4 and CSFAB\#3) was evaluated. The angle of the rotating barrel, the speed at which it rotates and the feed-rate of the pelletized raw-material are three variables that were determined. The amount of time the raw material resides in the "hot zone" of the kiln will control the cementitious phases that form before the clinker exits the kiln. The ideal residence time will be evaluated by adding 100 blue pellets to the feed pellets, which are brown (Figure 26). As the blue pellets exit the kiln a distribution may be calculated to determine the appropriate feed rate, barrel angle, and rotational speed.

Table 14 shows the three primary controlling variables tube inclination, tube rotational speed and feed rate. To optimize the settings for a residence time of approximately 35 minutes, the actual throughput and average residence times were determined. Figure 27 graphically demonstrates the variation in residence time from the kiln settings listed in Table 14. Run 3 has an average residence time of approximately 35 minutes allowing sufficient time for the formation of Klein's compound within the clinker. Therefore the rotary kiln was operated with a tube inclination of $1.8^{\circ}$, a tube speed of $2.8 \mathrm{RPM}$ and a feed rate of $12.7 \mathrm{lbs} / \mathrm{hr}$.

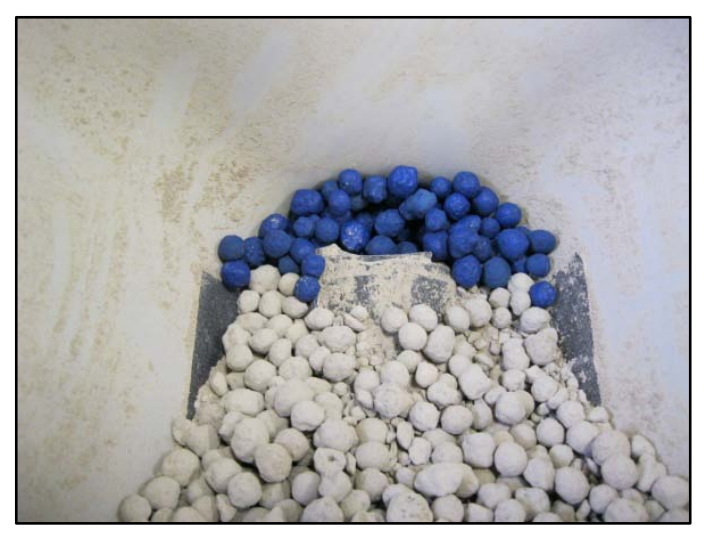

Figure 26. Blue pellets passing through material feeder into the rotary kiln during the residence-time evaluation. 
Table 14. Residence time evaluation for pelletized raw material passing through the rotary kiln.

\begin{tabular}{|c|c|c|c|c|c|}
\hline Run & $\begin{array}{c}\text { Tube } \\
\text { Inclination }\end{array}$ & $\begin{array}{c}\text { Tube Speed } \\
\text { (RPM) }\end{array}$ & $\begin{array}{c}\text { Feed Rate } \\
\text { (lbs/hr) }\end{array}$ & $\begin{array}{c}\text { Actual Throughout } \\
\text { (g/min) }\end{array}$ & $\begin{array}{c}\text { Average Residence Time } \\
\text { (min) }\end{array}$ \\
\hline 1 & $1.8^{\circ}$ & 3.0 & 11.3 & 45 & 22.61 \\
\hline 2 & $2.5^{\circ}$ & 3.5 & 12.7 & 55 & 22.79 \\
\hline 3 & $1^{\circ}$ & $\mathbf{2 . 8}$ & 12.7 & 60 & 34.60 \\
\hline 4 & $2.0^{\circ}$ & 2.8 & 12.7 & 64 & 32.91 \\
\hline
\end{tabular}

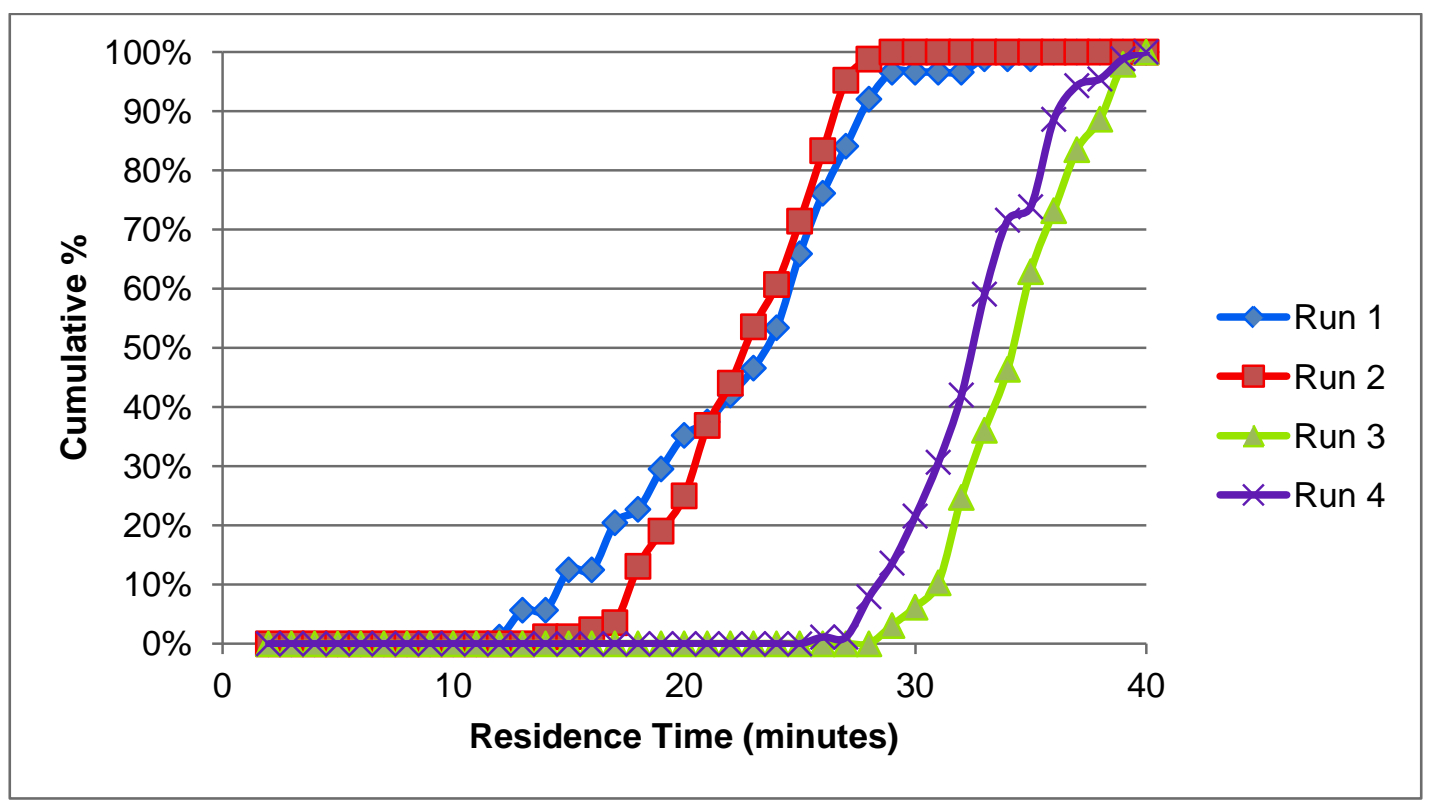

Figure 27. Cumulative \% curves based on the frequency data for the residence time of the raw-material pellets passing through the rotary kiln. 
The two CSA clinker formulations were clinkered at $1300^{\circ} \mathrm{C}$ (Figure 28) with the operating parameters highlighted in Table 14. Approximately $30 \mathrm{~kg}$ of CSAB\#4 clinker was produced and $43 \mathrm{~kg}$ of CSFAB\#3 was produced. Each clinker was milled to cement fineness of 15 microns and then blended with anhydrite at $30 \%$ by weight (Figure 29 ).

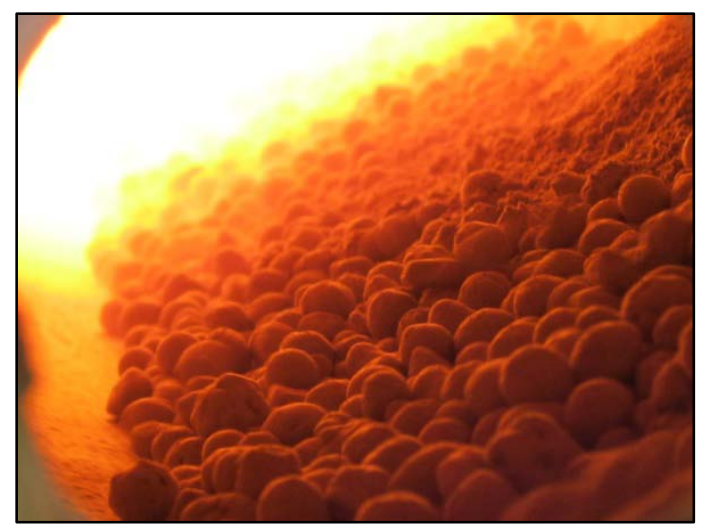

Figure 28. Pelletized raw material passing entering the kiln and passing through the central "hot zone" within the rotary kiln. 

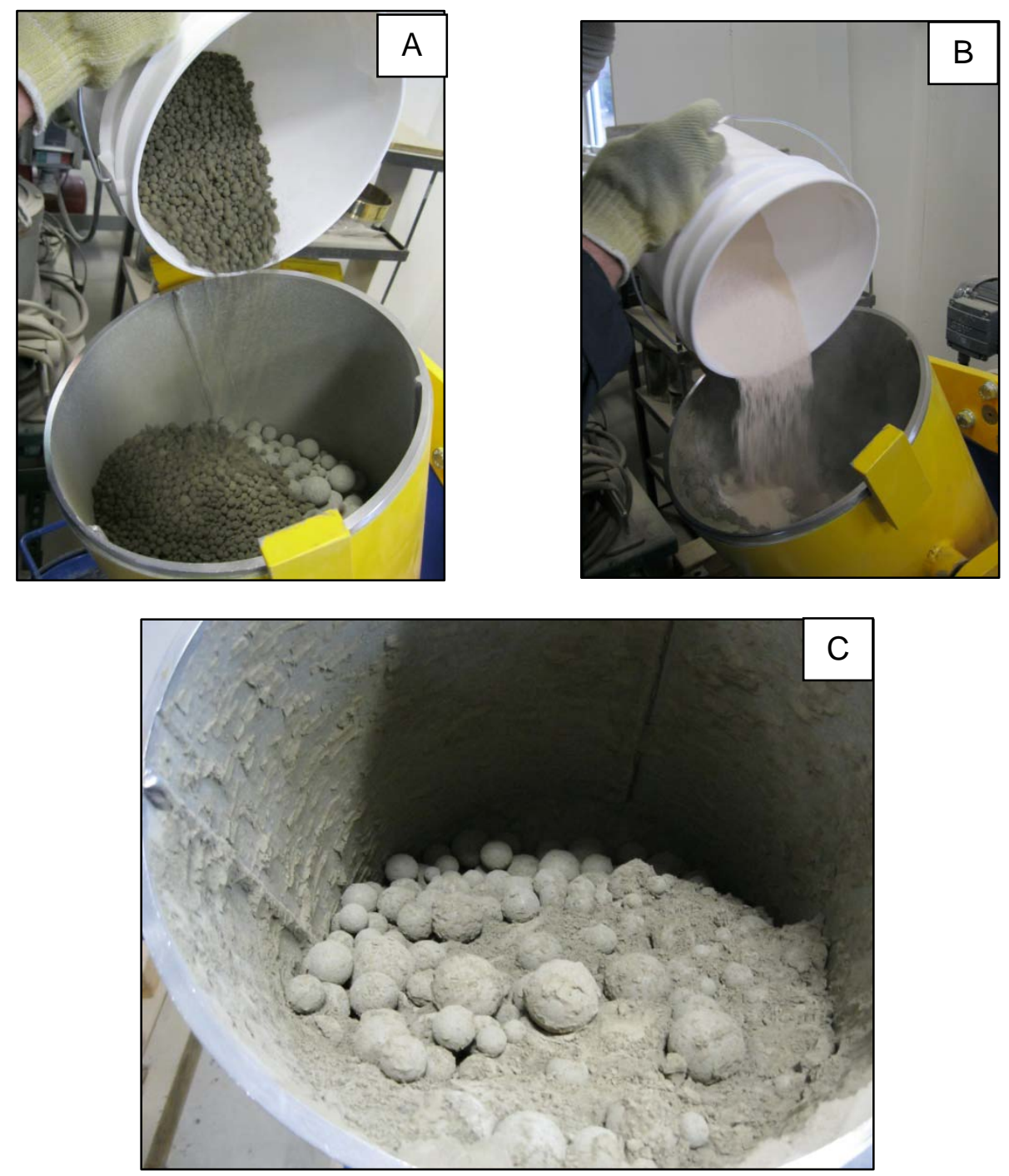

Figure 29. A) CSA Clinker product added to ball mill; B) Anhydrite added to milled CSA clinker; C) Final cement product in ball mill.

Based on previous research, cement formulations that optimize the levels of coal combustions by-products were chosen to produce quantities of cement sufficient for concrete testing. In general, to produce $1 \mathrm{cu} . \mathrm{ft}$. of "average" concrete requires approximately $21 \mathrm{lbs}$ of CSA cement. It was estimated that the kiln was capable of producing $5 \mathrm{lbs}$ of clinker per hour, which equates to approximately $6.75 \mathrm{lbs}$ of cement product per hour. Within the time frame of the project, the goal of cement production was two-fold: to provide sufficient quantity of cement for evaluation of CSA concrete strength and durability, and to demonstrate a significant research capability of the center in sustainable construction materials research. Accordingly, included in this project was the production of two CSA cements and a 100\% byproduct or "clinkerless" cement, the latter of which is composed of fluidized bed combustion (FBC) ash, pulverized coal combustion (PCC) fly ash and flue gas desulfurization (FGD) gypsum plaster. 


\section{Formulation and Production of CSA Cements}

To produce the CSA cements, the raw materials were first proportioned and blended, followed by milling to achieve a particle size distribution of less than 100 microns. The raw materials were then pelletized and pre-calcined at $900^{\circ} \mathrm{C}$. The calcined materials were then fired in the kiln at $1250-1300^{\circ} \mathrm{C}$ to produce clinker. The clinker was then milled along with FGD gypsum to produce the CSA cement. Several hundred pounds of each CSA cement was produced. These materials were then used to produce mortar and concrete which were evaluated according to ASTM procedures.

CSA production focused on maximizing byproduct utilization. The basic components were FBC bed ash, FGD gypsum, red mud, limestone and bauxite. Table 15 lists the sources of the materials, and Table 16 provides the chemical composition and loss on ignition (LOI). Note that high iron bauxite is termed "HIB", and low iron bauxite is termed "LIB".

Table 15. Source of raw materials for CSA cement production.

\begin{tabular}{|l|c|}
\hline \multicolumn{1}{|c|}{ Material } & Source \\
\hline Limestone Fines & Limestone quarry; Georgetown, KY \\
\hline FBC Spent Bed Material & Gilbert Power Plant; Maysville, KY \\
\hline High Iron Bauxite (HIB) & Buzzi Unicem Signal Mountain Plant; Chattanooga, TN \\
\hline Low Iron Bauxite (LIB) & Ward's Natural Science \\
\hline FGD Gypsum & KY Utilities Mill Creek Station; Louisville, KY \\
\hline
\end{tabular}

Table 16. Chemical Composition of Raw Materials.

\begin{tabular}{|l|c|c|c|c|c|c|c|c|c|}
\hline & $\mathrm{SiO}_{2}$ & $\mathbf{A l}_{2} \mathbf{O}_{3}$ & $\mathbf{F e}_{2} \mathbf{O}_{3}$ & $\mathbf{C a O}$ & $\mathbf{M g O}$ & $\mathbf{S O}_{3}$ & $\mathbf{N a}_{2} \mathbf{O}$ & $\mathbf{K}_{\mathbf{2}} \mathbf{O}$ & $\mathbf{L O I}$ \\
\hline Limestone & 4.33 & 1.61 & 0.45 & 47.67 & 1.93 & 0.48 & 0.02 & 0.36 & 41.59 \\
\hline Spent Bed & 11.62 & 4.67 & 2.81 & 47.21 & 2.59 & 27.22 & 0.01 & 0.32 & 1.90 \\
\hline HIB & 10.19 & 48.98 & 21.89 & 3.69 & 0.49 & 0.04 & 0.22 & 0.47 & 12.08 \\
\hline LIB & 6.21 & 59.86 & 7.12 & 0.10 & 0.23 & 0.13 & 0.02 & 0.02 & 28.03 \\
\hline Gypsum & 1.63 & 2.38 & 0.56 & 29.16 & 0.14 & 41.93 & 0.02 & 0.04 & 25.05 \\
\hline
\end{tabular}

The CAER had sufficient quantities of limestone, FGD gypsum, and FBC spent bed to complete the project. Thus, additional red mud and bauxite were acquired, approximately two (2) 55 gallon barrels each.

A high-iron and low-iron CSA formulation was produced during this project. For each formulation, three mixtures were prepared for a burnability study, with each comprising a different proportion of limestone. Each of the components w separately milled to the desired fineness using equipment described in the previous section. Components for each CSA clinker were blended in the desired proportions and likely agglomerated using pelletization or pressing to prepare kiln feed. Pellets were then fired in the kiln to produced CSA clinker, which was then milled in a separate ball mill to the desired fineness. Calcium sulfate, in the form of FGD gypsum, was used to "activate" the clinker and thus produce a cement product. The gypsum was added as-received and after heating to $5000 \mathrm{C}$ to form anhydrous calcium sulfate. The level 
of addition was $30 \%$ by mass of the CSA clinker. Class F fly ash will also be added as a pozzolanic admixture.

\section{Cement Formulation}

Two formulations of cement containing FBC spent bed as a raw material were calculated using normative equations based on stoichiometry. The assumed crystalline phases were calcium oxide ( $\mathrm{CaO}$ or " $\mathrm{C}$ " in cement notation), calcium sulfoaluminate $\left(\mathrm{Ca}_{4} \mathrm{Al}_{6} \mathrm{O}_{12} \mathrm{SO}_{4}\right.$ or $\mathrm{C}_{4} \mathrm{~A}_{3} \mathrm{~S}$ '), dicalcium silicate $\left(\mathrm{Ca}_{2} \mathrm{SiO}_{4}\right.$ or $\left.\mathrm{C}_{2} \mathrm{~S}\right)$, ferrite $\left(\mathrm{Ca}_{4} \mathrm{Al}_{2} \mathrm{Fe}_{2} \mathrm{O}_{10}\right.$ or $\left.\mathrm{C}_{4} \mathrm{AF}\right)$, and calcium sulfate $\left(\mathrm{CaSO}_{4}\right.$ or CS'). Figure 30 lists the proportions of the raw materials for each of the two cement clinker formulations, while Table 17 provides the calculated phase compositions. In these equations, $\mathrm{CaO}$ ("C") is at first assumed to be $0.50 \%$, but will be determined in each clinker. After the cement clinkers are produced in the rotary kiln, FGD gypsum will be milled with the clinkers to produce the final cement products.

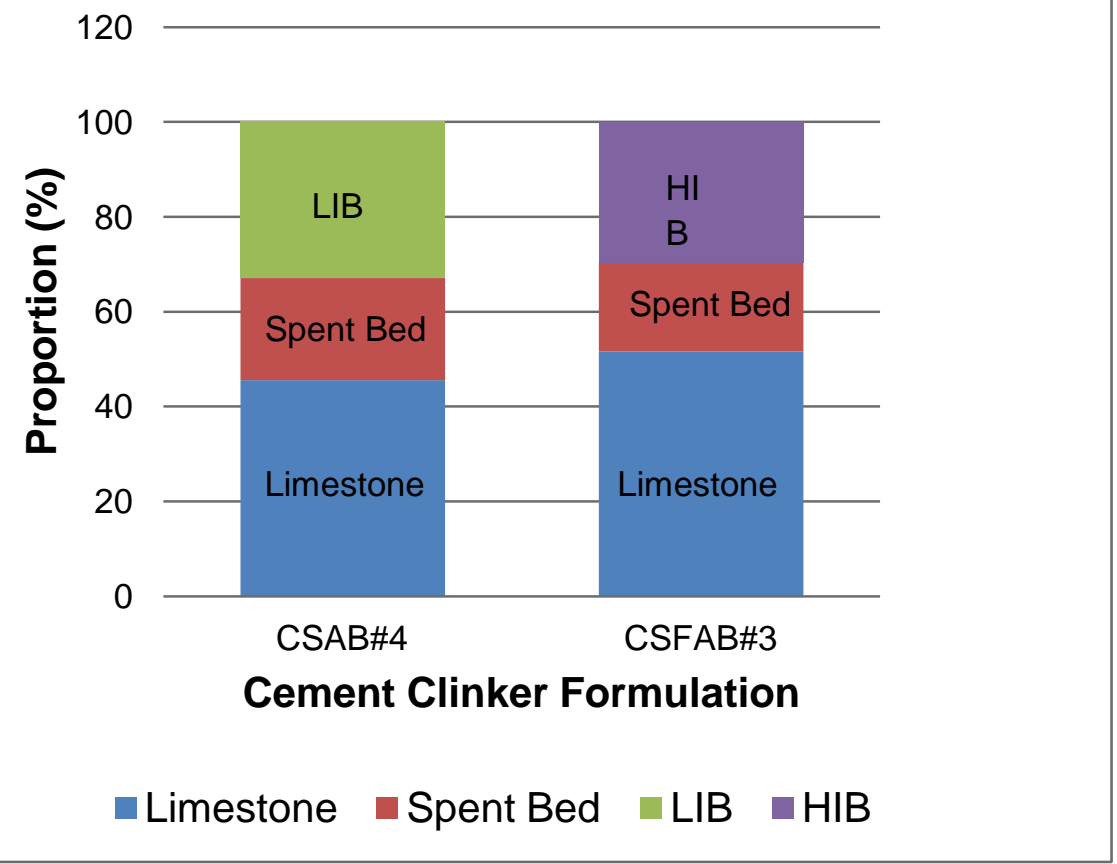

Figure 30. Proportions of raw materials for CSAB\#4 and CSFAB\#3 clinkers. 
Table 17. Calculated Phase Compositions for the CSAB\#4 and CSFAB\#3 clinkers.

\begin{tabular}{|l|c|c|}
\hline \multicolumn{1}{|c|}{ Phase } & CSAB\#4 & CSFAB\#3 \\
\hline $\mathbf{C}$ & 0.50 & 0.50 \\
\hline $\mathbf{C}_{4} \mathbf{A}_{3} \mathbf{S}^{\prime}$ & 53.95 & 31.33 \\
\hline $\mathbf{C}_{2} \mathbf{S}$ & 26.02 & 28.87 \\
\hline $\mathbf{C}_{4} \mathbf{A F}$ & 13.36 & 29.85 \\
\hline $\mathbf{C S}^{\prime}$ & 2.44 & 5.40 \\
\hline
\end{tabular}

\section{Pelletization of Raw Materials}

After the cement clinkers were formulated, pellets were prepared for the CSAB\#4 and CSFAB\#3. An initial trial was conducted and the CSAB\#4 pellets were fired in a zirconia crucible for $950^{\circ} \mathrm{C}$ for 30 minutes followed by $1300^{\circ} \mathrm{C}$ for 30 minutes. X-ray diffraction (XRD) data indicated that the expected phases were present and that free lime $(\mathrm{CaO})$ was below detection. It was concluded that this formulation was acceptable and thus approximately 100 lbs (45 kg) of pelletized raw material was prepared and screened to +4 mesh, $-3 / 8$ inch $(+4.75 \mathrm{~mm},-9.5 \mathrm{~mm}$; Figure 31$)$. These pellets will be processed through the rotary kiln after it is installed at the CAER.

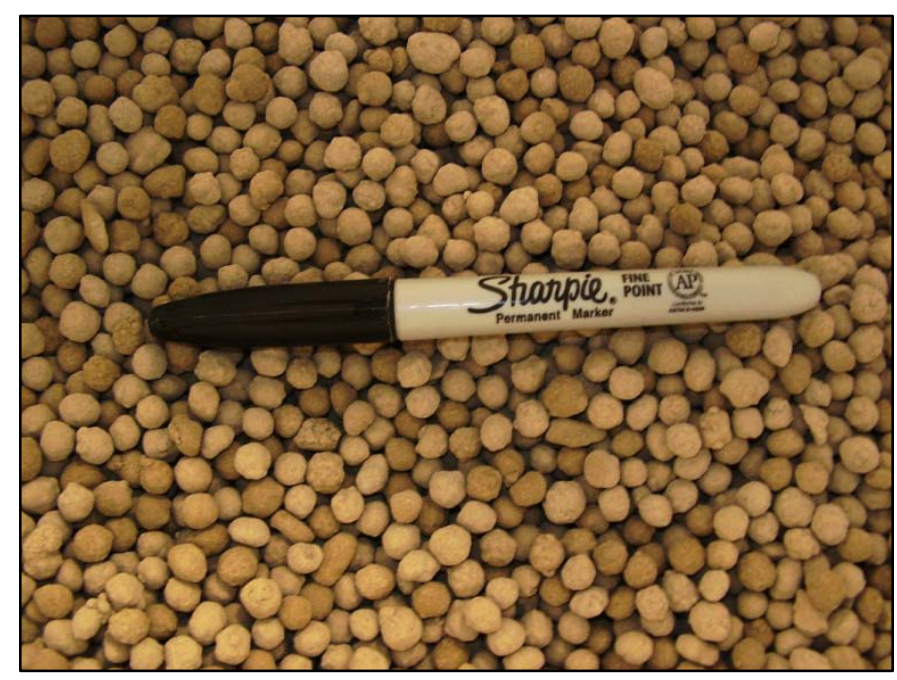

Figure 31. CSAB\#4 pelletized raw materials.

An initial trial was conducted and the CSFAB pellets were fired in a zirconia crucible for $950^{\circ} \mathrm{C}$ for 30 minutes followed by $1275^{\circ} \mathrm{C}$ for 30 minutes. X-ray diffraction (XRD) data indicated that the desired phases $\left(\mathrm{C}_{4} \mathrm{~A}_{3} \mathrm{~S}^{\prime}, \mathrm{C}_{2} \mathrm{~S}\right.$, and $\left.\mathrm{C}_{4} \mathrm{AF}\right)$ were present and that free lime $(\mathrm{CaO})$ was present but at acceptable levels (Figure 32). It was concluded that this formulation was acceptable and thus approximately $100 \mathrm{lbs}(45 \mathrm{~kg})$ of raw material is being prepared and pelletized for cement production. 


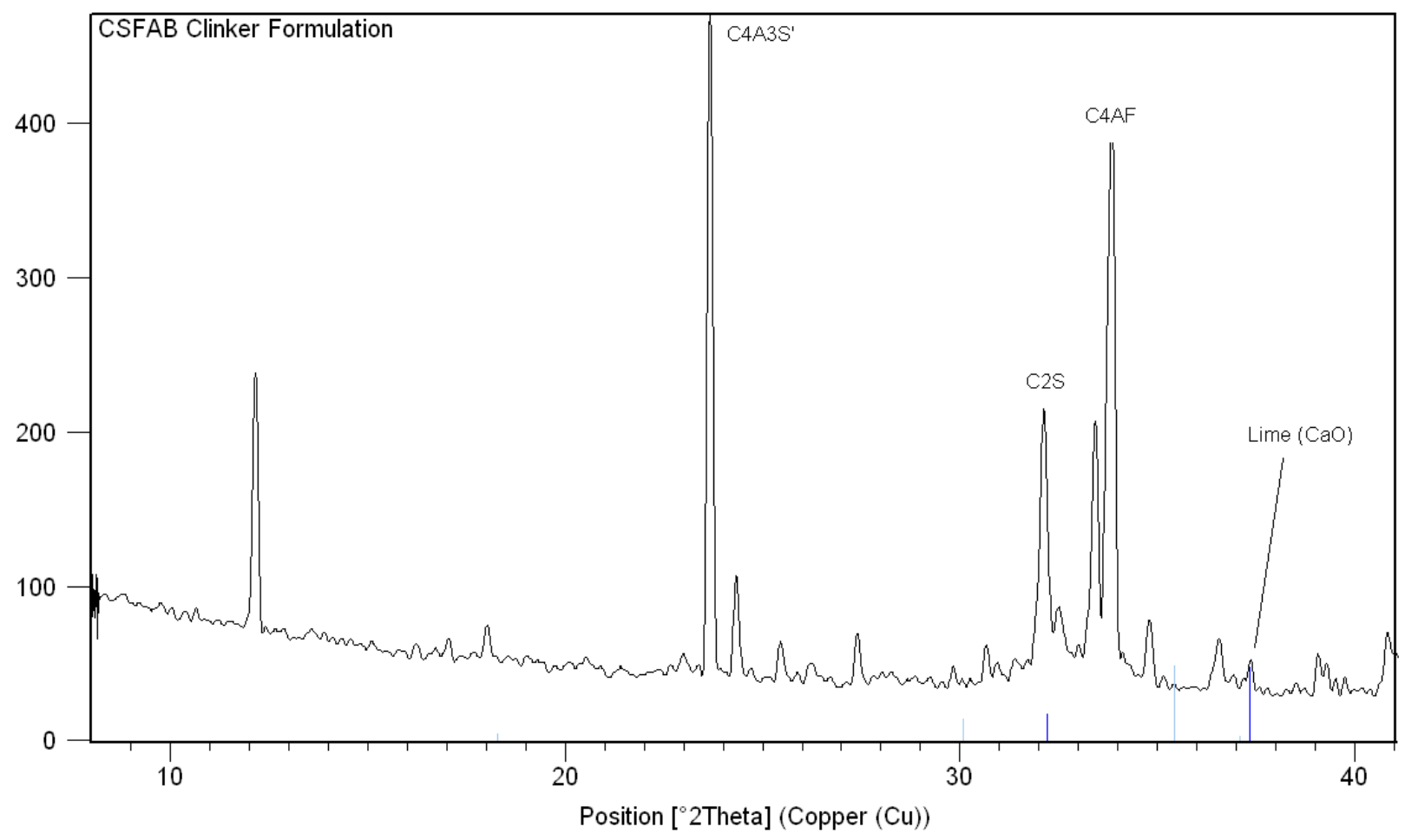

Figure 32. X-ray diffraction pattern for CSFAB clinker.

A small batch of CSFAB raw materials was pelletized and fired to confirm the formulation prior to larger-scale production of pelletized feed. The batch was calcined at $950^{\circ} \mathrm{C}$ for 30 minutes, followed by firing at $1275^{\circ} \mathrm{C}$ for 30 minutes. X-ray diffraction analysis indicated that the clinker phases were similar to those from the first burnability study, with the exception of a more prominent free lime peak (Figure 33$)^{1}$. These data were confirmed by free lime analysis, which indicated a lime content of $4.19 \%$. Re-firing the clinker for 30 additional minutes reduced the free lime content to $2.99 \%$, which is still higher than desired.

\footnotetext{
${ }^{1}$ The term "burnability" is used in cement science to denote the quantity of free lime present in clinker after heat treatment, or the time needed at a specified temperature to reduce the free lime content to a desired value. In general, it qualitatively indicates if a certain formulation can be successfully processed using the specified heating regime, in this case, $950^{\circ} \mathrm{C}$ for 30 minutes followed by $1275-1300^{\circ} \mathrm{C}$ for 30 minutes.
} 


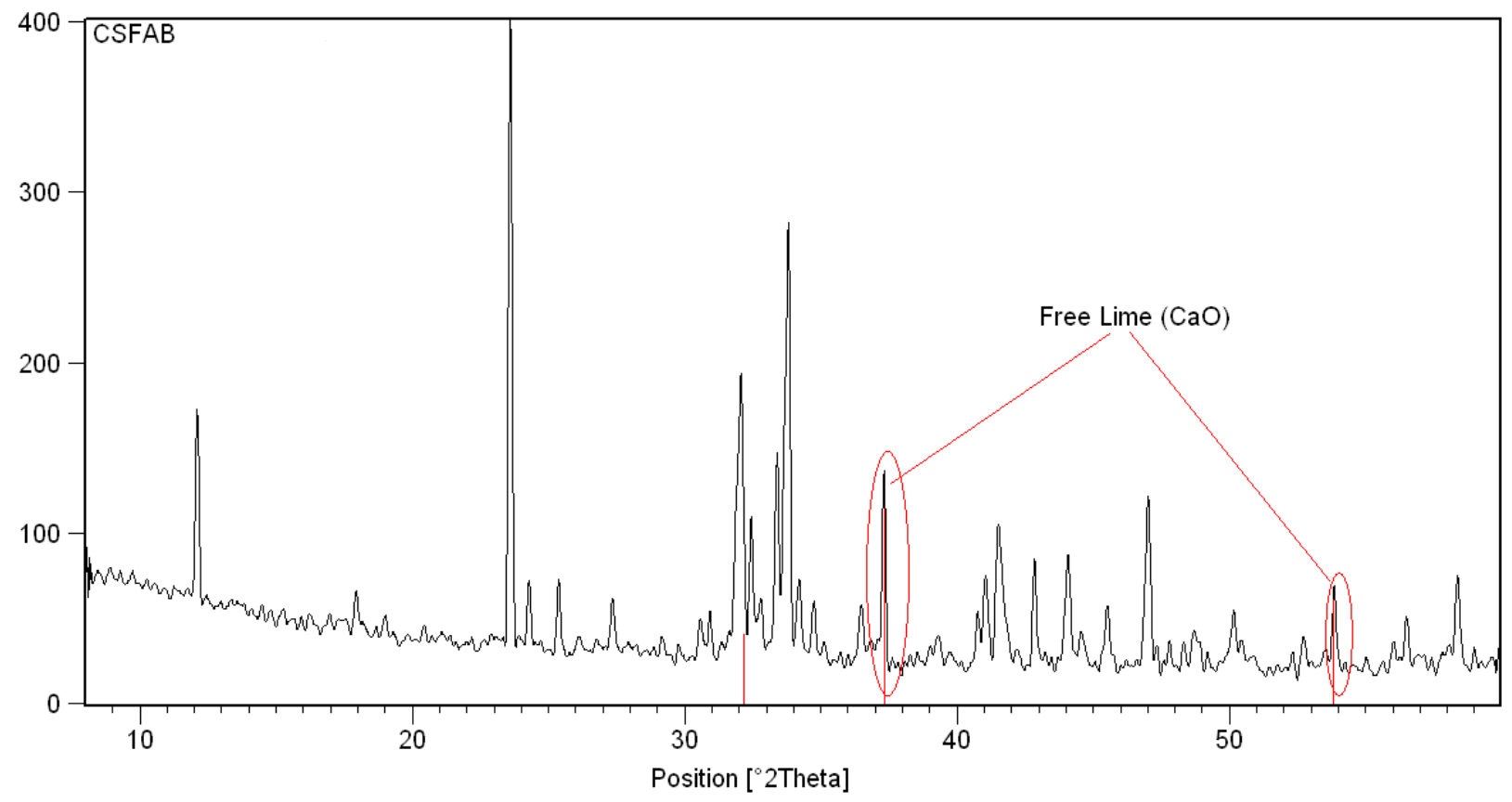

Figure 33. XRD spectrum of pelletized CSFAB after firing to $1275^{\circ} \mathrm{C}$.

These data indicated that either the firing conditions are insufficient for this formulation and/or that the clinker formulation needed adjustment. Chemical analysis of the clinker suggested the latter, because the total lime content was substantially higher than calculated based on the proportions of the individual raw materials, their chemical composition, and loss on ignition (Table 18). However, the reduction in free lime content after re-firing for 30 minutes at $1275^{\circ} \mathrm{C}$ suggested that the firing time of 30 minutes might be insufficient for this formulation.

Table 18. Calculated and measured composition of selected elements in CSFAB clinker.

\begin{tabular}{|l|c|c|c|c|c|c|c|}
\hline & $\mathrm{SiO}_{2}$ & $\mathrm{Al}_{2} \mathrm{O}_{3}$ & $\mathrm{Fe}_{2} \mathrm{O} 3$ & $\mathrm{CaO}$ & $\mathrm{MgO}$ & $\mathrm{SO}_{3}$ & Free Lime \\
\hline Calculated & 10.00 & 22.56 & 10.03 & 46.48 & 3.20 & 5.94 & 0.50 \\
\hline Actual & 10.51 & 21.86 & 7.13 & 49.23 & 3.14 & 8.21 & 4.19 \\
\hline
\end{tabular}

Based on these data, two additional proportions of raw materials were formulated: a low lime ("LL") formulation and a medium lime ("ML") formulation. These mixtures were blended, milled, and pressed into 1 inch $(25.4 \mathrm{~mm})$ diameter disks, then fired under the same conditions described above. A third mixture, high lime ("HL"), was included and comprised the same proportions as the original pelletized CSFAB formulation described above. The chemical composition of these clinkers is shown in Table 19. As expected, the low lime formulation contained the lowest total $\mathrm{CaO}$ and free lime content. 
Table 19. Chemical composition of three CSFAB formulations.

\begin{tabular}{|c|c|c|c|c|c|c|c|}
\hline Formulation & $\mathbf{S i O}_{\mathbf{2}}$ & $\mathbf{A l}_{2} \mathbf{O}_{3}$ & $\mathbf{F e}_{2} \mathbf{O} 3$ & $\mathbf{C a O}$ & $\mathbf{M g O}$ & $\mathbf{S O}_{3}$ & Free Lime \\
\hline $\mathbf{H L}$ & 10.00 & 21.74 & 7.54 & 49.27 & 3.08 & 8.06 & 2.06 \\
\hline $\mathbf{M L}$ & 10.57 & 22.11 & 7.37 & 47.89 & 3.10 & 7.65 & 0.96 \\
\hline LL & 10.29 & 22.83 & 7.30 & 47.04 & 3.03 & 7.81 & 0.66 \\
\hline
\end{tabular}

XRD spectra of the three formulations are shown in Figure 34. These data confirm that the "LL" formulation contained the least free lime.

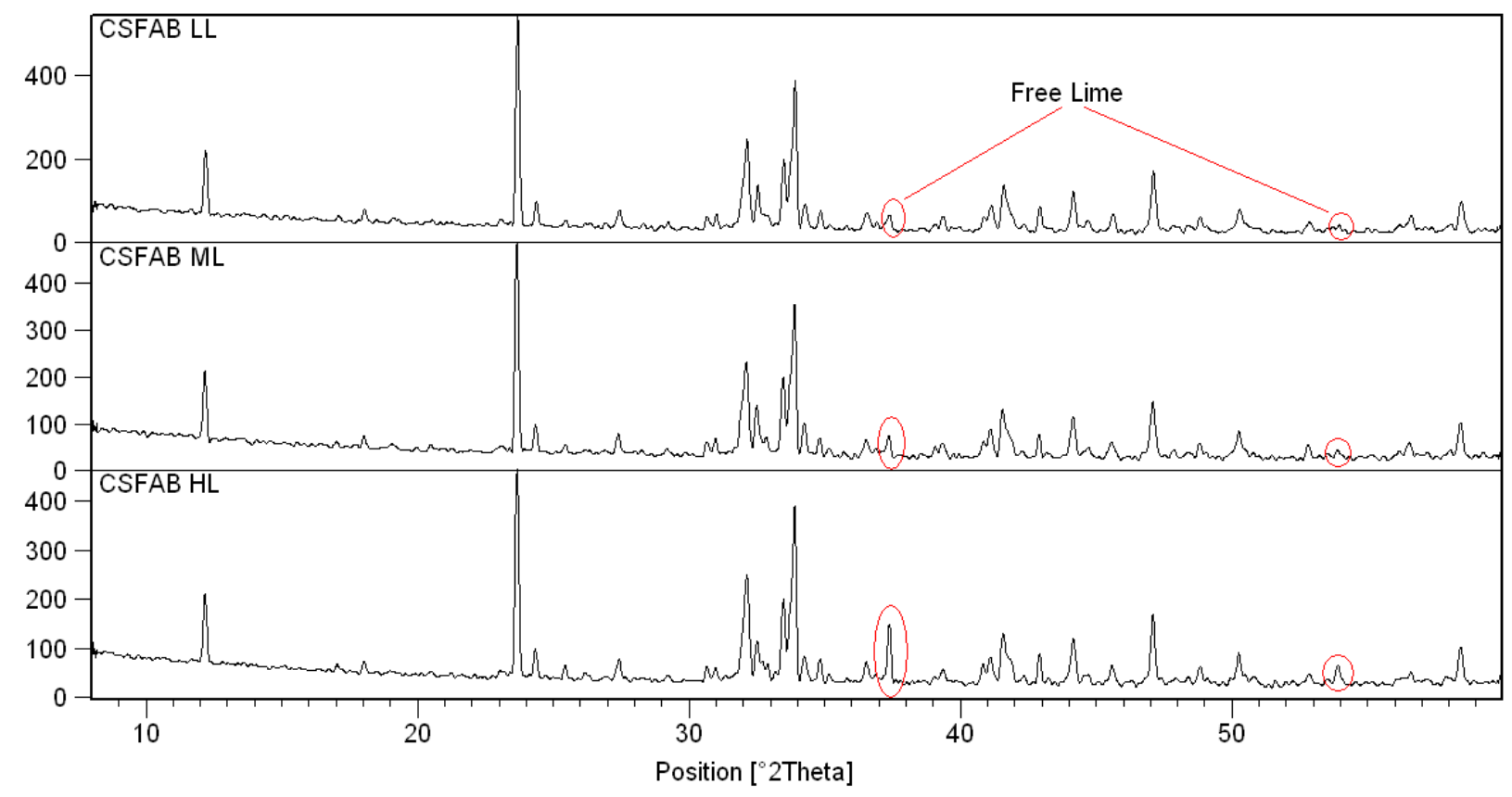

Figure 34. XRD spectra of the HL, ML, and LL formulations.

Because a free lime content of less than $1 \%$ is desired, the LL formulation was selected for the larger scale production of CSFAB clinker in the rotary kiln. Therefore, approximately $100 \mathrm{lbs}$ of pelletized raw materials were prepared. A sample of the pelletized LL formulation feed was sampled and fired at the conditions described above (i.e. $950^{\circ} \mathrm{C}$ for $30 \mathrm{~min} ; 1275^{\circ} \mathrm{C}$ for $30 \mathrm{~min}$ ), and the clinker analyzed by XRD (Figure 35). The lime content was estimated to be 1\%, which is acceptable. However, the data also indicate that pelletization produces a less-reacted clinker than when the raw materials are pressed into disks. This is probably caused by the pellets being less dense than the disks, which would likely result in a slower diffusion of atoms at the clinkering temperatures. Therefore, it will probably be necessary to increase the processing time (i.e. > 30 minutes) in the rotary kiln to achieve more complete clinkering reactions. 


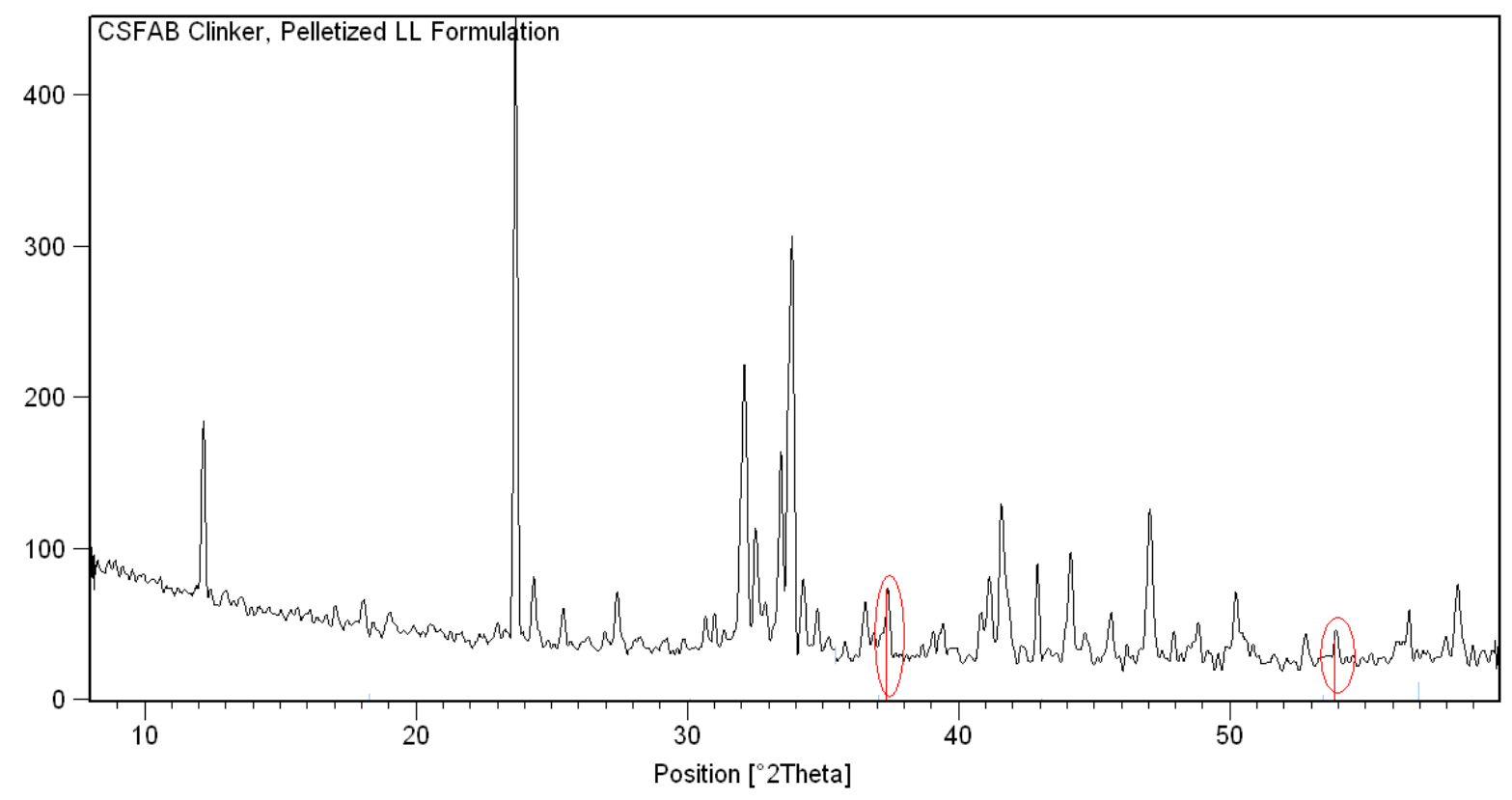

Figure 35. XRD spectrum of pelletized low lime (LL) CSFAB clinker. Circles denote free lime peaks.

\section{Production of "Clinkerless" Cement}

"Clinkerless" low-energy cement is prepared by blending FBC ash with Class F fly ash, without a clinkering process. Because the strength gain of this cement is slow, calcium sulfate hemihydrate ("hemihydrate") is added to the mixture to achieve sufficient early strength. An added benefit is that the hemihydrate can be prepared from FGD gypsum.

The FGD gypsum was first pressed into disks, using a force of approximately 2,268 $\mathrm{kg}(5,000$ lbs), followed by autoclaving at $130^{\circ} \mathrm{C}$ and 3 bar saturated steam pressure to produce alphacalcium sulfate hemihydrate (i.e. plaster). The plaster was ball-milled with the FBC ash and Class F fly to produce the clinkerless cement. Approximately $45 \mathrm{~kg}(100 \mathrm{lbs})$ of clinkerless cement was prepared for mortar and concrete testing.

The hemihydrate was processed in 5 batches, and each was examined by XRD to ensure that the gypsum converted to hemihydrate. Figure 36 provides an XRD spectrum of one batch. The diffraction peaks are consistent with crystalline calcium sulfate hemihydrate, which indicates that complete conversion occurred. 


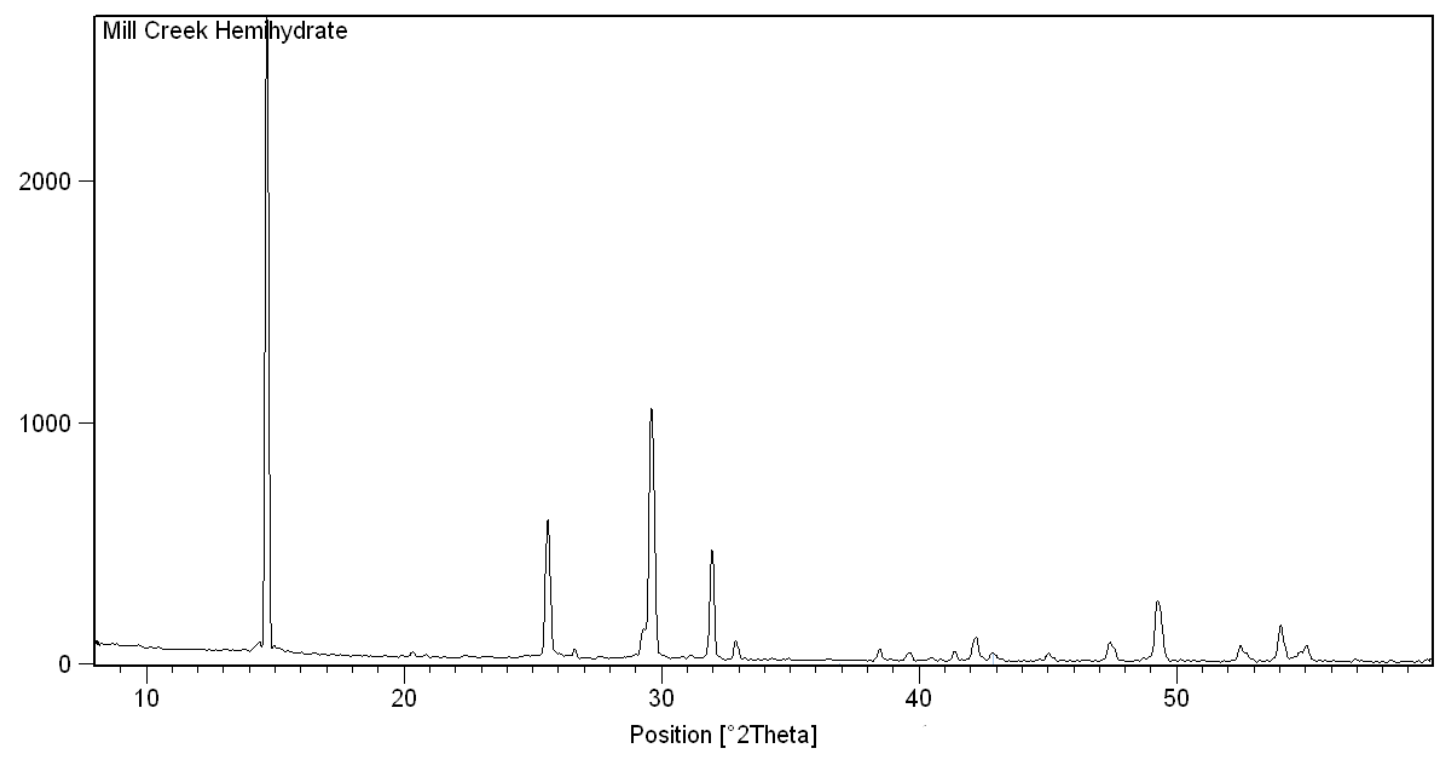

Figure 36. XRD spectrum of FGD calcium sulfate hemihydrate.

After autoclaving, the hemihydrate was dried and crushed to -20 mesh (850 microns). Two formulations of clinkerless cement were prepared using the hemihydrate, FBC ash, and ultrafine Class F fly ash; the properties of these materials were described in the Oct-Dec 2010 report. The primary difference in the formulations is the quantity of hemihydrate $(\mathrm{HH})$, which comprised $0 \%, 25 \%, 50 \%$ and $100 \%$ of the cement. The proportions of cement formulations prepared are provided in Table 20. The reason for selecting these formulations was to determine if adequate early strength can be achieved with $<50 \%$ hemihydrate, while still maintaining long-term dimensional stability. These experiments are being conducted in advance of testing hydrophobic polymer admixtures on the system (rationale described in the Oct-Dec 2010 report).

Table 20. Proportion of materials used in clinkerless cement formulations.

\begin{tabular}{|l|c|c|c|c|}
\hline \multicolumn{1}{|c|}{ Material } & $\mathbf{0 \%} \mathbf{~ H H}$ & $\mathbf{2 5 \%} \mathbf{H H}$ & $\mathbf{5 0 \%} \mathbf{H H}$ & $\mathbf{1 0 0 \%} \mathbf{H H}$ \\
\hline FBC Spent Bed (g) & 1000 & 752 & 500 & 0 \\
\hline Ultrafine Class F FA (g) & 1000 & 748 & 500 & 0 \\
\hline Hemihydrate (g) & 0 & 500 & 1000 & 2000 \\
\hline
\end{tabular}

Previous research at the CAER has investigated the performance of clinkerless cement. Four types of CCBs were used to make the clinkerless cement: FGD gypsum, FBC spent bed material, ordinary Class F fly ash, and a processed Class F ultra fine ash (UFA). The ordinary fly ash was obtained directly from a central Kentucky power plant, whilst the ultra fine ash was obtained using a hydraulic classifier that produced a very fine ash product with a median particle size of 5 microns. The spent bed material was obtained from the East Kentucky Power Cooperative Gilbert Unit at Spurlock Power Station in Maysville, Kentucky. Their chemical compositions are provided in Table 21, and are similar to those materials being used in the current project. The FGD gypsum was used to produce calcium sulfate hemihydrate, which was 
milled at a 50\% addition rate with the FBC ash and fly ash to produce the clinkerless cement. Thus, half of the clinkerless cement comprised hemihydrate, while the remainder comprised FBC spent bed material and Class F fly ash.

Table 21. Chemical composition of CCPs used in previous research.

\begin{tabular}{|c|c|c|c|c|}
\hline Oxide (\%) & FGD Gypsum & FBC Spent Bed & Class F FA & UFA \\
\hline $\mathrm{SiO}_{2}$ & 4.54 & 12.77 & 52.75 & 54.34 \\
\hline $\mathrm{TiO}_{2}$ & 0.13 & 0.26 & 1.20 & 1.56 \\
\hline $\mathrm{Al}_{2} \mathrm{O}_{3}$ & 1.09 & 5.25 & 22.94 & 31.47 \\
\hline $\mathrm{Fe}_{2} \mathrm{O}_{3}$ & 0.60 & 3.15 & 14.92 & 5.21 \\
\hline $\mathrm{CaO}$ & 40.15 & 48.23 & 2.67 & 1.35 \\
\hline $\mathrm{MgO}$ & 0.37 & 2.47 & 0.90 & 1.1 \\
\hline $\mathrm{K}_{2} \mathrm{O}$ & 0.06 & 0.36 & 2.72 & 2.66 \\
\hline $\mathrm{Na}_{2} \mathrm{O}$ & $<0.01$ & 0.05 & 0.42 & 0.41 \\
\hline $\mathrm{P}_{2} \mathrm{O}_{5}$ & 0.04 & 0.13 & 0.19 & 0.28 \\
\hline $\mathrm{SO}_{3}$ & 53.67 & 27.83 & 0.64 & 0.07 \\
\hline Free $\mathrm{Lime}$ & nd & 23.0 & nd & nd \\
\hline
\end{tabular}

The results showed that the optimum ratio, in the context of compressive strength development and dimensional stability, for FBC:fly ash was approximately 40:60 to 50:50. Blends of 70:30 FBC:FA produced higher long-term strengths, but their expansion was considerably higher. It was also determined that the cement prepared using ultrafine fly ash (UFA) performed substantially better than cement containing ordinary fly ash (FA), especially at early ages (Figure 37). 


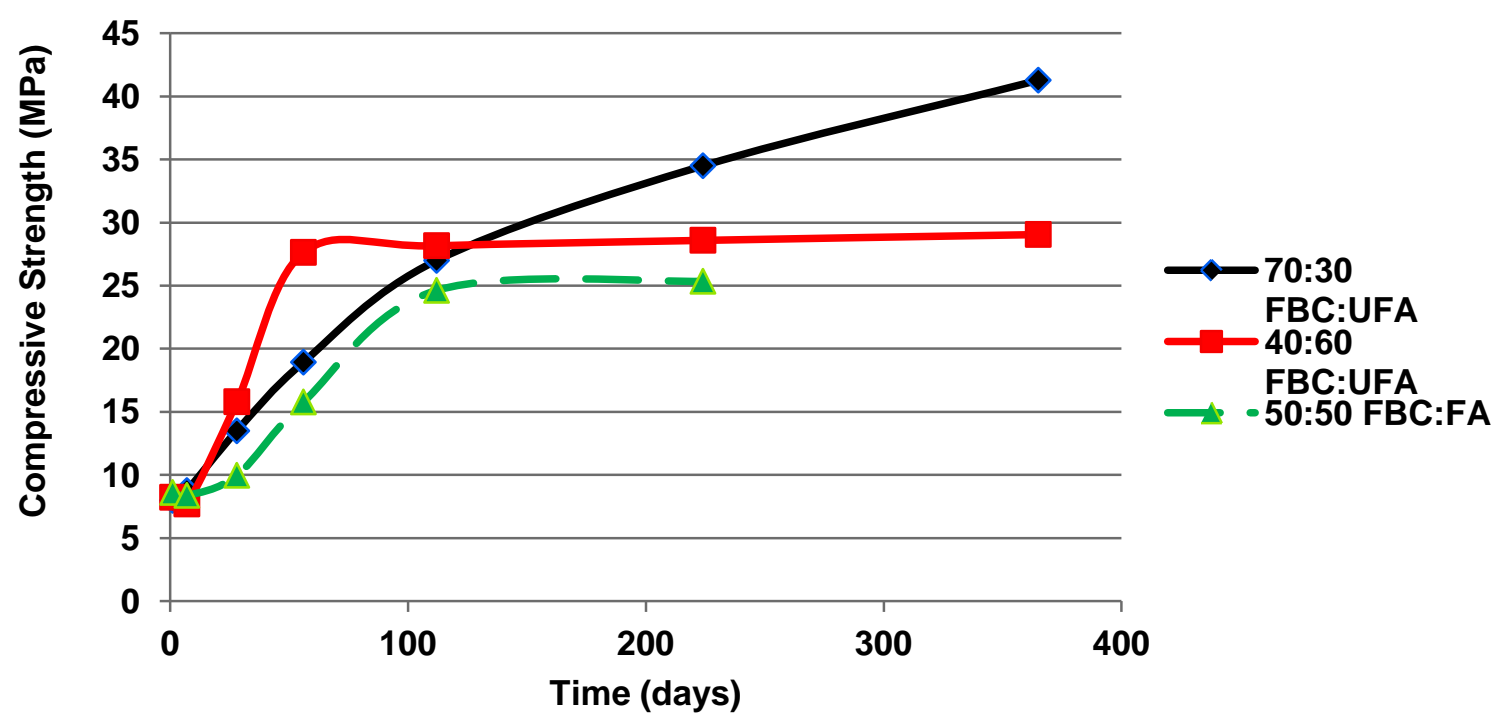

Figure 37. Compressive strength of mortar prepared with different clinkerless cement blends.

In order to determine the correct dosage of set-retarding admixture, paste samples were prepared with different dosages of sodium citrate: $0,2,4$ and $8 \mathrm{mg}$ per gram of $\mathrm{HH}$. The pastes were prepared by mixing $5 \mathrm{~g}$ of clinkerless cement with $2 \mathrm{ml}$ of water and a specific amount of sodium citrate. The cement pastes were mixed with a spatula and placed into an isothermal calorimeter to determine the approximate time of setting.

Figures $38 \& 39$ show the exothermic reaction profiles for hydration of two of the cements, which occurs primarily from the hemihydrate component. Interestingly, the sodium citrate was more effective at retarding the set of the $50 \% \mathrm{HH}$ cement than the $25 \% \mathrm{HH}$ cement, even though the citrate dosage was normalized to mass of hemihydrate in the cement. Based on these data, $4 \mathrm{mg}$ citrate per gram of hemihydrate was selected for the dosage for each of the two cements prepared. 


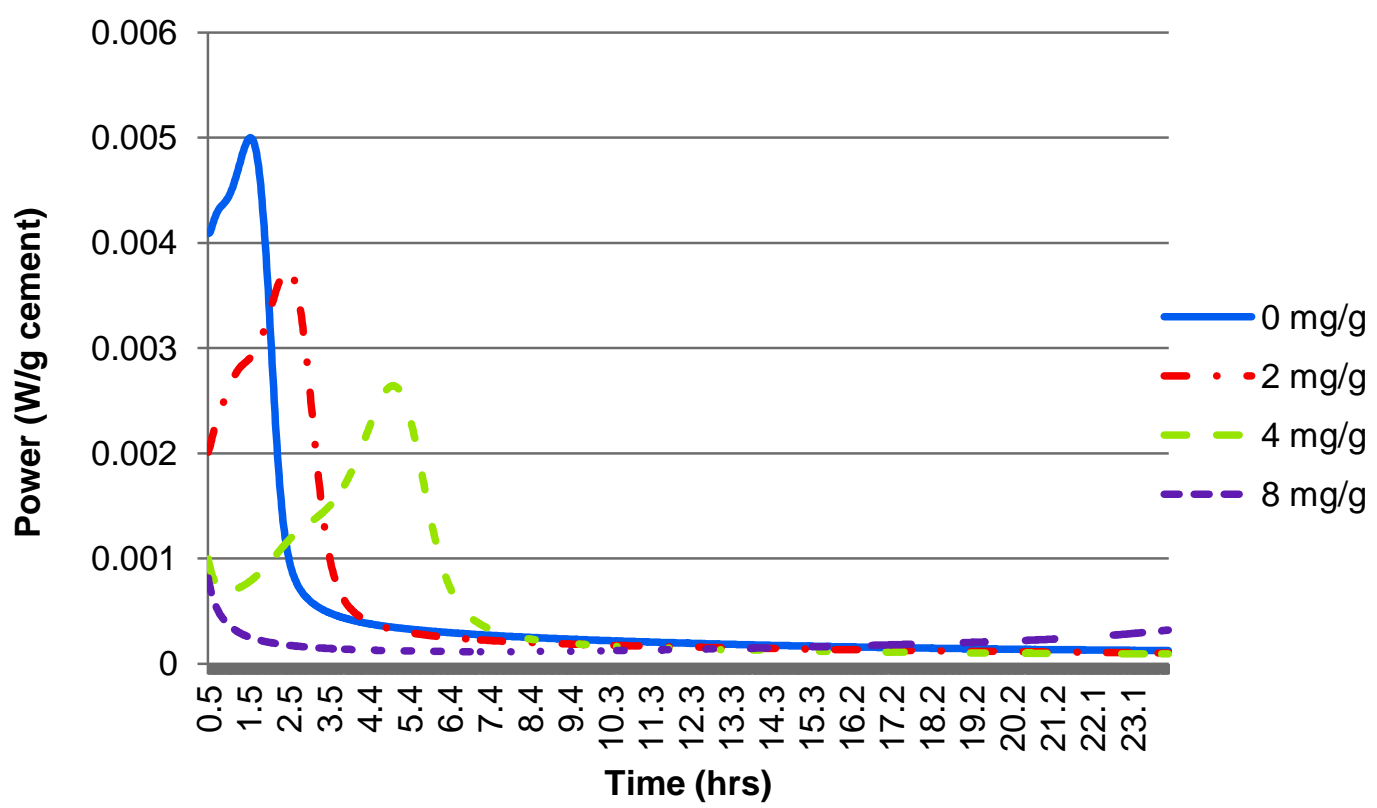

Figure 38 . Calorimetry of $25 \% \mathrm{HH}$ clinkerless paste with 4 dosages of set retarder.

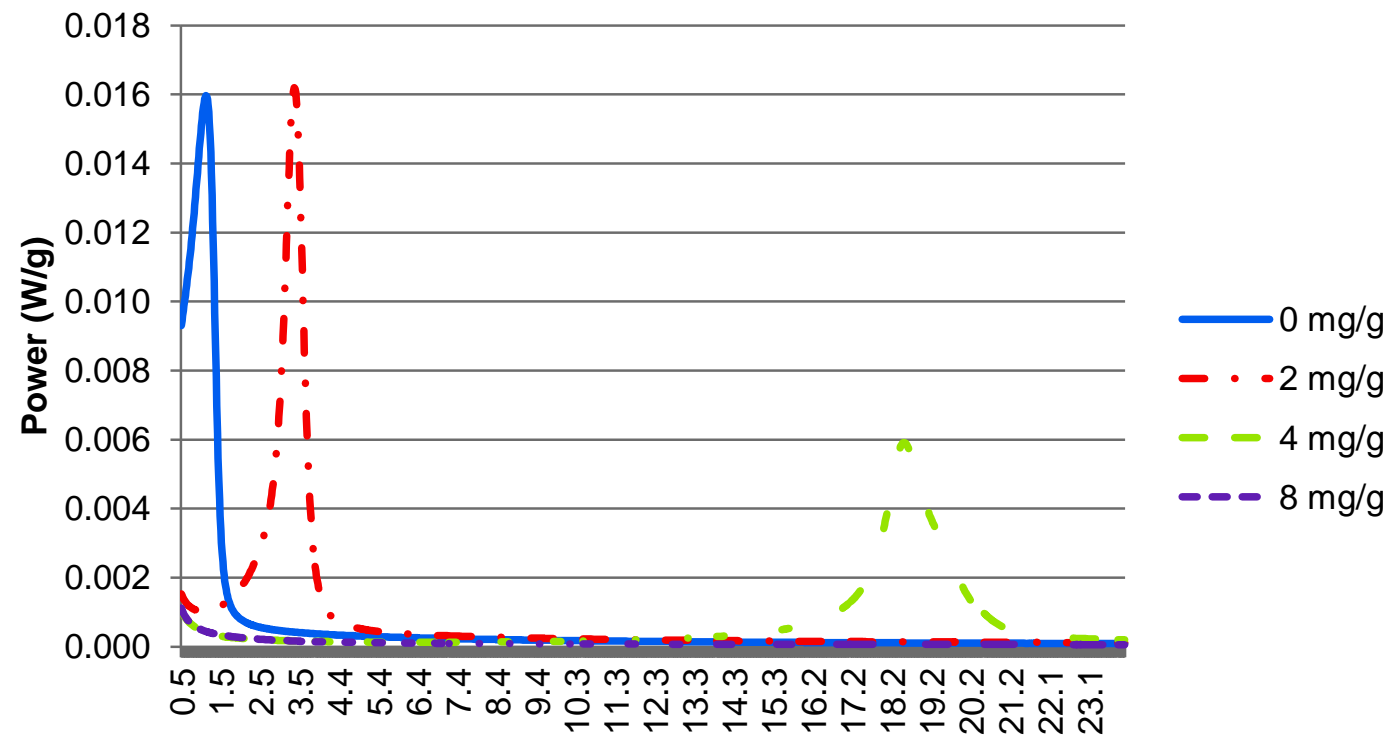

Time (hrs)

Figure 39. Calorimetry of $50 \% \mathrm{HH}$ clinkerless paste with 4 dosages of set retarder.

The use of a water-repelling admixture, which was based on calcium stearate, showed promise for reducing the amount of expansion of the clinkerless cement mortar and concrete, as well as improving the durability. However, the solubility of the hemihydrate component of the 
clinkerless cement was still too high for good long-term durability with outdoor exposure (Figure 40), particularly when subjected to numerous freezing-thawing cycles.
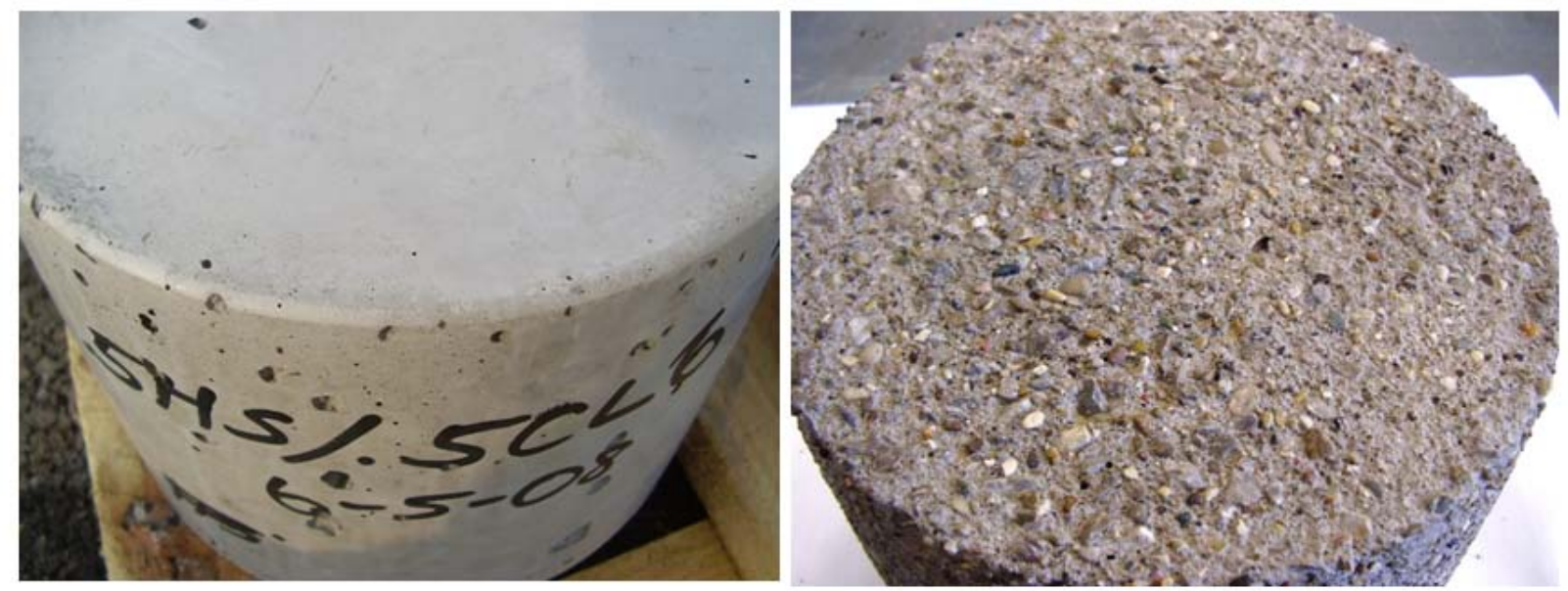

Figure 40. Specimen of clinkerless cement concrete; after 1 day exposure (left) and after 2 years exposure (right). Note the exposure of the aggregate caused by gradual dissolution of the cement component.

Based on this previous work, it was decided that one focus of clinkerless cement research for this project will be to evaluate the effects of several admixtures that can induce some degree of water repellency to the cement. These include ethylene vinyl acetate copolymers and silanebased additives. During this reporting period, production of clinkerless cement was initiated. To produce calcium sulfate hemihydrate, the FGD gypsum was moistened with $7.5 \%$ water, placed into a 2.25 in (57 mm) diameter steel pellet mold, and pressed at 4,000 lbs (1815 kg) to form a compacted disk. Multiple disks were then placed into a steam autoclave and heated at $130^{\circ} \mathrm{C}$ and 3 bars saturated steam pressure for 4 hours. The disks of calcium sulfate hemihydrate were then removed from the autoclave and dried at $100^{\circ} \mathrm{C}$ for a minimum of 12 hours. Approximately $20 \mathrm{~kg}$ of hemihydrate will be prepared for mortar and concrete testing.

In order to test the effect of hydrophobic admixtures on clinkerless cement mortar and concrete, approximately $40 \mathrm{~kg}$ of clinkerless cement will be produced. The hemihydrate will be milled with FBC ash and ultrafine fly ash (UFA) and blended with the different admixtures. The hemihydrate will comprise $50 \%$ of the cement; with the remainder comprising FBC spent bed and UFA at a ratio of 50:50.

A second set of experiments, which was initiated during this reporting period, investigated the conversion in situ of the anhydrous calcium sulfate (anhydrite) in the FBC spent bed to calcium sulfate hemihydrate. The FBC material contains $50-55 \%$ anhydrite, which was formed in the combustor. During hydration of the FBC ash in clinkerless cement, the anhydrite slowly dissolves and provides calcium and sulfate needed for the formation of the cementitious mineral ettringite $\left(\mathrm{Ca}_{6} \mathrm{Al}_{2} \mathrm{O}_{6}\left(\mathrm{SO}_{4}\right)_{3} \cdot 32 \mathrm{H}_{2} \mathrm{O}\right)$. The formation of ettringite in an FBC/fly ash mixture is fairly slow, primarily because of the slow rate of aluminum release from the fly ash. The addition of hemihydrate provides a short-term strength gain, but is too soluble to provide durability in 
outdoor exposure. Thus, minimizing the amount of hemihydrate in clinkerless cement can potentially improve durability, but at the expense of short-term strength. One possible solution is to convert the anhydrite present in the FBC spent bed to hemihydrate, which could serve two important functions: provide short-term strength gain, from the hydration of the hemihydrate, and contribute to longer-term strength by supplying calcium and sulfate for ettringite formation.

To accomplish the conversion of FBC anhydrite to hemihydrate, the FBC spent bed was prehydrated with $55 \%$ water for 21 days. This material was placed in an autoclave, heated at $130^{\circ} \mathrm{C} / 3$ bar in saturated steam for 4 hours, and then dried at $100^{\circ} \mathrm{C}$. Figure 41 shows the XRD spectrum of the hydrated FBC ash. After hydration, most of the anhydrite was converted to gypsum and only a small quantity of ettringite formed. Figure 42 shows the XRD spectrum of this material after treatment in the autoclave and indicates that the gypsum was converted to hemihydrate and, unexpectedly, anhydrite.

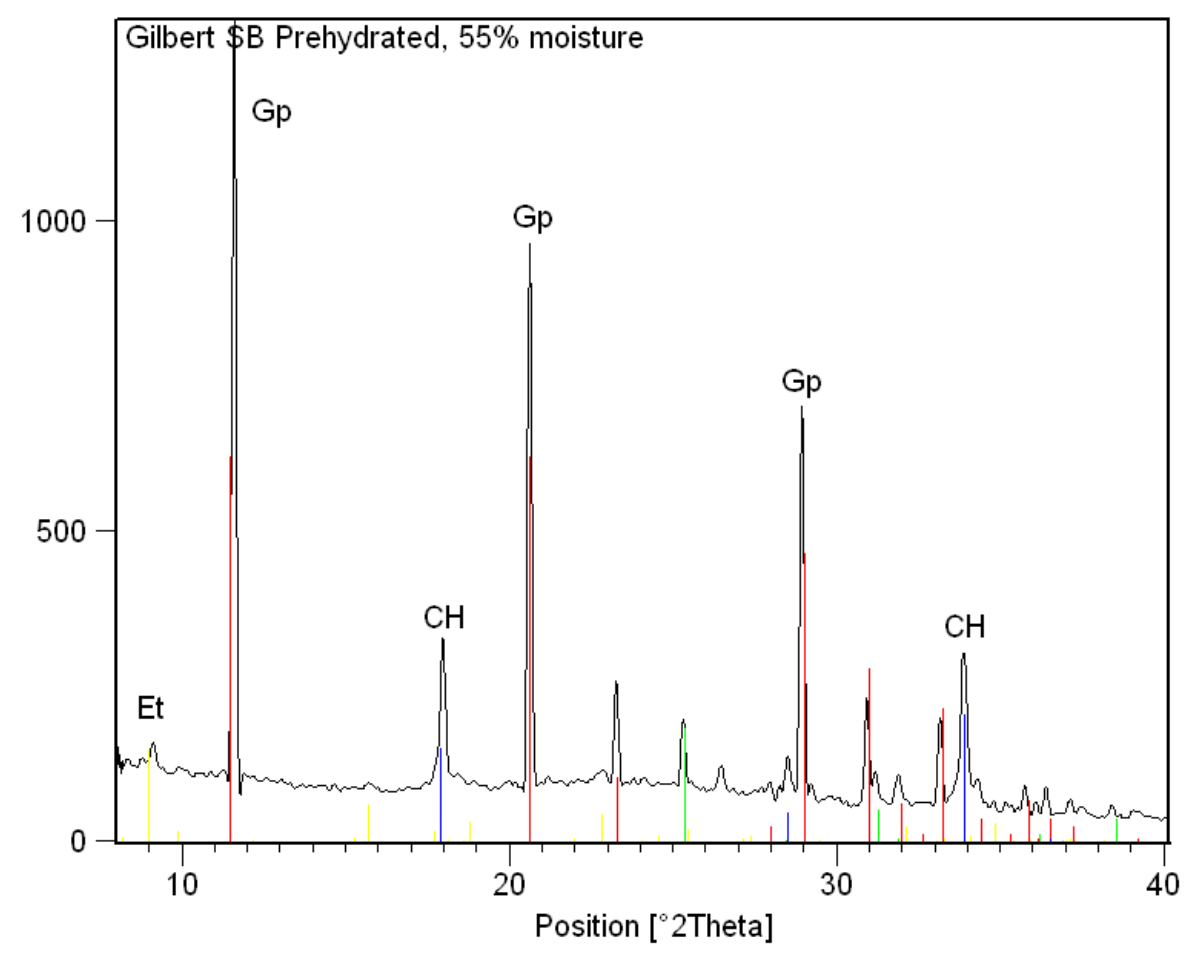

Figure 41. XRD spectrum of hydrated FBC spent bed material; Et=ettringite, $\mathrm{CH}=$ calcium hydroxide, Gp=gypsum. 


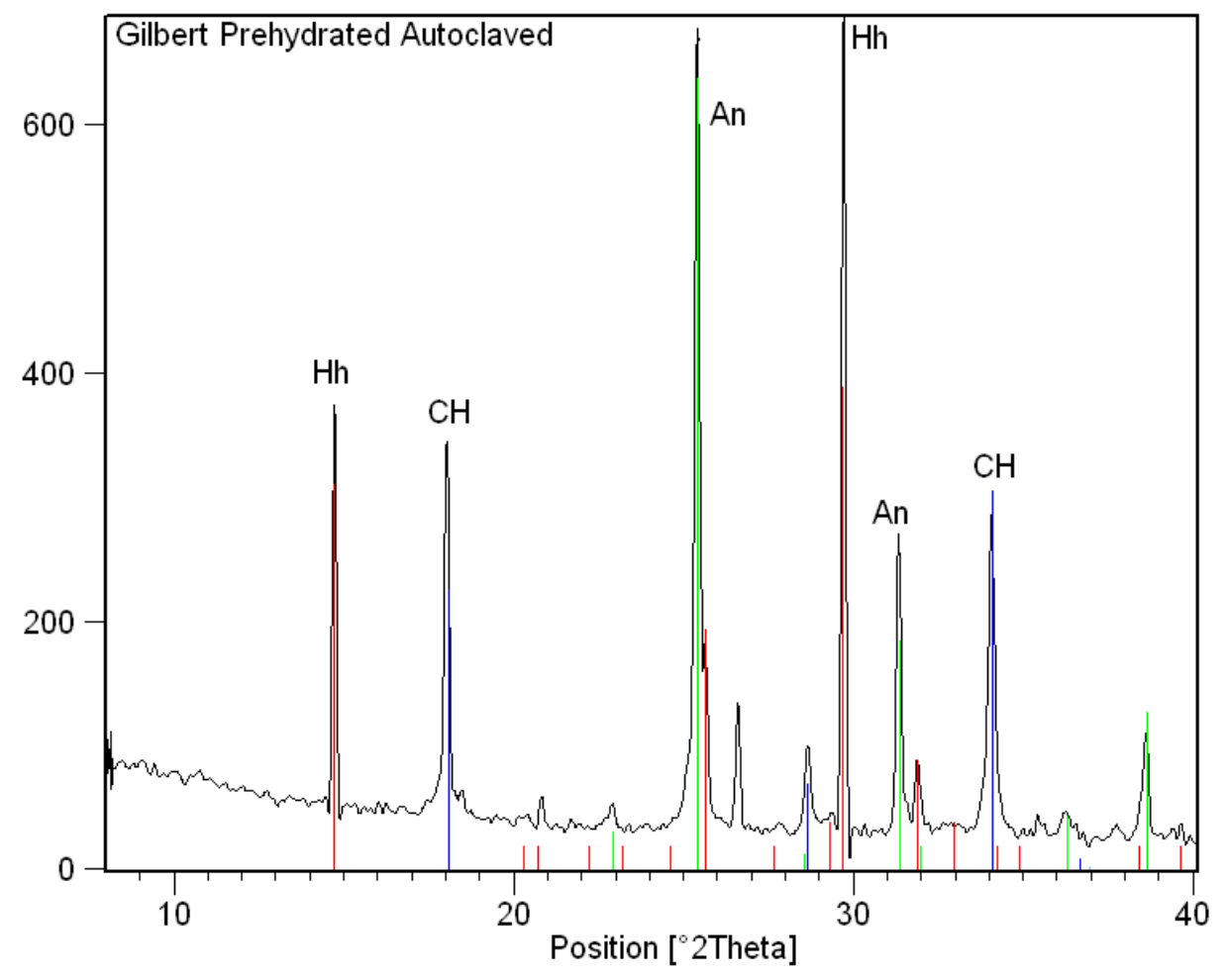

Figure 42. XRD spectrum of hydrated, autoclaved $\mathrm{FBC}$ spent bed; $\mathrm{CH}=$ calcium hydroxide, $\mathrm{An=anhydrite,}$ $\mathrm{Hh}=$ calcium sulfate hemihydrate.

The formation of anhydrite in the autoclave has not occurred in previous experiments and will be investigated in the next reporting period. Anhydrite is not desirable in this case because it does not provide the short-term strength that is achieved with calcium sulfate hemihydrate.

Another method to produce hemihydrate in situ is to heat gypsum in air to approximately 200$300^{\circ} \mathrm{C}$. Although this method is less expensive than the autoclave method, it generally produces an inferior product termed " $\beta$-hemihydrate". However, dehydrating gypsum in air to produce $\beta$-hemihydrate is successfully used in the wallboard industry, so it was used in this study to produce hemihydrate in situ. To accomplish this, the FBC spent bed was hydrated as described above, followed by heat treatment at $250^{\circ} \mathrm{C}$ for 4 hours. The product was analyzed by $X R D$, which indicated that hemihydrate was the main calcium sulfate phase in the material (Figure 43). Mortar cubes were prepared using this material, and the results are described in the next section. 


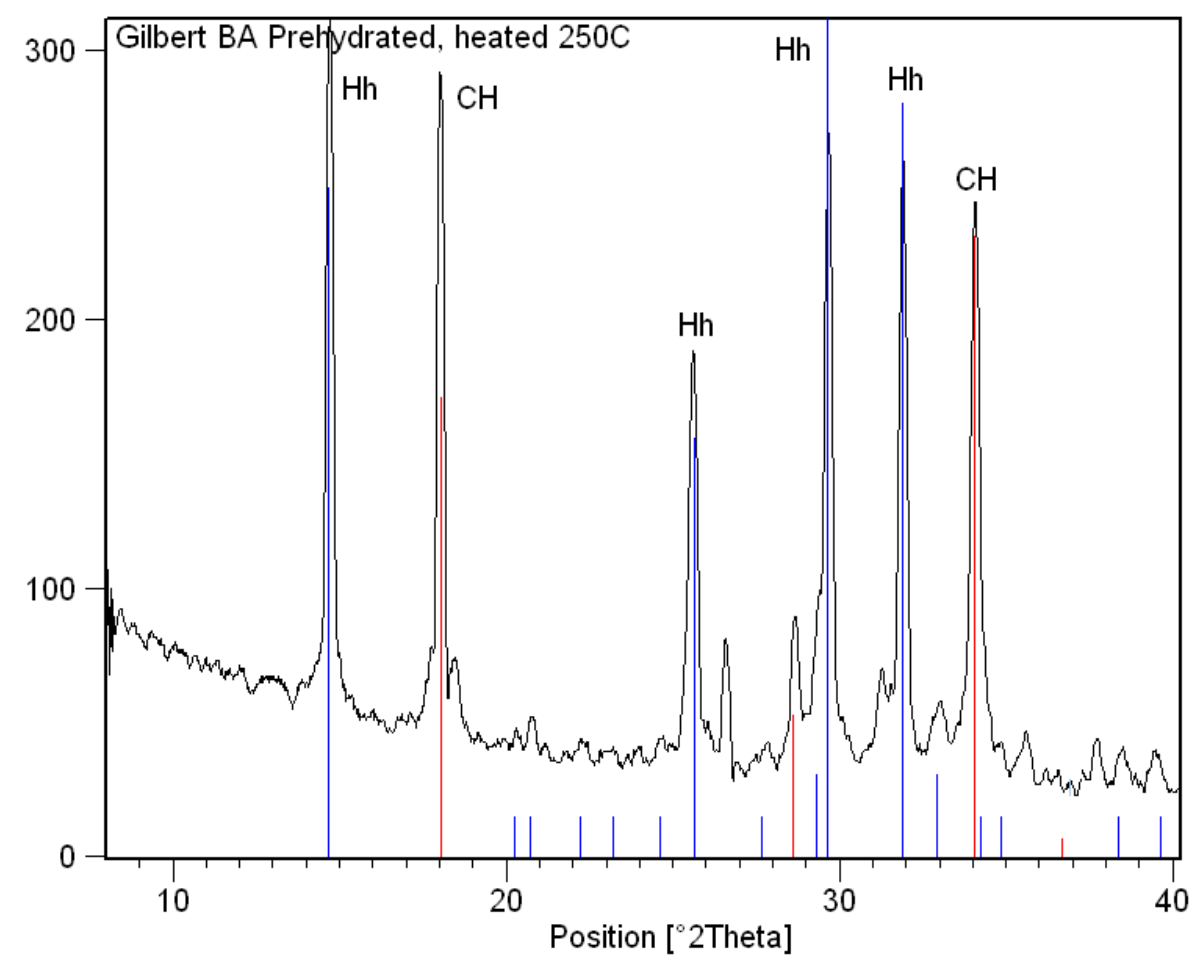

Figure 43. XRD spectrum of hydrated FBC spent bed material that was heated to $250 \mathrm{C}$ for 4 hours.

\section{Mortar and Concrete Production and Testing}

Mortar was prepared following ASTM testing methods (Table 22), using the proportions shown in Table 23, in a 5 qt. planetary mixer. The mortar was placed and compacted into $2 \times 2 \times 2$ in $(5.08 \mathrm{~cm})$ cube molds for compressive strength testing, and into 1 in X 1 in X 11 in $(2.54 \times 2.54$ $X 27.9 \mathrm{~cm}$ ) molds for expansion testing. In addition, a small quantity of mortar was placed into the isothermal calorimeter to verify set time.

Table 22. List of ASTM testing methods.

\begin{tabular}{|l|c|c|}
\hline \multicolumn{1}{|c|}{ Property } & Material & ASTM Standard(s) \\
\hline Compressive Strength & Mortar, Concrete & C 109, C 39 \\
\hline Drying shrinkage & Mortar & C 596 \\
\hline Expansion & Mortar & C 157 \\
\hline
\end{tabular}


Table 23. Proportions of materials for two mortar formulations.

\begin{tabular}{|l|c|c|c|c|}
\hline & $\mathbf{2 5 \%} \mathbf{~ H H}$ & $\mathbf{5 0 \%} \mathbf{H H}$ & CSAB\#4 & CSFAB\#3 \\
\hline Cement (g) & 500 & 500 & 500 & 500 \\
\hline Ottawa Sand (g) & 1375 & 1375 & 1375 & 1375 \\
\hline Water (g) & 175 & 175 & 220 & 220 \\
\hline Na Citrate (g) & 0.5 & 1.0 & 0.5 & 0.5 \\
\hline Water Reducer (ml) & 3.0 & 3.0 & 0.0 & 0.0 \\
\hline
\end{tabular}

\section{Clinkerless Mortar and Concrete}

The isothermal calorimetry data for the two hemihydrate mortar mixtures is shown in Figure 44. These data indicate that the set time of the mortars is faster than for paste, which is not unexpected. The greater degree of shear within the mortar during mixing often accelerates the set of mortar and concrete compared to paste.

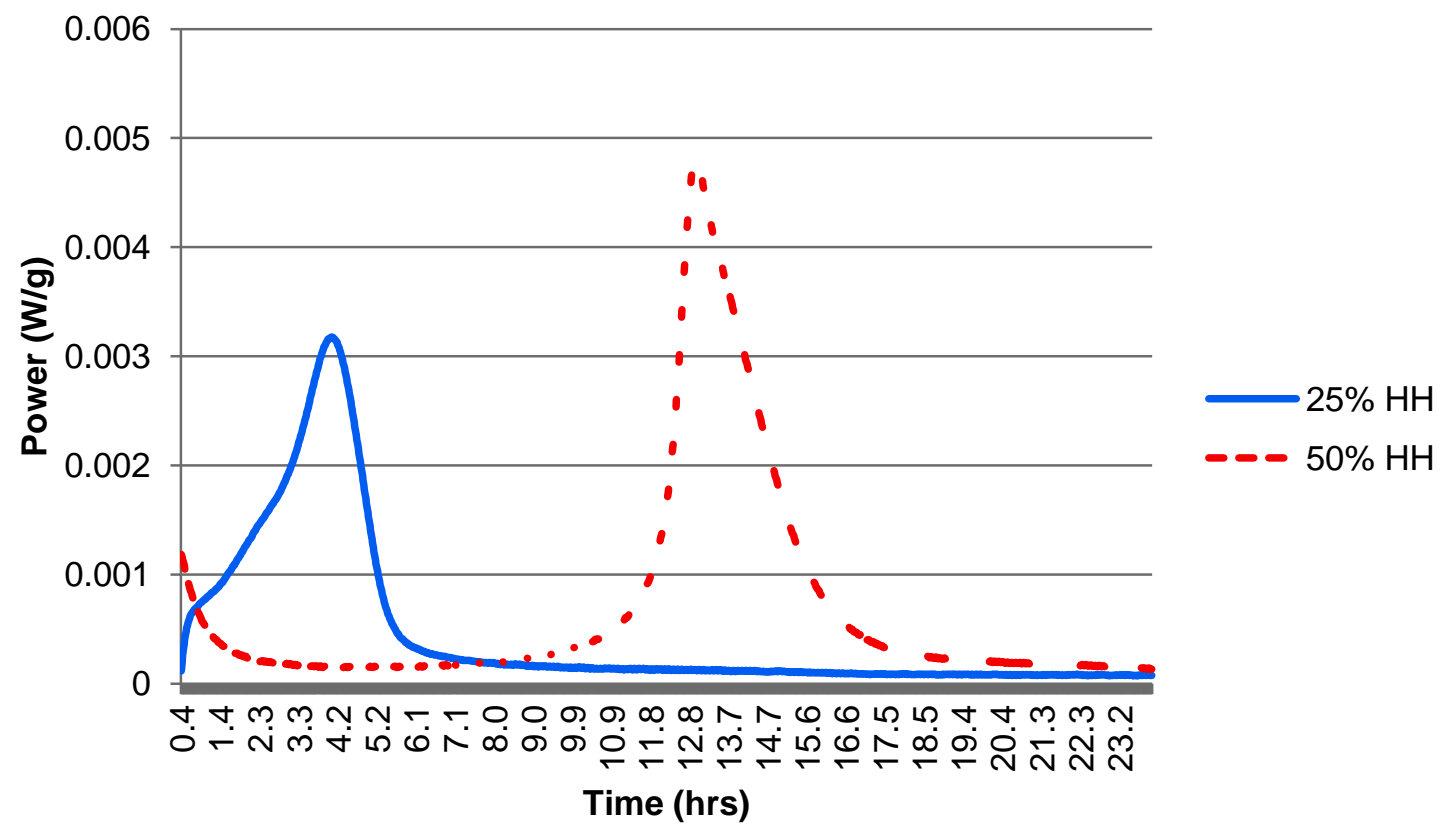

Figure 44 . Isothermal calorimetry data for $25 \%$ and $50 \% \mathrm{HH}$ mortars.

The compressive strength data for the two mortar mixtures are shown in Table 24. As expected, the $50 \% \mathrm{HH}$ mortar had a higher early strength than the $25 \% \mathrm{HH}$ mortar. The targeted 1 day strength was $1000 \mathrm{PSI}(6.9 \mathrm{MPa}$ ) which was not achieved by the $25 \% \mathrm{HH}$ mortar, although it did surpass this target within 1 week. Both formulations continued to rapidly gain strength and attained a compressive strength of over 6500 PSI after 112 days of curing (Figure 45). The expansion of the clinkerless cement mortar utilizing 25\% and 50\% 
hemihydrate was examined and the results are shown in Figure 45. Both mixes showed minimal expansion until after 10 days of curing at which point the $25 \% \mathrm{HH}$ mortar showed considerable expansion over the $50 \% \mathrm{HH}$ mix. This is primarily from the increased amount of expansive clinkerless material in this mix. More lime from portlandite is available to form ettringite which is the main contributor to the expansion.

Table 24. Unconfined compressive strength of mortar cube specimens.

\begin{tabular}{|c|c|c|}
\hline & 25\% HH & 50\% HH \\
\hline 1 Day MPa (PSI) & $4.55(660)$ & $13.8(2,001)$ \\
\hline 7 Day MPa (PSI) & $8.10(1,175)$ & $15.6(2,262)$ \\
\hline 32 Day MPa (PSI) & $25.80(3,741)$ & $26.95(3,908)$ \\
\hline 56 Day MPa (PSI) & $34.80(5,046)$ & $36.35(5,271)$ \\
\hline 112 Day MPa (PSI) & $50.25(7,286)$ & $45.55(6,605)$ \\
\hline
\end{tabular}

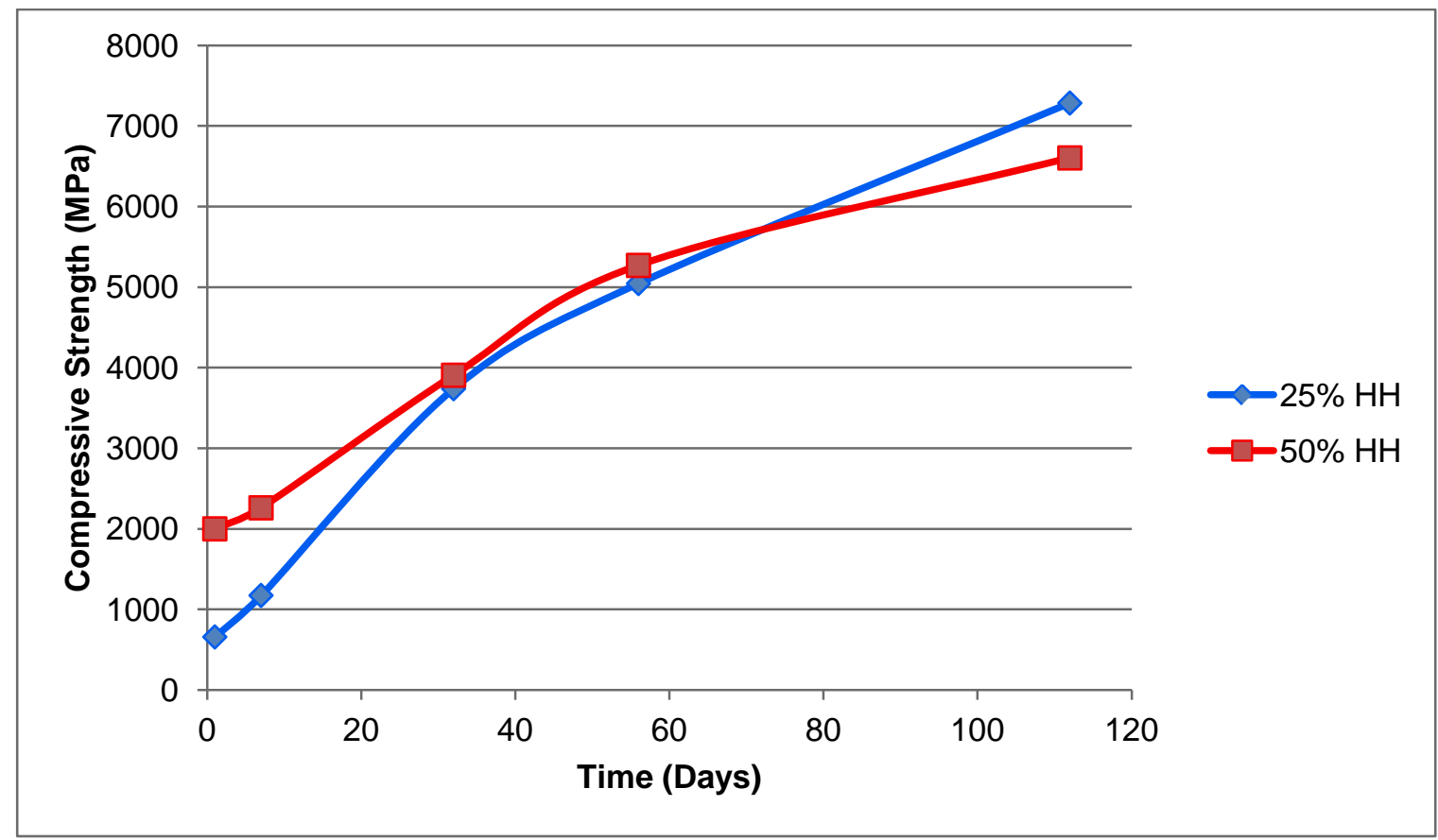

Figure 45. Unconfined compressive strength of mortar cube specimens.

The influence of hydrophobic-polymeric admixtures on the clinkerless cement mortar was evaluated for their affect on compressive strength and expansion properties of mortar specimens. Each admixture was used to prepare three mortar mixes, with each mix containing varying quantities of the polymeric powder; $0.5 \%, 1.0 \%$, and $2.0 \%$ by mass for HD15 and HD45. The maximum amount of $\mathrm{HD}^{\star *}$ admix used was set at $2.0 \%$ because at $3.0 \%$ the cubes were discarded because of their poor condition; they were very stiff and difficult to work with (Figure 46). The SEAL admix was proportioned at $0.05 \%, 0.1 \%$, and $0.2 \%$ by mass according to the manufacturers specifications. Figure 47 shows the mix summary for the clinkerless cement 
mortars that were prepared with the hydrophobic admixtures. Mortar cubes were prepared following ASTM C 305 protocols and were tested for compressive strength following ASTM C 109 on 1, 7, 28, 56, 112, and 224-days of curing. The expansion of the clinkerless cement mortars were tested following ASTM C 1038 protocols for cement mortar bars stored in water; and were tested on $7,14,21,28,35,42,49,56$, and 70-days of curing.

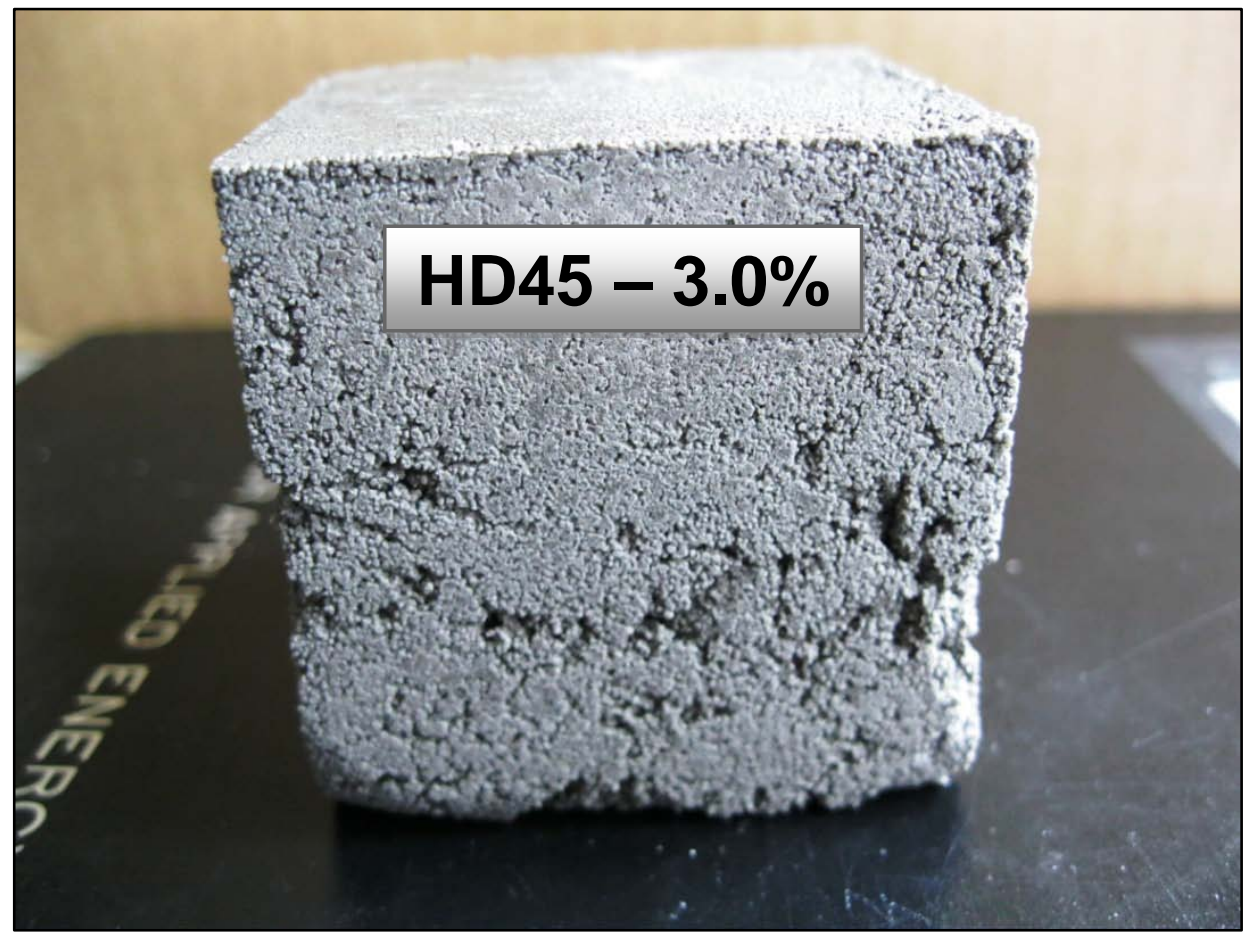

Figure 46. Clinker cement mortar cube prepared with HD45 admixture at 3.0\% by mass. 


\begin{tabular}{|c|c|c|c|}
\hline Casting Date & 2-Jun-11 & 2-Jun-11 & 25-May-11 \\
\hline Mortar Code & HD15 0.5\% & HD15 1\% & HD15 2\% \\
\hline $\begin{array}{c}\text { Admixture } \\
\text { Qty (g) }\end{array}$ & $\begin{array}{c}\text { Elotex HD1501 } \\
9.38\end{array}$ & $\begin{array}{c}\text { Elotex HD1501 } \\
18.75\end{array}$ & $\begin{array}{c}\text { Elotex HD1501 } \\
37.50\end{array}$ \\
\hline Mix Design & $\# 6$ & \#5 & $\# 3$ \\
\hline Gilbert FBC (g) & 188.0 & 188.0 & 188.0 \\
\hline Ghent UFA (g) & 187.0 & 187.0 & 187.0 \\
\hline Hemihydrate (g) & 125.0 & 125.0 & 125.0 \\
\hline Graded Sand (g) & 1375.0 & 1375.0 & 1375.0 \\
\hline Na Citrate (g) & 0.5 & 0.5 & 0.5 \\
\hline Glenium 3030 (ml) & 0.0 & 0.0 & 0.0 \\
\hline Water (g) & 175.0 & 175.0 & 175.0 \\
\hline w:cm ratio & 0.350 & 0.350 & 0.350 \\
\hline Flow \% & & & nd \\
\hline Ambient Temperature & 22.6 & 22.6 & 23.6 \\
\hline Casting Date & 31-May-11 & 2-Jun-11 & 6-Jun-11 \\
\hline Mortar Code & HD45 0.5\% & HD45 1\% & HD45 2\% \\
\hline $\begin{array}{c}\text { Admixture } \\
\text { Qty (ml/kg cement) }\end{array}$ & $\begin{array}{c}\text { Elotex HD4500 } \\
9.38 \\
\end{array}$ & $\begin{array}{c}\text { Elotex HD4500 } \\
18.75 \\
\end{array}$ & $\begin{array}{c}\text { Elotex HD4500 } \\
37.50 \\
\end{array}$ \\
\hline Mix Design & $\# 1 \mathrm{~A}$ & $\# 7$ & $\# 8$ \\
\hline Gilbert FBC (g) & 188.0 & 188.0 & 188.0 \\
\hline Ghent UFA (g) & 187.0 & 187.0 & 187.0 \\
\hline Hemihydrate (g) & 125.0 & 125.0 & 125.0 \\
\hline Graded Sand (g) & 1375.0 & 1375.0 & 1375.0 \\
\hline Na Citrate (g) & 0.5 & 0.5 & 0.5 \\
\hline Glenium 3030 (ml) & 0.0 & 0.0 & 0.0 \\
\hline Water (g) & 175.0 & 175.0 & 175.0 \\
\hline w:cm ratio & 0.350 & 0.350 & 0.350 \\
\hline \multicolumn{4}{|l|}{ Flow \% } \\
\hline Ambient Temperature & 25.3 & 22.6 & 23.1 \\
\hline Casting Date & 31-May-11 & 6-Jun-11 & 31-May-11 \\
\hline Mortar Code & SEAL 0.05 & SEAL 0.1 & SEAL 0.2 \\
\hline $\begin{array}{c}\text { Admixture } \\
\text { Qty (g) }\end{array}$ & $\begin{array}{c}\text { Elotex SEAL200 } \\
0.94\end{array}$ & $\begin{array}{c}\text { Elotex SEAL200 } \\
1.88\end{array}$ & $\begin{array}{c}\text { Elotex SEAL200 } \\
3.75\end{array}$ \\
\hline Mix Design & $\# 4 \mathrm{~A}$ & $\# 9$ & \#2 \\
\hline Gilbert FBC (g) & 188.0 & 188.0 & 188.0 \\
\hline Ghent UFA (g) & 187.0 & 187.0 & 187.0 \\
\hline Hemihydrate (g) & 125.0 & 125.0 & 125.0 \\
\hline Graded Sand (g) & 1375.0 & 1375.0 & 1375.0 \\
\hline Na Citrate (g) & 0.5 & 0.5 & 0.5 \\
\hline Glenium $3030(\mathrm{ml})$ & 3.0 & 0.0 & 0.0 \\
\hline Water (g) & 175.0 & 175.0 & 175.0 \\
\hline w:cm ratio & 0.355 & 0.350 & 0.350 \\
\hline Flow \% & & & nd \\
\hline Ambient Temperature & 25.3 & 23.1 & 25.3 \\
\hline
\end{tabular}

Figure 47. Mix summary for mortar prepared with hydrophobic admixtures. 
Figures 48, 49, and 50 illustrate the effect of hydrophobic admixtures on the unconfined compressive strength of the clinkerless cement mortar cubes. The HD15 admix with the copolymer of vinyl acetate, vinyl versatate yielded lower compressive strength than the control mortar cubes at $1,7,28$, and 56 days of curing. Proving to have a negative effect on the overall strength of the clinkerless mortar (Figure 48). However the HD45 admix, which is similar to HD15, however it contains an acrylate showed similar compressive strength results as the HD15 admix. The lowest percentage of HD45, 0.5\%, showed some signs of enhanced strength performance at 56 days relative to the control mortar, suggesting some possible long-term benefit of this polymeric admixture (Figure 49). The SEAL admix, which is a highly active, silane based waterproofing agent had similar compressive strengths at 1 and 7 days and surpassed the control strength at 56 days of curing (Figure 50). The linear strength gain of the SEAL mortar cubes indicates an increased long-term strength performance, proving to be a good benefit to this gypsum-based cement system.

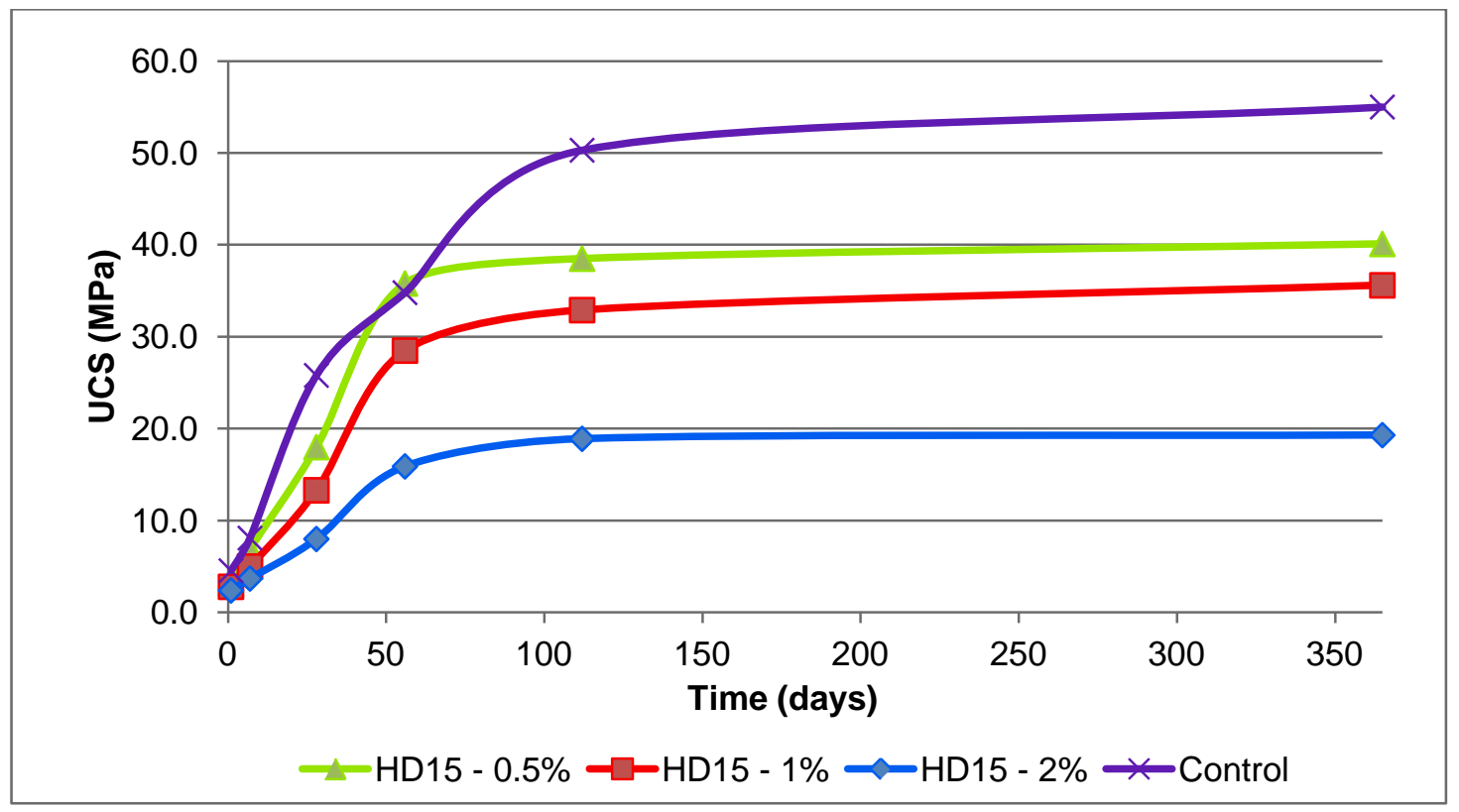

Figure 48. Unconfined compressive strength of mortar cube specimens. 


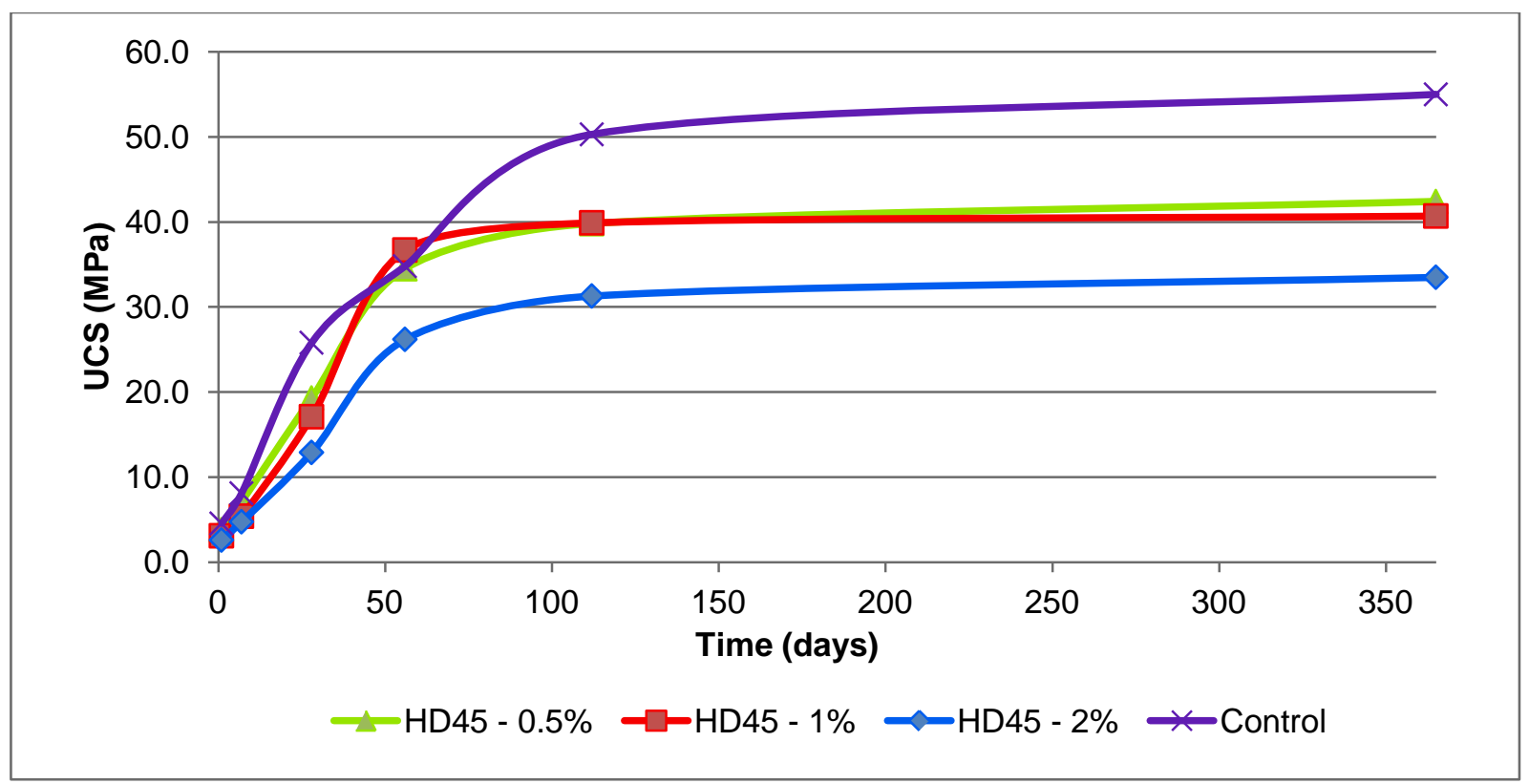

Figure 49. Unconfined compressive strength of mortar cube specimens.

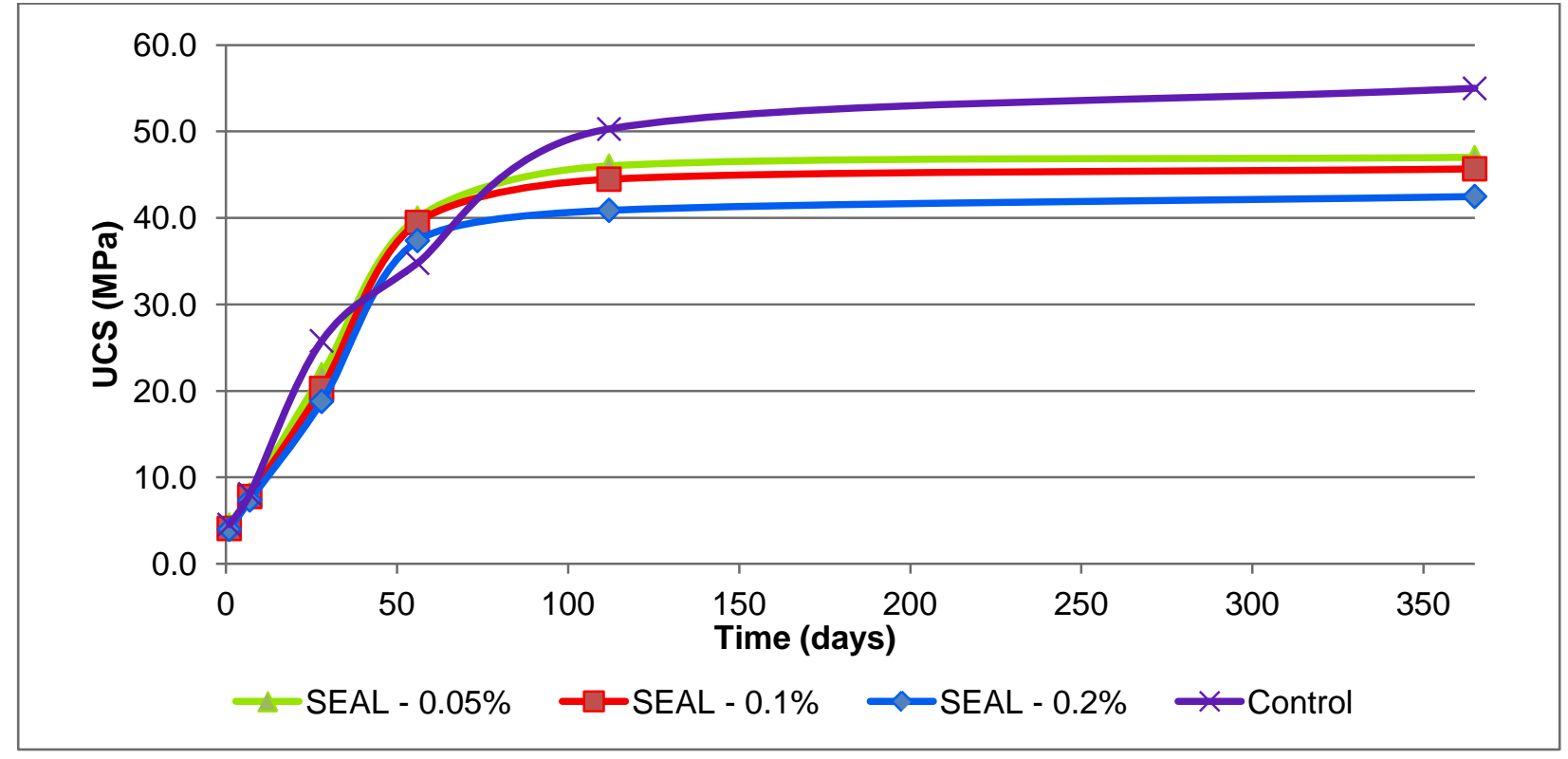

Figure 50. Unconfined compressive strength of mortar cube specimens.

The influence of the hydrophobic admixtures on the expansion of the clinkerless cement can be seen in Figure 51. Each mix that contained the hydrophobic admix experienced an increase in the time of expansion within the first 30 days, before equilibrating. While the control mortar, without a hydrophobic admix did not begin expanding until after 10 days however the expansion 
did not equilibrate until after 50 days of curing. The reduced expansion seen with HD15 $-0.5 \%$ and both the Seal $-0.25 \%$ and $0.05 \%$ admixtures may be attributed to the reduction of the water cement ratio which resulted in reduced moisture expansion. With the improved long-term compressive strength performance of the SEAL admix along with the slight reduction in mortar expansion after 40 days indicates an added benefit to the use of the SEAL admix in concrete.

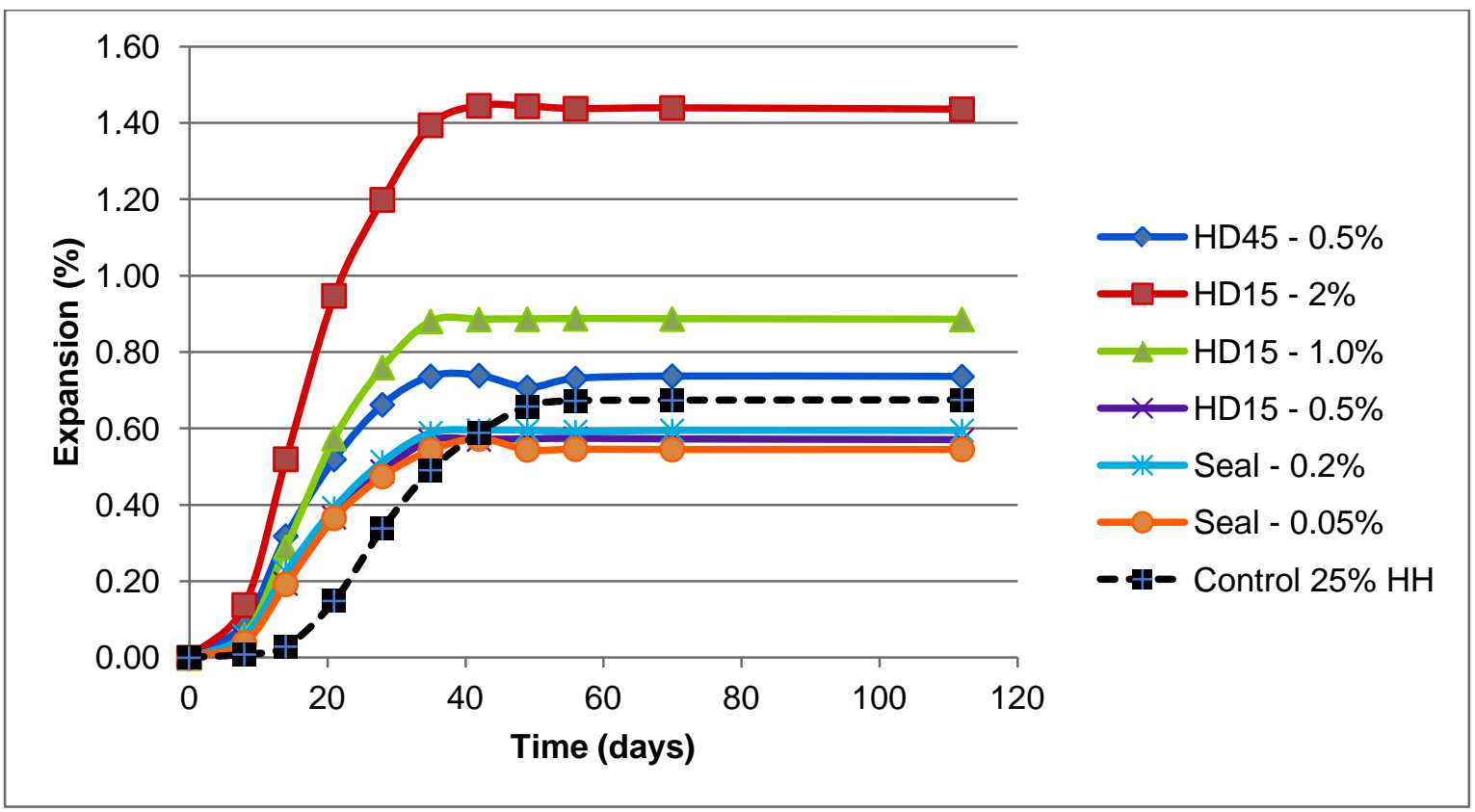

Figure 51. Expansion of mortar bar specimens with hydrophobic admixture. 
Water-repelling admixtures were blended with the cement to induce a degree of hydrophobicity to the mortar/concrete. Calcium stearate and ethylene vinyl acetate copolymer will be evaluated for their efficacy in improving durability of the clinkerless cement mortar and concrete.

Mortar was prepared using the hydrated $/ 250^{\circ} \mathrm{C} F B C$ spent bed material described above. Since there was already hemihydrate in the FBC material, only $25 \%$ by weight of additional hemihydrate was added to the cement. The mix proportions are provided in Table 25. Figure 52 shows the compressive strength development of the mortar over the course of approximately 3 months. The 1 day strength, which occurs primarily from the hydration of the hemihydrate, was approximately $5 \mathrm{MPa}(725 \mathrm{PSI})$. This was not as high as when $50 \%$ hemihydrate was added previously, which suggests that the $\mathrm{FBC}$ hemihydrate was not as effective at providing short term strength. After 3 months the cubes achieved a strength of $29.2 \mathrm{MPa}(4,230 \mathrm{PSI})$, which was close to the targeted strength of $31 \mathrm{MPa}(4,500 \mathrm{PSI})$, although the rate of strength gain was too slow.

Table 25. Proportions of ingredients for hydrated/250C cement mortar.

\begin{tabular}{|l|c|}
\hline FBC Spent Bed (g) & $\mathbf{1 9 1 . 0}$ \\
\hline Class F FA (g) & 191.0 \\
\hline Hemihydrate (g) & 118.0 \\
\hline Sand (g) & 1375.0 \\
\hline Water (g) & 195.0 \\
\hline Water Repellant (g) & 2.40 \\
\hline Sodium Citrate (g) & 0.42 \\
\hline
\end{tabular}

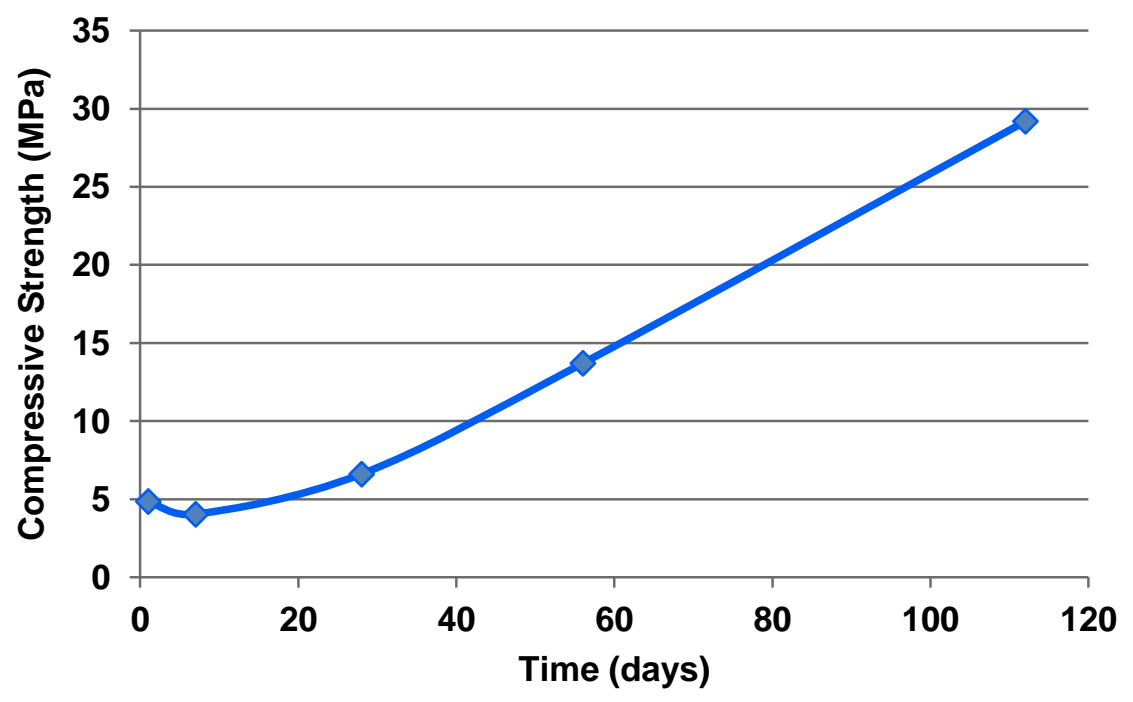

Figure 52. Compressive strength of hydrated $/ 250^{\circ} \mathrm{C} \mathrm{FBC} \mathrm{cement} \mathrm{mortar.}$

Additional experiments will focus on producing the hemihydrate phase in situ using the autoclave method. The investigation will include confirming the formation of anhydrite and 
determining a method to avoid it. Mortar specimens will be prepared from this material to investigate strength development and dimensional stability.

A separate series of experiments was designed as a follow-up to previous work by investigating the addition of ground, granulated blast furnace slag (GGBS) to the clinkerless cement. In particular, the goal was to improve the strength and durability of the clinkerless cement blends that contain ordinary Class F fly ash. In these experiments, a Grade 120 GGBS (Table 26) was blended in different proportions with FBC ash, Class F fly ash, and hemihydrate, and ASTM C109 mortars were prepared from the cement blends. The proportions of these mortars are provided in Table 27. In an effort to increase the available surface area of the ordinary Class $F$ fly ash, some of the sand (137.5 g) was replaced with fly ash in the mortars. The water repelling admixture was Chryso Pave 200, and sodium citrate was used to retard the rapid setting of the hemihydrate. The mortar cubes were cast at constant flow (i.e. workability) and were cured in a temperature-controlled mist room at $100 \%$ relative humidity.

Table 26. Major oxides in GGBS.

\begin{tabular}{|c|c|c|c|c|c|c|c|c|}
\hline & $\mathrm{SiO}_{2}$ & $\mathrm{Al}_{2} \mathrm{O}_{3}$ & $\mathrm{Fe}_{2} \mathrm{O}_{3}$ & $\mathrm{CaO}$ & $\mathbf{M g O}$ & $\mathrm{Na}_{2} \mathrm{O}$ & $\mathbf{K}_{2} \mathrm{O}$ & $\mathbf{S O}_{3}$ \\
\hline GGBS & 35.52 & 10.45 & 0.99 & 38.69 & 10.83 & 0.18 & 0.48 & 2.47 \\
\hline
\end{tabular}

Table 27. Mixture proportions for GGBS mortars.

\begin{tabular}{|l|c|c|c|c|}
\hline & $\mathbf{5 \%}$ Slag & $\mathbf{1 0 \%}$ Slag & $\mathbf{2 0 \%}$ Slag & $\mathbf{0 \%}$ Slag \\
\hline FBC Spent Bed (g) & 126.0 & 119.3 & 106.0 & 132.5 \\
\hline Class F FA (g) & 263.5 & 256.8 & 243.5 & 270.0 \\
\hline Hemihydrate (g) & 223.0 & 211.5 & 188.0 & 235.0 \\
\hline GGBS (g) & 25.0 & 50.0 & 100.0 & 0.0 \\
\hline Graded Sand (g) & 1237.5 & 1237.5 & 1237.5 & 1237.5 \\
\hline Water (g) & 195.0 & 195.0 & 195.0 & 200.0 \\
\hline Water Repellant (g) & 2.40 & 2.40 & 2.40 & 2.40 \\
\hline Sodium Citrate (g) & 0.84 & 0.84 & 0.84 & 0.84 \\
\hline
\end{tabular}

The addition of slag generally improved the strength of the mortar cubes (Figure 53), and improved the overall integrity of the mortar at the later ages. 


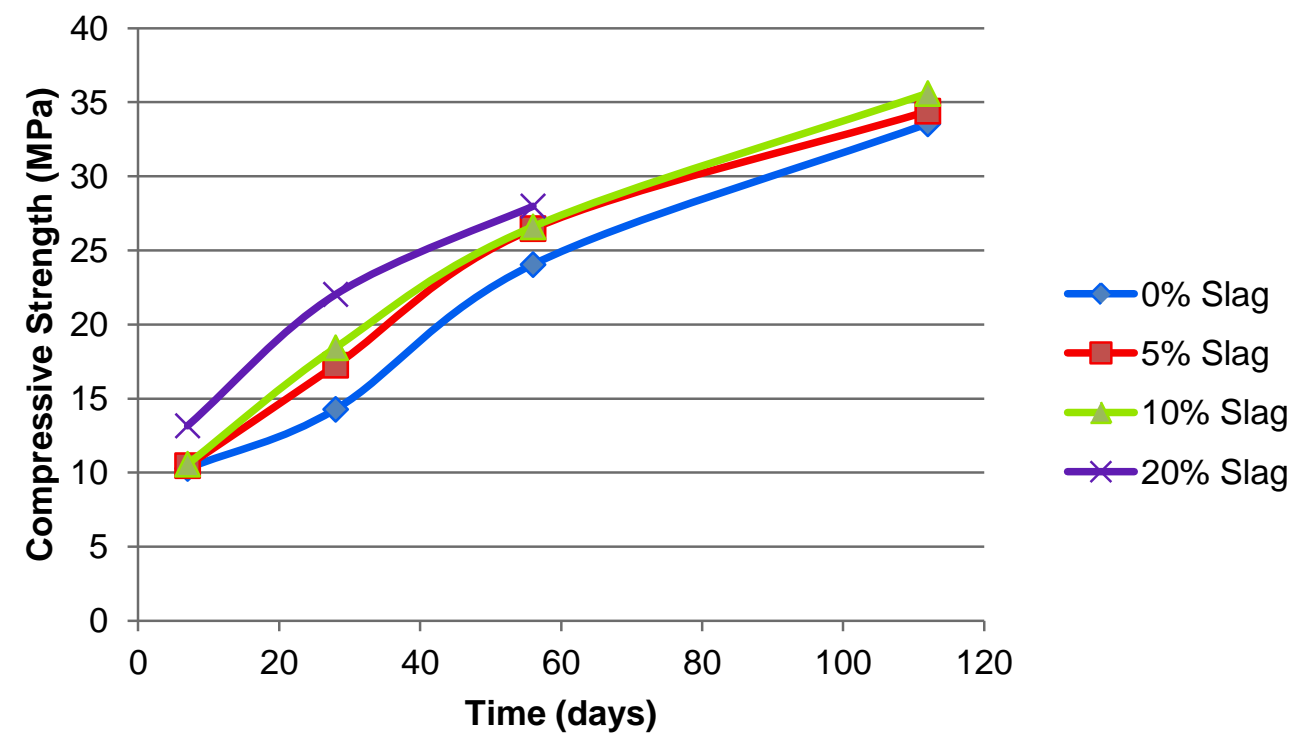

Figure 53. Unconfined compressive strength of mortar cubes with and without GGBS.

\section{CSA Mortar and Concrete Testing}

Mortar cubes were prepared for the CSA cement formulations following ASTM C 305 and C 109 protocols. As expected for rapid-setting, high-strength CSA cements, the 1-day strength significantly exceeded that of Type-I ordinary Portland cement (OPC) for the CSAB\#4 cement (Figure 54). The CSFAB\#3 mortar had similar 1-day strengths as OPC, however the CSAbased cement continued to gain strength at a greater rate than that of OPC. The leveling-off of strength gain for the CSAB mortar was a result of the consumption of the available ettringiteforming compounds. The extremely-high strength of the CSAB\#4 cement is attributed to the large amount of Klein's compound and anhydrite available in the cement. The CSFAB\#3 cement has a lesser amount of Klein's compound which explains the slower strength gain after 1-day of curing compared to CSAB\#4. 


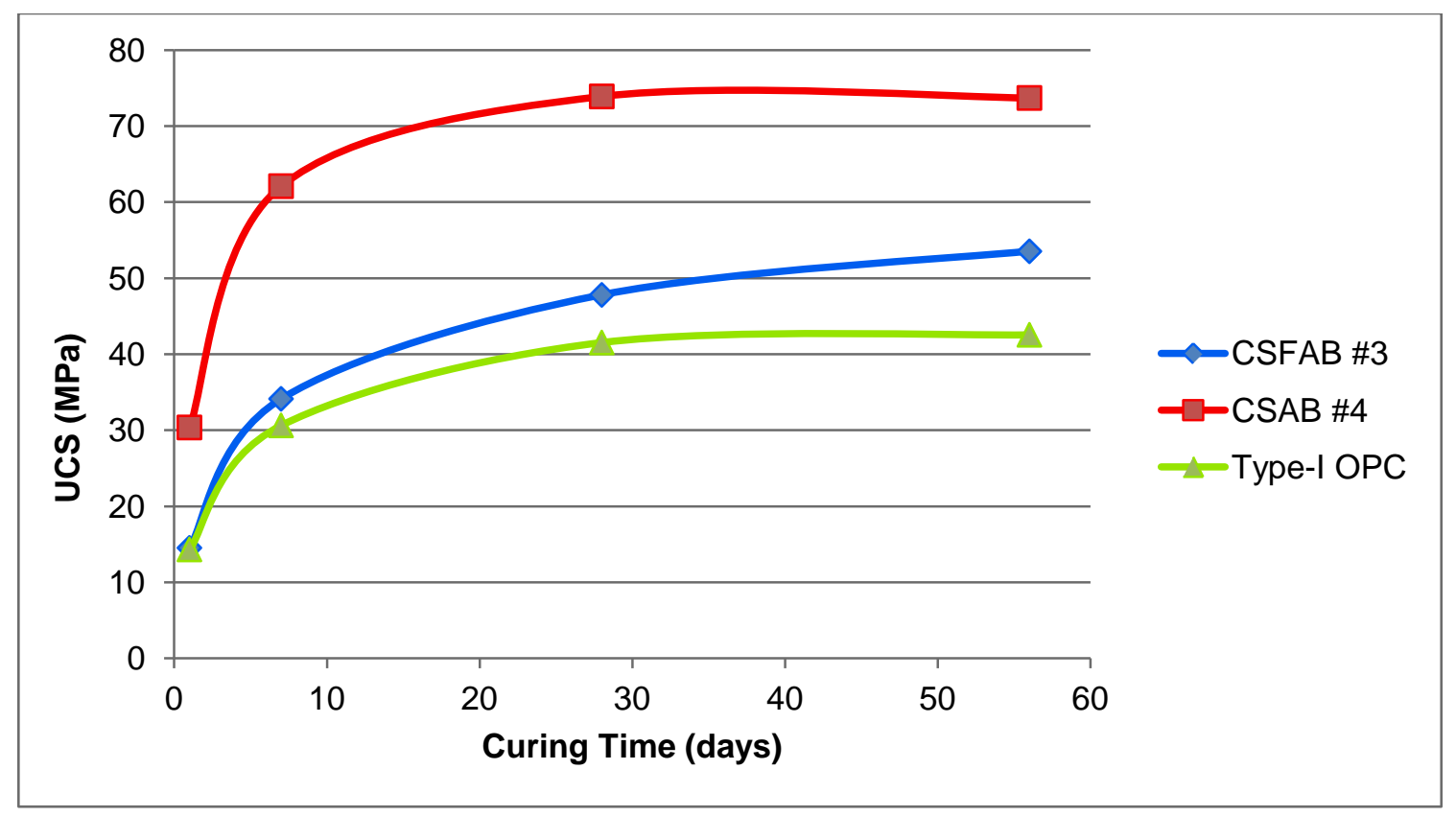

Figure 54. Unconfined compressive strength of mortar cube specimens.

The CSA cements were evaluated for strength performance in concrete. Concrete mixtures were proportioned and mixed following ASTM methods (Figure 55). 3 in. x 6 in. cylindrical specimens were made following ASTM C 192. The first set consisted of CSAB\#4 concrete, the second set contained CSFAB\#3 cement. The water:cementitious material ratio was set at 0.44. Polycarboxylate high-range water reducer (BASF Glenium 3030) was used to increase slump. $\mathrm{Na}$ Citrate was used to control the set time of the CSA cements. Each set of cylinders (two cylinders) were tested on 1, 7, and 28 days for unconfined compressive strength (UCS). Testing will continue beyond this reporting period to include 56 and 112 days for UCS.

Figure 56 provides the CSA concrete compressive strength data, the strength The CSAB\#4 concrete doubled the strength of the CSFAB\#3 concrete at one day of curing, and continued to increase at a similar rate until 28 days. At 28-days of curing the CSFAB\#3 concrete attained a higher compressive strength, $61.4 \mathrm{MPa}$ (8895 psi) than the CSAB\#4 concrete, 57.6 MPa (8352 psi). As the CSFAB\#3 concrete continued to gain strength at 28 days the CSAB\#4 concrete appears to have a reduction in strength. The high quantity of Klein's compound in the CSAB\#4 cement leads to the formation of monosulfate as the available sulfate in the system is depleted. After 28 days there should be an increase in strength as the concrete structure becomes denser with ettringite formation with the release of additional sulfate compounds. 


\begin{tabular}{|c|c|c|}
\hline Casting Date & 2-Apr-12 & 2-Apr-12 \\
\hline Mortar Code & CSAB\#4 & CSFAB\#3 \\
\hline Mix Design (kg) & $\# 1$ & \#2 \\
\hline Cement & 3.50 & 3.50 \\
\hline Coarse Aggregate $(20 \mathrm{~mm})$ & 6.83 & 6.83 \\
\hline Coarse Aggregate (10mm) & 4.02 & 4.02 \\
\hline Fine Aggregate & 8.93 & 8.93 \\
\hline Na Citrate (g) & 18.00 & 18.00 \\
\hline Glenium 3030 (ml) & 7.5 & 7.50 \\
\hline Water & 1.54 & 1.54 \\
\hline w:cm ratio & 0.44 & 0.44 \\
\hline Ambient Temperature & 21.7 & 21.7 \\
\hline
\end{tabular}

Figure 55. Mix summary for concrete prepared with the coal combustion byproduct cements fabricated in the rotary kiln.

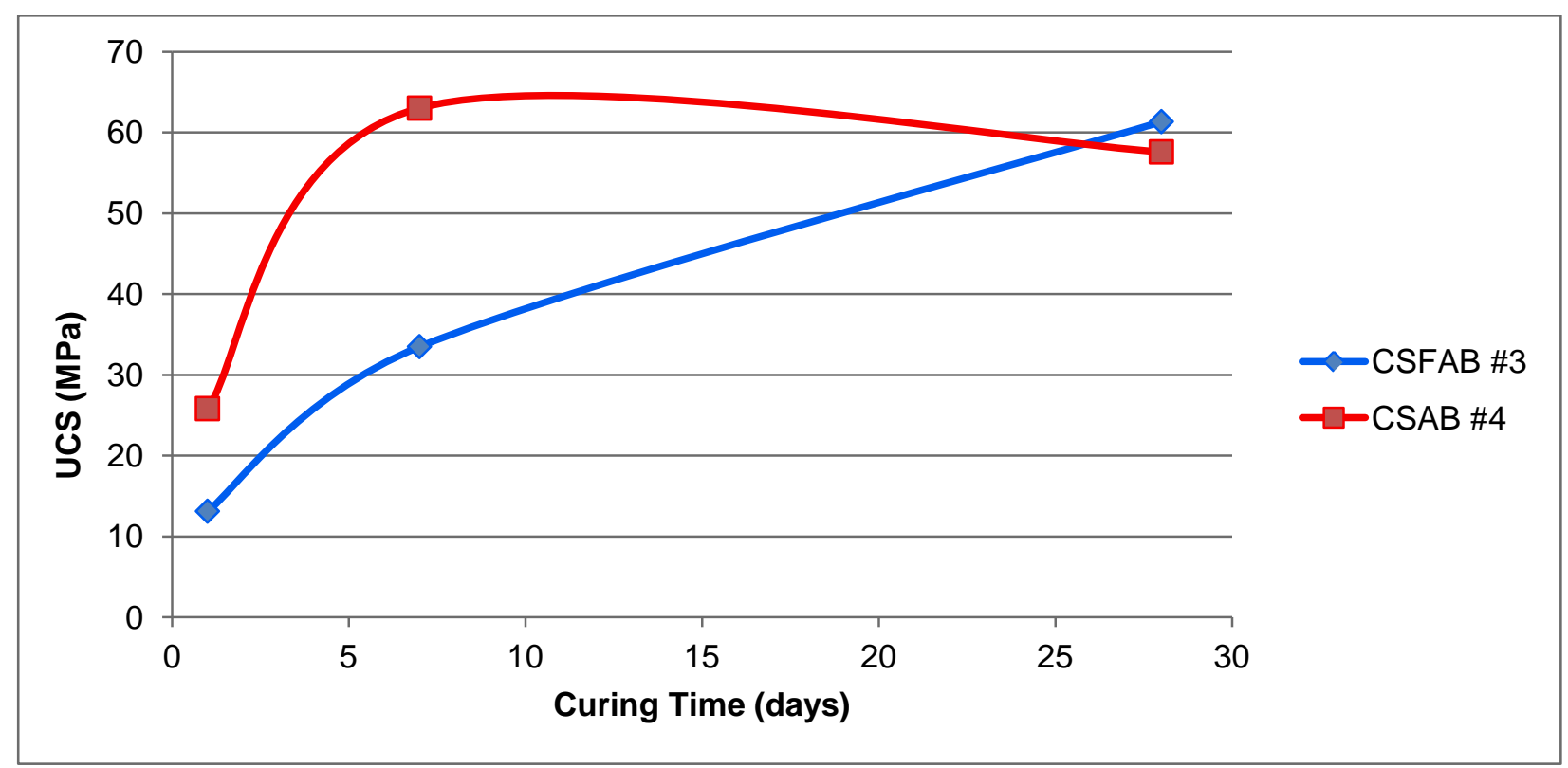

Figure 56. Unconfined compressive strength of concrete cylinder specimens with cement fabricated from coal combustion byproducts.

\section{Field Testing}

The completion of the sustainable construction materials laboratory provided an opportunity to place low-energy, high-byproduct content concrete sections around the laboratory. This was based on a recommendation by members of the Advisory Board, which was formed at the 
beginning of the project, to demonstrate low-energy cements being researched at CAER as much as possible at the University of Kentucky. It was felt that this would be necessary to get industry interested in some of these materials.

The first series of concrete sections are components of an $85 \mathrm{ft}$-long walkway that connects existing CAER buildings with the new laboratory. The concrete sections will be used to demonstrate the performance of low-energy concrete to visitors at the CAER, as well as to research the durability of various cement/concrete formulations. Table 28 provides the concrete mixture proportions of the test/demonstration sections.

Table 28. Mix proportions for low energy concrete sections.

\begin{tabular}{|l|c|c|c|c|c|c|c|c|}
\hline & $\# 1$ & $\# 2$ & $\# 3$ & $\# 4$ & $\# 5$ & $\# 6 A$ & $\# 6 B$ & $\# 7$ \\
\hline OPC (kg) & 47.6 & 13.7 & - & - & 42.0 & - & - & - \\
\hline CSA Cement (kg) & - & - & - & 54.5 & - & - & - & - \\
\hline FBC Spent Bed (kg) & - & - & 116 & - & - & 15.6 & 15.6 & - \\
\hline Class F FA (kg) & 20.4 & - & 42.8 & 13.6 & - & 20.3 & 20.3 & 17.2 \\
\hline Class C FA (kg) & - & - & - & - & - & - & - & 68.8 \\
\hline GGBS (kg) & - & 46.7 & - & - & - & - & - & - \\
\hline Hemihydrate (kg) & - & 8.24 & - & - & 42.0 & 31.9 & 31.9 & - \\
\hline Coarse Aggregate (kg) & 137 & 134 & 131 & 130 & 98.2 & 138 & 138 & 134 \\
\hline Fine Aggregate (kg) & 185 & 183 & 61.1 & 178 & 133 & 189 & 189 & 184 \\
\hline Water (kg) & 30.5 & 30.8 & 44.4 & 34.1 & 25.2 & 27.6 & 27.6 & 22.43 \\
\hline Micro Air (m) & 10.9 & 11.0 & 43.8 & 10.2 & - & 13.6 & 13.6 & 12.9 \\
\hline Glenium 3030 (ml) & 146 & - & - & 146 & - & - & - & - \\
\hline HPA (WRA) (g) & - & 225 & - & - & 200 & 3860 & $(400)$ & - \\
\hline Citric Acid (g) & - & - & - & - & 100 & 36.5 & 36.5 & 1227 \\
\hline KOH (g) & - & - & - & - & - & - & - & 1361 \\
\hline Sodium Borate (g) & - & - & - & - & - & - & - & 976 \\
\hline
\end{tabular}

Each batch of concrete comprised approximately $191 \mathrm{~L}\left(6.75 \mathrm{ft}^{3}\right)$ of concrete, with 2 batches prepared for each mixture. All of the mixtures contained aggregates consisting of $50 \%$ bottom ash and 50\% native materials (i.e. crushed limestone and river sand). Three gradations of bottom ash were donated by Charah Inc., which is an ash management company based in Louisville, Kentucky. The two coarsest materials ("EcoAggregate") were combined to produce a -1inch (25 mm) coarse aggregate, whereas the finer fraction ("EcoSand") was used as a partial replacement for river sand.

The base course of the walkway comprised the EcoSand bottom ash product, and was placed and compacted in a 4 inch thick layer (Figure 57). The ingredients for the different low-energy concrete mixtures were proportioned and mixed in a $12 \mathrm{ft}^{3}$ capacity gasoline-powered mixer (Figure 58). The fresh concrete was then placed, compacted and finished within steel forms (Figure 59). 


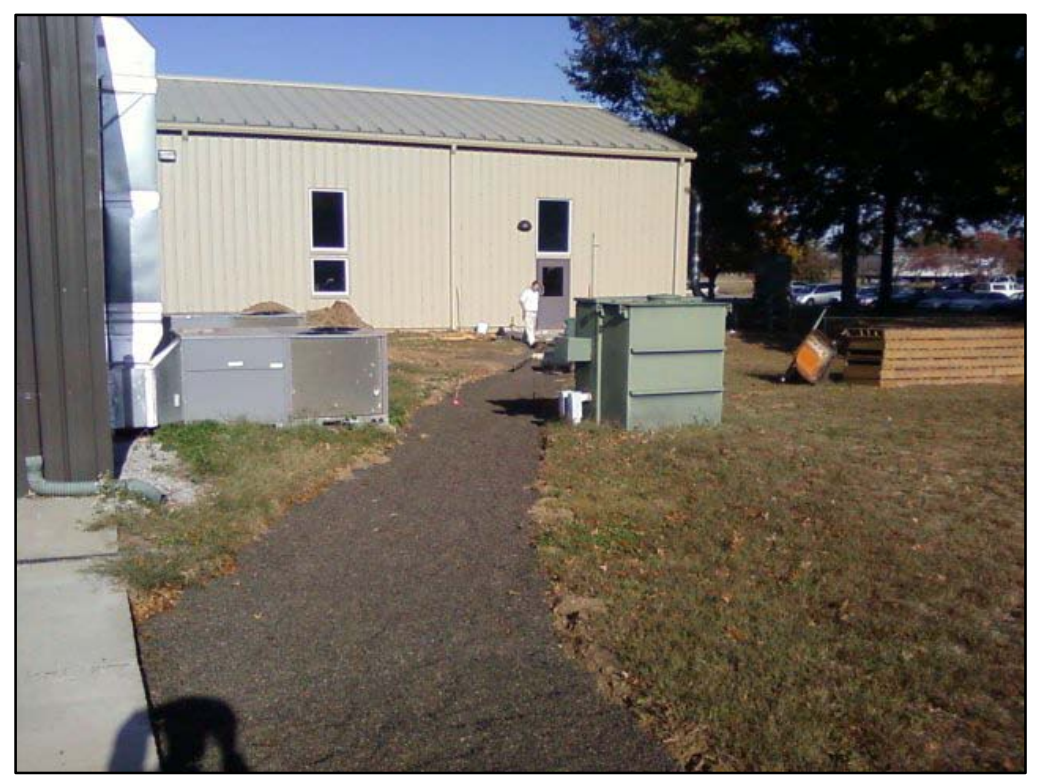

Figure 57. Walkway location showing bottom ash base course.

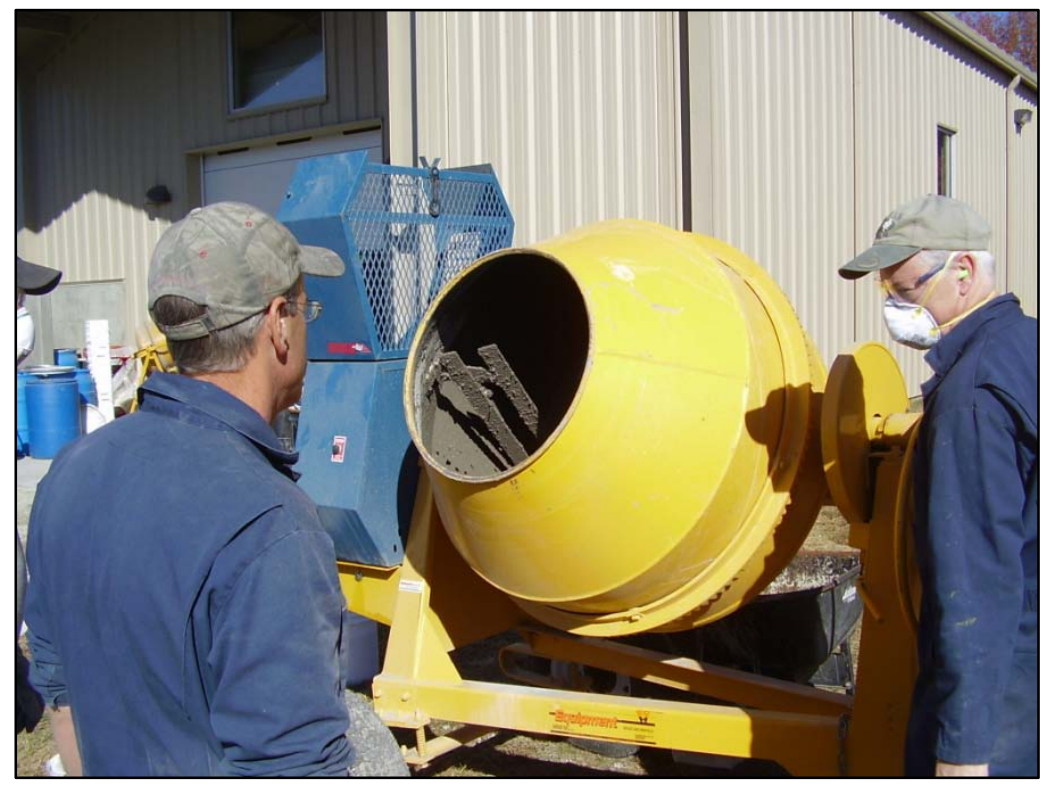

Figure 58. Mixing the concrete ingredients. 


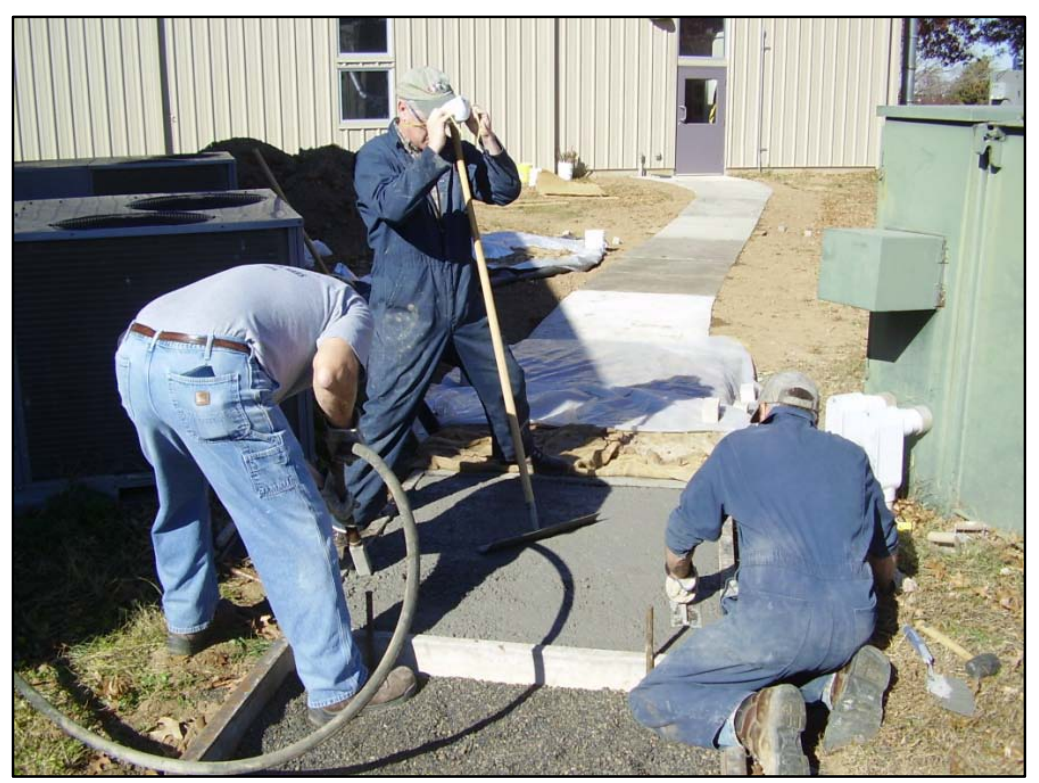

Figure 59. Placing and compacting a section of concrete.

Mixture \#1 is based on ordinary Portland cement (OPC), with a $30 \%$ replacement with Class $F$ fly ash. Mix \#2 contains "super-sulfated cement" which comprises 80\% GGBS and FGD \%hemihydrate and 20\% OPC. Mix \#3 cement comprises $70 \%$ as-received FBC spent bed and $30 \%$ Class F fly ash, with the spent bed also replacing the majority of fine aggregate (sand). This mix is based on research conducted at the University of Kentucky in the mid-late 1980s. Mix \#5 contains commercial rapid-repair cement produced by US Gypsum called "Duracal", which comprises approximately 50\% hemihydrate and 50\% OPC. Although the hemihydrate was not produced from FGD gypsum, this cement was used as a proxy for a highly sulfated cement that could potentially use FGD hemihydrate. The Mix designs \#6A and \#6B are very similar in that they comprise milled FBC spent bed, Class $\mathrm{F}$ fly ash, and hemihydrate (i.e. "clinkerless cement"), but use different types of admixtures to improve resistance to water ingress: \#6A contains a hydrophobic polymer (HPA), whereas \#6B contains a water repelling admixture (WRA) based on calcium stearate. The final mix (\#7) contains an alkali-activated Class C fly ash cement, sometimes called "geopolymer", which comprises approximately $96 \%$ fly ash, 3\% chemical activator ( $\mathrm{KOH}$ and citric acid) and 1\% retarder (sodium borate). These demonstration sections will be used to show visitors the potential of these materials in everyday construction, and will also be monitored for durability. Several of them are not expected to withstand repetitive freezing and thawing cycles, but the information will be very useful in future research. If these sections fail, they can easily be removed and replaced with improved formulations. 


\section{STUDENT OUTREACH}

The CAER partnered with the University of Kentucky (UK) College of Design to create viable products using concrete produced from coal ash. The single largest commercial use of fly ash is as a partial replacement for Portland cement in concrete and is commonly used to replace 20$30 \%$ of the cement component. A relatively recent invention is alkali-activated fly ash cement. Instead of containing $20-30 \%$ fly ash, this cement is composed of more than $96 \%$ fly ash, the remainder of which is an "activator" that contains potassium or sodium hydroxide and citric acid. Fly ash cement can gain remarkable strength in a very short time and can be made quite durable, but suffers from being rather temperamental to work with. If the mixture is not made precisely, it can either harden during mixing or never harden at all. This type of cement cannot be produced from eastern U.S. Class F fly ash, but requires ash produced from burning western U.S. coal. However, it has great potential as a sustainable construction material because it uses a large volume of coal combustion byproducts (CCBs).

The collaboration between the CAER and the College of Design seeks to create viable products using fly ash cement. This project integrates two main goals of both entities: research at CAER that seeks to maximize responsible use of coal ash; and the fabrication of marketable products from waste materials by College of Design students and faculty. The process begins with students in FAD (Fabrication and Design) class creating a design for a product, in this case planters, through animation software using specific drawing techniques. The design is then transformed to produce a mold. Once the files are prepared they can be converted into a tool path which is sent to a computer numerical controlled (CNC) router. The machine then precisely mills a mold for the planter. The mold doesn't always come off the machine perfectly so there is usually some hand craft work required to get the parts to line up and become liquid tight before the pour. With the mold ready, the concrete is poured and allowed to harden. Then the de-molding process begins and the planter/product is revealed. The concrete mixture used to produce the planters is provided in Table 29.

Table 29. Mix formulation for alkali-activated concrete.

\begin{tabular}{|c|c|}
\hline Component & Quantity \\
\hline Class C Fly Ash $\left(\mathrm{kg} / \mathrm{m}^{3}\right)$ & 920 \\
\hline Bottom Ash $\left(\mathrm{kg} / \mathrm{m}^{3}\right)$ & 786 \\
\hline Potassium Hydroxide $\left(\mathrm{kg} / \mathrm{m}^{3}\right)$ & 14.5 \\
\hline Citric Acid $\left(\mathrm{kg} / \mathrm{m}^{3}\right)$ & 13.1 \\
\hline Sodium Borate $\left(\mathrm{kg} / \mathrm{m}^{3}\right)$ & 10.4 \\
\hline Water:Cementitious & 0.31 \\
\hline 3-Day Compressive Strength (PSI) & 4225 \\
\hline
\end{tabular}

Instead of using a traditional aggregate such as river sand, bottom ash from one of UK's heating plants were obtained from Tom Gregory, UK Physical Plant Division. Although the bottom ash is weaker than river sand, it also has a considerably lower density and can reduce the weight of 
the concrete planters. Another advantage to using bottom ash is its porosity, which can provide a reservoir of moisture that is available for internal curing of the concrete. With the fly ash cement plus bottom ash aggregate, the concrete planters comprised approximately $86 \%$ coal ash, with the remaining $14 \%$ being the activator plus water.

During the week of December 14-18, 2009, the FAD students made the concrete planters at the CAER. The molds were prepared ahead of time at the College of Design fabrication shop. The concrete was mixed, placed into the molds, and generally hardened within 30 minutes. Within 3 days curing, the compressive strength was greater than 4000 PSI (Table 1). After removing the material from the mold, the planters were cleaned, sealed with clear polyurethane, and assembled into their completed forms. The various designs can be viewed at http://www.uky.edu/Design/FlyAsh/. Overall, the activity between the CAER and the College of Design has been a success for both entities. It demonstrates that coal ash concrete can be a viable substitute for traditional concrete that would otherwise use Portland cement and quarried aggregates as the major ingredients, and that using it can essentially create "green" products with potential market value out of what is often positioned as an unusable material. It also provided students with experience using coal ash in materials design, which they will take with them into the workplace after graduation.

\section{CONSLUSIONS}

\section{Conclusions for Clinkerless Cements}

This study has provided an understanding of the cementitious and expansive reactions involved during the hydration of "clinkerless" cement prepared using Gilbert FBC byproducts. The free lime and calcium sulfate present in the Gilbert spent bed and fly ash can impart cementitious properties to these materials when they are mixed with water, which means they could potentially be used instead of Portland cement in mortar and concrete. The formation of ettringite is the principal cementitious reaction. The Gilbert fly ash contained significantly more alumina than the spent bed and therefore formed more ettringite. It was possible to "activate" the Gilbert spent bed by providing an alumina source such as Class F fly ash. However, the high $\mathrm{pH}$ of the paste component of mortar and concrete prepared with the Gilbert materials caused colloidal ettringite to form, which caused expansion in every formulation. Likewise, when contacted with soil and large amounts of water, the lime and calcium sulfate from the spent bed material reacted with alumina from the soil to form expansive ettringite. Milling the Gilbert spent bed material seemed to accelerate the expansion.

Based on the foregoing, potential methods to control expansion have been identified for future work. As was discussed earlier, the formation of colloidal ettringite at a high $\mathrm{pH}$ causes excessive absorption of water by the ettringite in a manner similar to swelling clay. Thus, water needs to be restricted from the material while the ettringite is forming. This is probably why FBC spent bed materials have been successfully used in various fills, but have exhibited expansion problems in others: the ingress of large quantities of water needs to be prevented through 
proper design of the fill. It is postulated here that the water ingress does not need to be controlled in perpetuity, but only during the period where there remains unreacted lime in the system. Thus, the use of water-repelling admixtures (i.e. such as those used for masonry block manufacture) and/or sealants could provide a means to prevent water from entering the hydrated FBC material during the ettringite forming period. With proper proportioning of the FBC materials and Class $\mathrm{F}$ fly ash, it might be possible to complete the cementitious strength-forming reactions in 6 months or less, after which significant expansion would not occur.

Another problem with using FBC-based clinkerless cements instead of Portland cement was the slow strength gain of the former. To overcome this, addition of alkali (e.g. sodium hydroxide) to the paste could increase the dissolution rate of Class F fly ash, which would cause an increase in the rate of ettringite and calcium silicate hydrate formation, with a concomitant increase in strength. A second strategy could be to blend the clinkerless cement with rapid hardening cement (RHC). The RHC would provide early strength, whilst the pozzolanic reactions in the clinkerless component would provide additional longer-term strengths. One rapid hardening material worth exploring is plaster (calcium sulfate hemihydrate), which can be made entirely from FGD gypsum. Plasters can gain strength very quickly, via the hydration of the hemihydrates to form gypsum, and could thus provide high early strength. However, gypsum has a high solubility, which limits the quantity that could be used as a component of clinkerless cement. Water-repelling admixtures could thus be of additional benefit in that they could inhibit the dissolving of the gypsum cement.

\section{Conclusions for Low-Energy CSA Cements}

The Gilbert fluidized bed combustion material has potential for use in the production of calcium sulfoaluminate belite cements. The utilization of the Gilbert CFBC spent bed material in CSAB cement shows potential as a large-volume use for the material. Heating FBC bottom ash, PCC fly ash, limestone, and bauxite at $1250^{\circ} \mathrm{C}$, produced a large quantity of Klein's compound and belite. The Gilbert FBC ash provides needed calcium sulfate and, particularly, calcium oxide. The calcium oxide within the ash is an effective substitute for limestone, which is required as a raw material for CSAB cement clinker. In fact, if changes in the Gilbert FBC combustion process were to result in substantially less lime in the spent bed material, its' value as a CSAB clinker raw material would be limited since FGD gypsum would provide a more concentrated and refined source of calcium sulfate.

The synthesized CSAB clinkers were soft and readily milled to cement fineness. Milling the clinker with FGD gypsum was effective in provide the additional calcium and sulfate required to "activate" the clinker to form ettringite. The compressive strength of the commercial and laboratory CSAB cements produced high-early strengths that exceeded those of ordinary Portland cement. Additional long-term strength was possibly provided by hydration of dicalcium silicate $\left(\mathrm{C}_{2} \mathrm{~S}\right)$ within the clinker. The durability of the laboratory CSAB cements was similar to 
that of commercially available CSAB cements. The tests in which the CSAB cements performed well were resistance to deicer chemicals, drying shrinkage and resistance to freezing and thawing. However, all of the CSAB cements carbonated more rapidly than OPC and tended to undergo strength regression as carbonation became more extensive. Thus, the CSAB cements would likely provide little protection for reinforcing steel within concrete.

Milling the laboratory CSAB clinker with Class F fly ash, in addition to FGD gypsum, appeared to improve the dimensional stability of CSAB mortar. In every cement that contained fly ash addition, destructive expansion did not occur and drying shrinkage improved. However, fly ash addition generally decreased the compressive strength, although the water reduction achieved with the fly ash helped to offset this (see Table 11). Future work will focus on optimizing the quantity of fly ash addition to provide maximum water reduction benefits and minimize the strength loss.

A major issue regarding the production of CSAB cement is one of cost. Because CSAB clinker production requires substantial quantities of bauxite, the cost of these cements is high. In order to minimize or eliminate bauxite, alternatives to this raw material were pursued. One approach was to formulate high-ferroaluminate CSAB cements using feed materials that contain high percentages of iron. High-iron calcium aluminate cements are currently produced where rapid strength gain and fire resistance is desired. The replacement of some bauxite with high-iron raw materials will have the net effect of replacing some of the aluminum with iron, which is considerably less expensive. The feed materials included coal fly ash and red mud, which is a byproduct of bauxite processing. The production of high-ferroaluminate CSAB cements was thus pursued in this research.

\section{REFERENCES}

American Coal Ash Association (ACAA), 2006, CCP Production and Use Survey, www.acaausa.org/associations/8003/files/2006 CCP Survey (Final-8-24-07).pdf

LA Ash, Inc., 2008, www.laash.net

Berry, E.E., Hemmings, R.T. and Cornelius, B.J., 1991, Commercialization Potential of AFBC Concrete: Part 2. Volume 2: Mechanistic Basis for Cementing Action. EPRI GS-7122, Volume 2, Research Project 2708-4, Final Report, January 1991.

Bland, A.E., Jones, C.E., Rose, J.G. and Jarrett, M.N., 1987, in Proceedings of the 1987 International Conference on Fluidized Bed Combustion, Volume Two, American Society of Mechanical Engineers, pp. 947-953. 
Brown, A.D.R., 1993, in Concrete 2000: Economic and Durable Construction Through Excellence, Proceedings of the International Conference held at the University of Dundee, Scotland, UK, September 1993.

Hemmings, R., 2007, Introduction to By-Products Produced by Clean Coal Technologies Part 2. Applications, in The Science of Ash Utilization Short Course, 2007 World of Coal Ash, Covington, Kentucky.

Hopkins, T.C. and Beckham, T.L., 1999, in Proceedings of the 1999 International Ash Utilization Symposium, Lexington, KY, Paper \#86, www.flyash.info/1999/durabil/hopk2.pdf

Glasser, F.P. and Zhang, L., 2001, Cement and Concrete Research, 31, pp. 1881-1886.

Mehta, P.K., 1973, Cement and Concrete Research, 3, pp. 1-6.

Quillin, K., 2001, Cement and Concrete Research, 31, pp. 1341-1349.

U.S. Geological Survey (USGS), 2006 Minerals Yearbook: Bauxite and Alumina, http://minerals.usgs.gov/minerals/pubs/commodity/bauxite/index.html\#myb

Zhang, L. and Glasser, F.P., 1999, in Modern Concrete Materials: Binders, Additions and Admixtures, Proceedings of the International Conference held at the University of Dundee, Scotland, UK, September 1999, R. K. Dhir and T. D. Dyer, ed., pp. 261-274

Zhang, L., Su, M. and Wang, Y., 1999, Advances in Cement Research, 11, pp 15-21 